\title{
WestVirginiaUniversity
}

THE RESEARCH REPOSITORY @ WVU

Graduate Theses, Dissertations, and Problem Reports

2012

\section{Strength Evaluation of Wood I-Joist with Sinusoidal Web}

\author{
Bradley McGraw \\ West Virginia University
}

Follow this and additional works at: https://researchrepository.wvu.edu/etd

\section{Recommended Citation}

McGraw, Bradley, "Strength Evaluation of Wood I-Joist with Sinusoidal Web" (2012). Graduate Theses, Dissertations, and Problem Reports. 3365.

https://researchrepository.wvu.edu/etd/3365

This Thesis is protected by copyright and/or related rights. It has been brought to you by the The Research Repository @ WVU with permission from the rights-holder(s). You are free to use this Thesis in any way that is permitted by the copyright and related rights legislation that applies to your use. For other uses you must obtain permission from the rights-holder(s) directly, unless additional rights are indicated by a Creative Commons license in the record and/ or on the work itself. This Thesis has been accepted for inclusion in WVU Graduate Theses, Dissertations, and Problem Reports collection by an authorized administrator of The Research Repository @ WVU. For more information, please contact researchrepository@mail.wvu.edu. 


\title{
Strength Evaluation of Wood I-Joist with Sinusoidal Web
}

\author{
Bradley McGraw \\ Thesis submitted to the \\ College of Engineering and Mineral Resources \\ at West Virginia University \\ in partial fulfillment of the requirements \\ for the degree of \\ Master of Science \\ in \\ Civil and Environmental Engineering \\ Indrajit Ray, Ph.D., Chair \\ An Chen, Ph.D., Co-Chair \\ David DeVallance, Ph.D.
}

Department of Civil and Environmental Engineering

\author{
Morgantown, West Virginia \\ 2012
}

Keywords: I-Joist; Sinusoidal Web; Strength Evaluation; Buckling Capacity

Copyright @2012 Bradley McGraw 


\section{Abstract \\ Strength Evaluation of Wood I-Joist with Sinusoidal Web}

\section{Bradley McGraw}

Wood I-joists are highly efficient, lightweight structural members used for long span applications. However, because of the high strength to stiffness ratio and thin-walled nature of the web, buckling or sudden loss of stability is a primary concern. Recently at West Virginia University a new structural wood composite panel has been developed using discarded veneermill residues. These panels were manufactured with a sinusoidal geometry and used as web material in I-joists. The profiling of the web is designed to increase the buckling capacity of the joists.

This thesis is focused on the evaluation of the strength, stiffness, and stability of this composite wood I-joist with sinusoidal web. Joists were manufactured at two different depths and also with flat webs for comparison. An evaluation of the web in compression, lateral-torsional buckling of the joists, the rotational stiffness through torsion testing, and an evaluation of the joists in four point bending are presented. Finite element analysis was performed along with the experimental evaluations. The finite element predictions are compared with the experimental results. 


\section{ACKNOWLEDGEMENTS}

I would like to thank my advisor Dr. Julio Davalos. I would also like to express my sincere gratitude to my co-advisor Dr. An Chen for his guidance, assistance, and support throughout the last few years. Without their knowledge, assistance, and encouragement this project would have been impossible. I also have to express thanks towards Dr. Indrajit Ray and Dr. David DeVallance for their time and assistance, and for the evaluation of this thesis. The generous contributions and guidance of Dr. Elemer Lang and Dr. Levente Denes must not be forgotten. Without them this project never would have happened.

My appreciation goes to Paul Ludrosky and Jerry Nestor for their invaluable assistance in the wood shop and structures lab. I also have to thank David Turner for his time and help in the machine shop. The laboratory assistance of Andrew Grubler, Marcus Bailey, and Paden Wilson also should be acknowledged. I also have to thank my fellow graduate students and residents of B11.

This work is supported by the Wood Utilization Project, the WVU Department of Civil and Environmental Engineering, and the WVU Department of Forestry and Natural Resources. I also have to acknowledge the Weyerhaeuser Trus Joist Company in Buckhannon, WV; the Universal Veneer Company located in Newark, Ohio; and John Noffsinger and the Weyerhaeuser OSB mill in Buckhannon, WV for their very generous donations.

Last but not least, I cannot give enough thanks to my family and friends for all they have done for me over the years. Thanks again to all I have mentioned and those whom I may have left out. 


\section{TABLE OF CONTENTS}

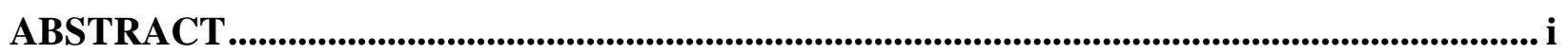

ACKNOWLEDGEMENTS _................................................................................................

TABLE OF CONTENTS ….......................................................................................................

LIST OF FIGURES ............................................................................................................. vii



ABBREVIATIONS ........................................................................................................................................ xii

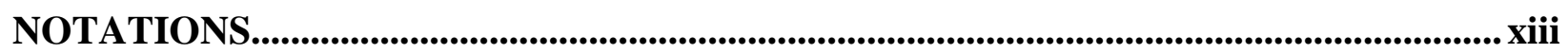

CHAPTER 1 INTRODUCTION AND LITERATURE REVIEW ....................................... 1

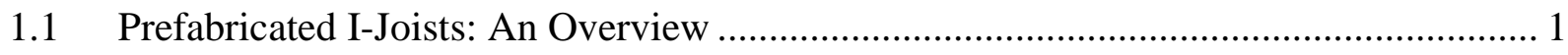

1.1.1 Development of Prefabricated I-Joists................................................................... 1

1.1.2 Commercially Available I-Joists.......................................................................... 3



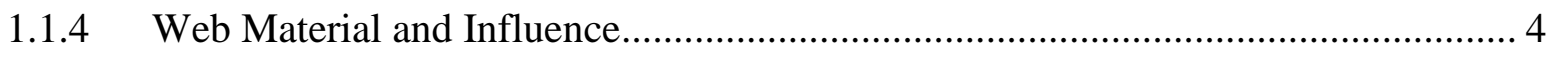





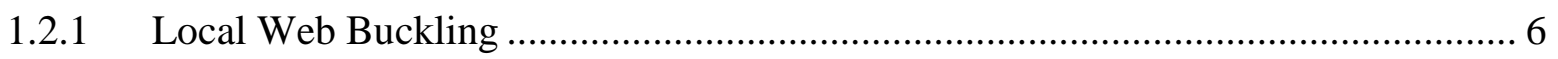

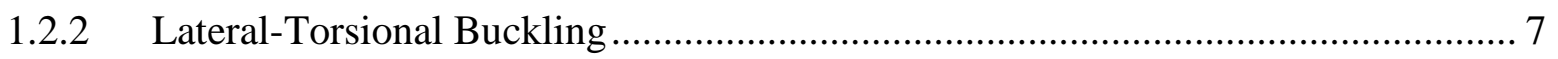

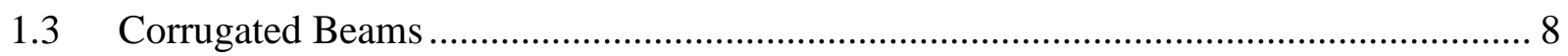





CHAPTER 2 TEST SAMPLES AND FINITE ELEMENT MODELING .............................. 14

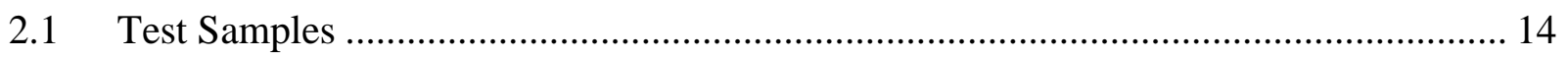






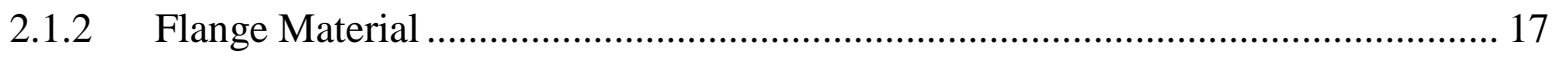

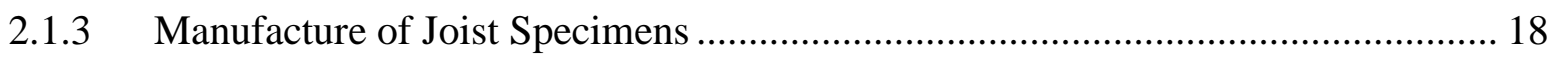

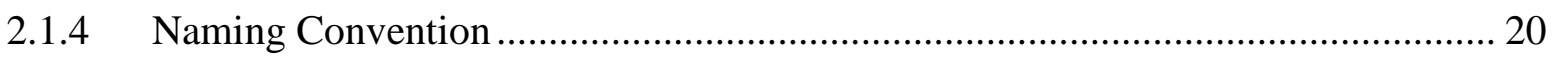

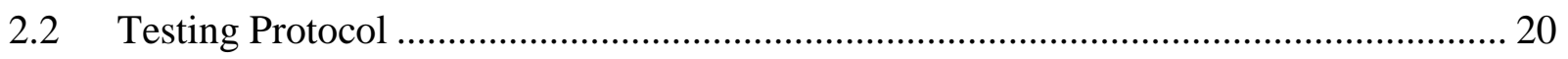

2.2.2 Lateral-Torsoinal Buckling .......................................................................... 21



2.2.4 Four-Point Bending ............................................................................. 22

2.3 Finite Element Modeling Procedure ……………….............................................. 22

2.3.1 Formulation of the Geometric Model ………................................................. 23

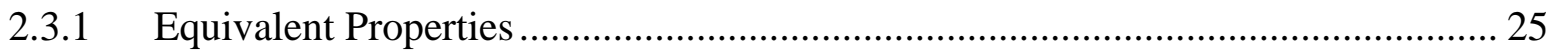

CHAPTER 3 EVALUATION OF I-JOIST WEB IN COMPRESSION ................................ 26



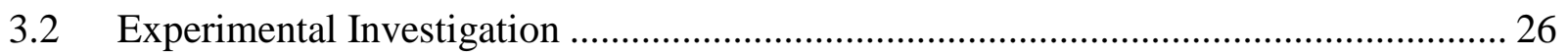

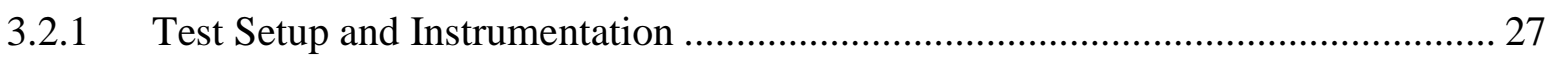



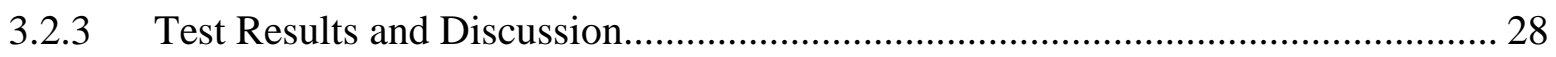

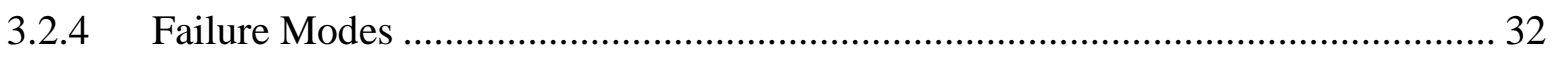



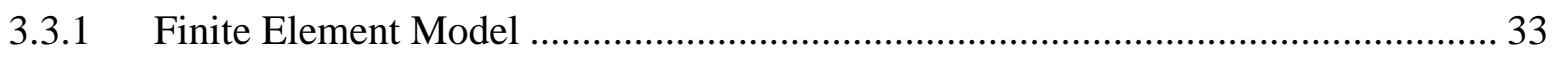

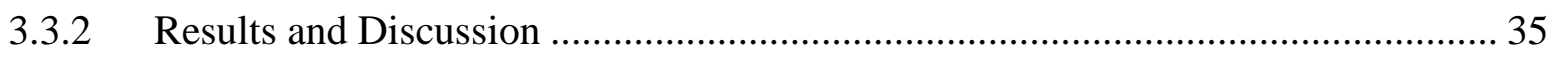

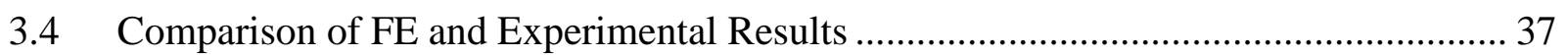

CHAPTER 4 LATERAL-TORSIONAL BUCKLING OF COMPOSITE I-JOISTS.......... 38

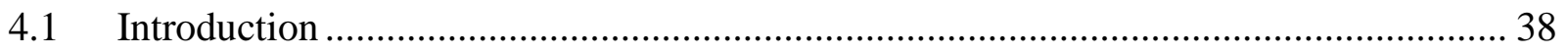

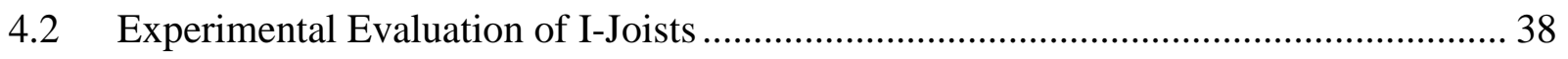

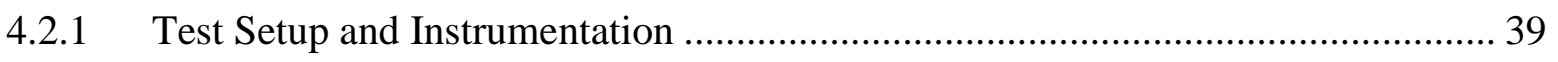

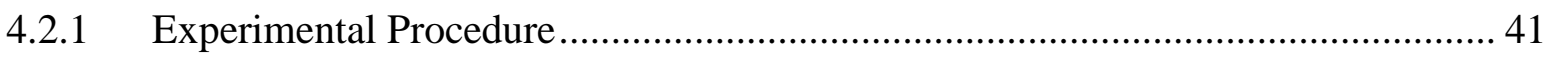

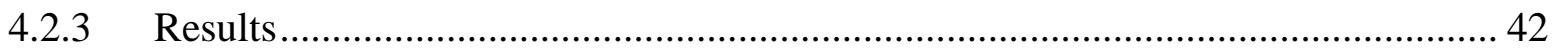



4.4 Comparison of FE and Experimental Results ............................................................. 49

CHAPTER 5 EVALUATION OF I-JOISTS IN TORSION...............................................5 50 


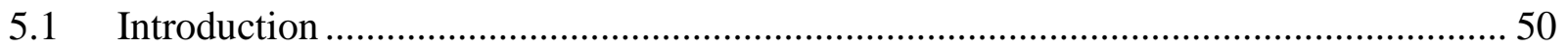

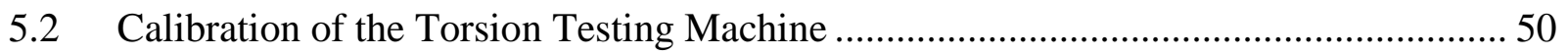

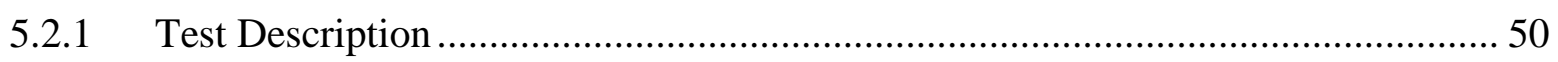

5.2.2 Analytical Predictions for Aluminum Bar ........................................................ 52

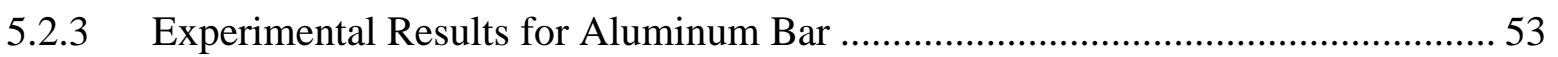

5.2.4 Finite Element Modeling of Aluminum Bar .......................................................... 56

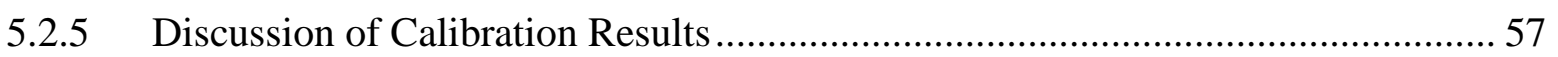



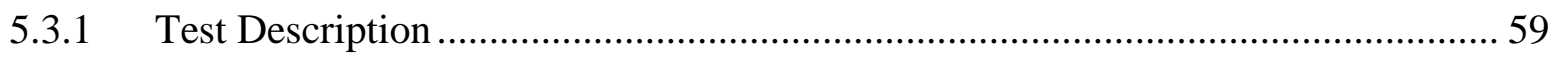

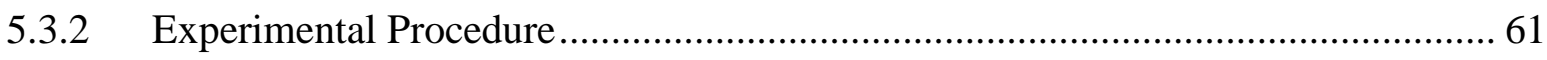

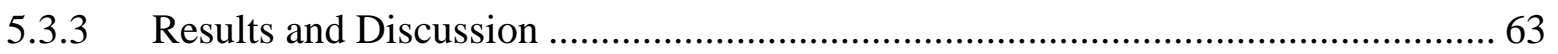

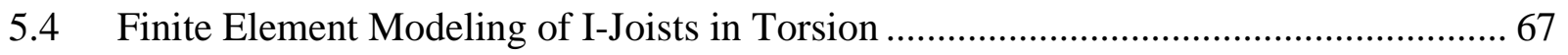

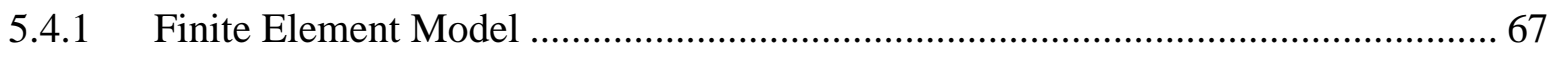

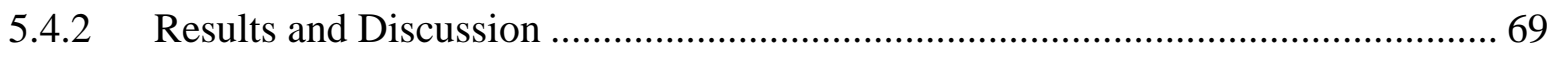

5.5 Comparison of FE and Experimental Results .......................................................... 70

CHAPTER 6 EVALUATION OF I-JOISTS IN FOUR-POINT BENDING ......................... 71

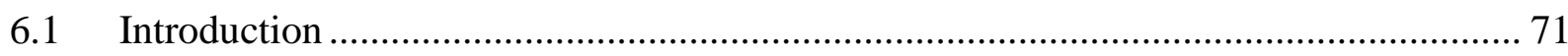

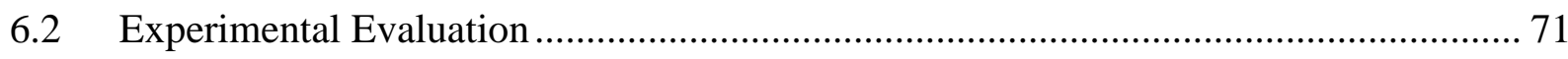

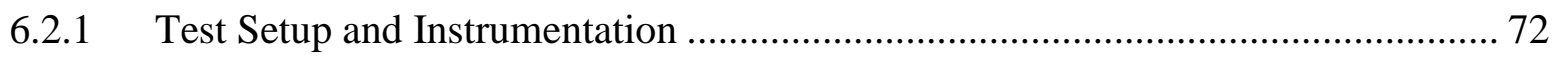

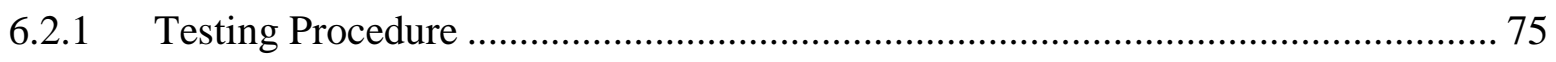





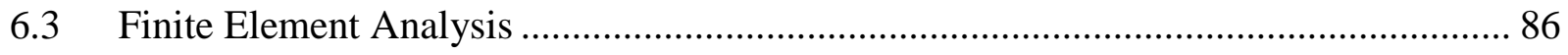



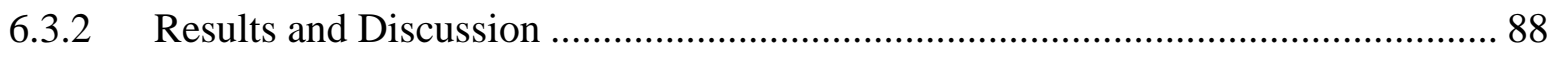

6.4 Comparison of FE and Experimental Results ............................................................ 89

CHAPTER 7 CONCLUSIONS AND RECOMMENDATIONS ............................................... 91

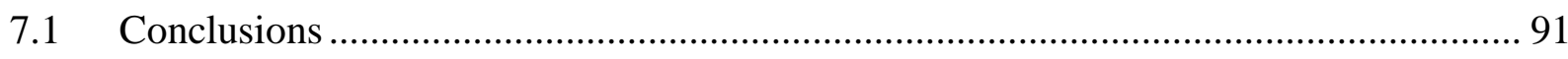

7.1.1 Evaluation of the I-Joist Web in Compression ..................................................... 91

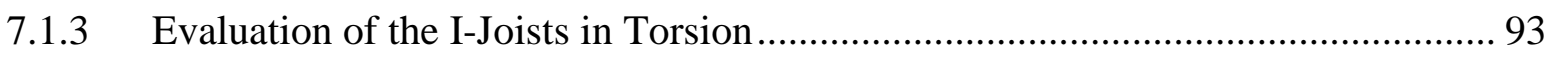

7.1.4 Evaluation of the I-Joist in Four-Point Bending ..................................................... 94 


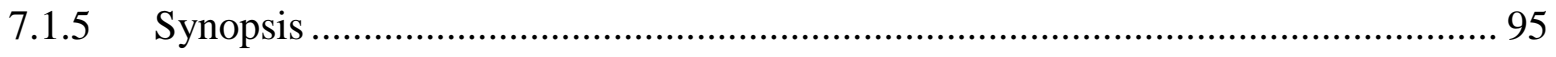

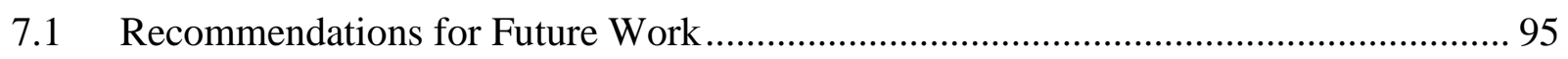

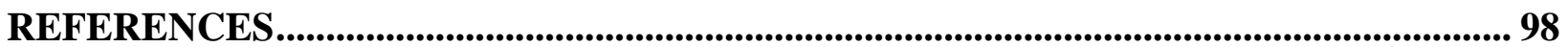




\section{LIST OF FIGURES}

Figure 2.1 Veneer-Mill Clippings and Sinusoidal Wave Template ................................... 16

Figure 2.2 Finished Flat and Sinusoidal CompositeWeb Panels ..................................... 17

Figure 2.3 Cross-Sectional Geometries of the Four I-Joist Groups .................................. 18

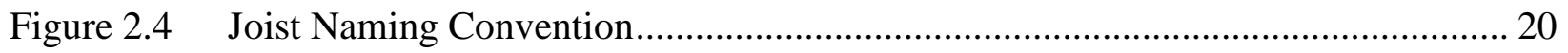

Figure 2.5 Finite Element Model of Composite I-Joist with Flat Web ............................... 24

Figure 2.6 Finite Element Model of Composite I-Joist with Sinusoidal Web ....................... 24

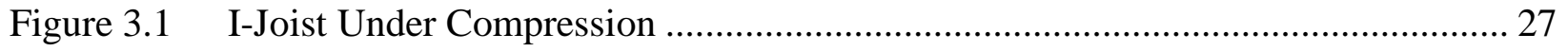

Figure 3.2 Load vs. Displacement Plot of Typical Joist Sample in Compression .................. 28

Figure 3.3 Load vs. Strain Plot of Typical Joist Sample in Compression.............................. 29

Figure 3.4 Web Local Buckling of I-Joist in Compression................................................. 32

Figure 3.5 Shear Failure of I-Joist in Compression.................................................... 32

Figure 3.6 Finite Element Model of Flat Web in Compression ........................................ 34

Figure 3.7 Finite Element Model of Sinusoidal Web in Compression ................................. 34

Figure 3.8 Compressive Buckling of Flat Web from FE Analysis ................................... 36

Figure 3.9 Compressive Buckling of Sinusoidal Web from FE Analysis ............................ 36

Figure 4.1 Cantilever Clamped-End Support .............................................................. 39

Figure 4.2 Steel Hanger for Load Applicaton ........................................................... 40

Figure 4.3 Measuring Devices and Loading Platform .............................................. 41

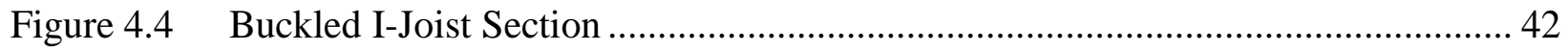

Figure 4.5 Typical Plot of Load vs. Deflection for Cantilever Beam Under Tip Loading ...... 43

Figure 4.6 Finite Element Model of Cantilever I-Joist ............................................. 47

Figure 4.7 Lateral-Torsional Buckling of I-Joist from FE Analysis .................................. 48 


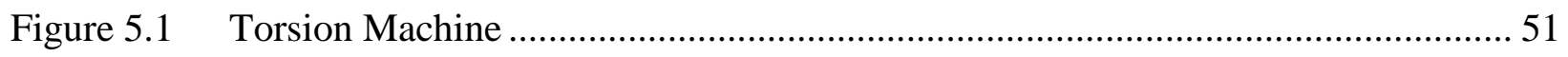

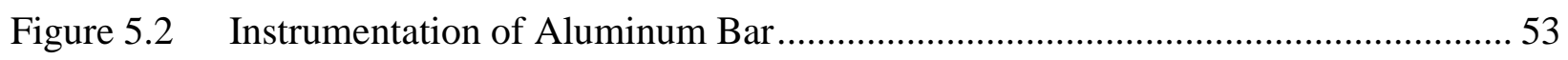

Figure 5.3 Deformed and Undeformed State of Aluminum Sample....................................... 54

Figure 5.4 Finite Element Model of Aluminum Bar in Torsion .............................................. 57

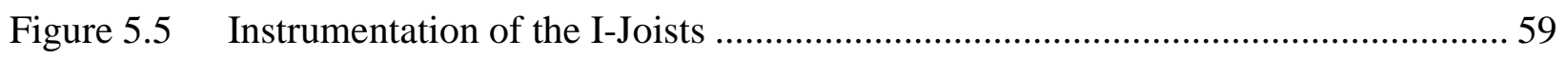

Figure 5.6 Sample Instrumented for Experimental Torsion Test ............................................. 60

Figure 5.7 Cross Sectional View of I-Joist in Torsion........................................................... 61

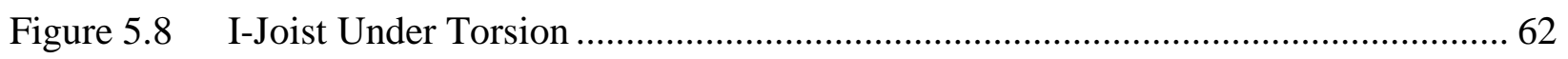

Figure 5.9 Typical Plot of Load vs. Displacement of I-Joist in Torsion ................................... 63

Figure 5.10 Typical Plot of Torque vs. Average Angle of Rotation of I-Joists in Torsion.... 64

Figure 5.11 Finite Element Model of Sinusiodal Web I-Joist in Torsion ............................. 68

Figure 5.12 Deformed Shape of I-Joist Under Torsion form FE Analysis .............................. 69

Figure 6.1 Four-Point Bending Configuration ……............................................................ 73

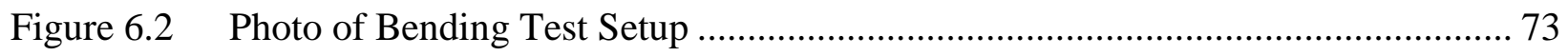

Figure 6.3 Lateral Supports Locations for Bending Test ....................................................... 74

Figure 6.4 Strain Gage Placement for Bending Test............................................................. 75

Figure 6.5 Typical Plot of Load vs. Deflection of Joist in Bending......................................... 78

Figure 6.6 Typical Plot of Load vs. Strain of Joist in Bending .............................................. 78

Figure 6.7 Shear Through the Flange-to-Web Connection of Sinusoidal Web Joist ................ 82

Figure 6.8 Shear Through the Flange-to-Web Connection of Flat Web Joist........................... 83

Figure 6.9 Shear Through the Web of a Sinusoidal Web Joist ................................................. 83

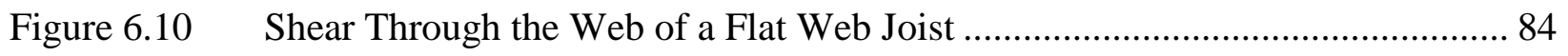

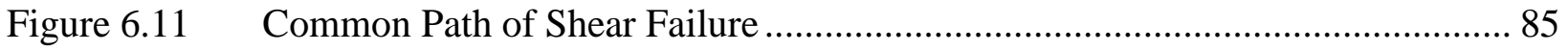


Figure 6.12 Simultaneous Shear of Top and Bottom Flange-Web Connections................... 86

Figure $6.13 \quad$ Web Failure in Compression.................................................................... 86

Figure 6.13 Finite Element Model for Beam Under Four-Point Bending ........................... 88

Figure 6.14 Buckling of I-Joist Under Bending From FE Analysis .................................. 89

Figure 6.15 Static Analysis of I-Joist Under Bending From FE..................................... 89 


\section{LIST OF TABLES}

Table 2.1 Equivalent Material Properties ……………………………………………...... 25

Table 3.1 Experimental Results of 10" Flat Web Joist Samples in Compression ................... 29

Table 3.2 Experimental Results of 10" Sinusoidal Web Joist Samples in Compression ........ 30

Table 3.3 Experimental Results of 16" Flat Web Joist Samples in Compression ................... 30

Table 3.4 Experimental Results of 16" Sinusoidal Web Joist Samples in Compression ........ 31

Table 3.5 Summary of Joist Samples in Compression......................................................... 31

Table 3.6 Web Compression Results from FE Analysis........................................................ 35

Table 3.7 Comparison of the Experimental and FE Results of Joists in Compression............ 37

Table 4.1 Experimental Results for 10" Flat Web Cantilever I-Joist .................................... 44

Table 4.2 Experimental Results for 10" Sinusoidal Web Cantilever I-Joist............................ 44

Table 4.3 Experimental Results for 16" Flat Web Cantilever I-Joist ...................................... 45

Table 4.4 Experimental Results for 16" Sinusoidal Web Cantilever I-Joist............................ 45

Table 4.5 Summary of Lateral-Torsinal Buckling Results ..................................................... 46

Table 4.6 Lateral-Torsional Buckling Results from Finite Element Analysis....................... 48

Table 4.7 Comparison of Experimental and FE Results ..................................................... 49

Table 5.1 Experimental Results for Aluminum Bar in Torsion ........................................... 55

Table 5.2 Summary of Analyses of Aluminum Bar in Torsion ............................................. 58

Table 5.3 Experimental Results for 10" Flat Web I-Joist in Torsion ....................................... 64

Table 5.4 Experimental Results for 10" Sinusoidal Web I-Joist in Torsion............................. 65

Table 5.5 Experimental Results for 16" Flat Web I-Joist in Torsion ...................................... 65

Table 5.6 Experimental Results for 16" Sinusoidal Web I-Joist in Torsion .............................. 66

Table 5.7 Summary of the Experimental Results of I-Joists in Torsion ................................. 67 
Table 5.8 Finite Element Results of I-Joists in Torsion................................................. 70

Table 5.9 Comparison of FE and Experimental Results for I-Joists in Torsion ................... 70

Table 6.1 Experimental Results for 10” Flat I-Joist in Bending ....................................... 79

Table 6.2 Experimental Results for 10” Sinusoidal I-Joist in Bending .............................. 79

Table 6.3 Experimental Results for 16" Flat I-Joist in Bending ...................................... 80

Table 6.4 Experimental Results for 16” Sinusoidal I-Joist in Bending .............................. 80

Table 6.5 Summary of I-Joist Bending Experimental Results ........................................ 81

Table 6.6 Results of the FE Analysis of I-Joist in Bending ............................................ 88

Table 6.7 Comparison of Experimental and FE Results of I-Joist Under Bending .............. 90 


\section{ABBREVIATIONS}

$\begin{array}{ll}\text { ASTM } & =\text { American Society for Testing and Materials } \\ \text { FE } & =\text { Finite Element } \\ \text { FRP } & =\text { Fiber-Reinforced Polymer } \\ \text { LVDT } & =\text { Linear Variable Differential Transducer } \\ \text { LVL } & =\text { Laminated Veneer Lumber } \\ \text { LSL } & =\text { Laminated Strand Lumber } \\ \text { OSB } & =\text { Oriented Strand Board } \\ \text { PSL } & \quad \text { Parallel Strand Lumber } \\ \text { SCL } & \quad \text { Structural Composite Lumber }\end{array}$




\section{NOTATIONS}
$\Delta \quad=\quad$ deflection
$\varepsilon \quad=\quad$ normal strain
$\theta \quad=\quad$ angle of rotation
$\mu \quad=\quad$ microstrain
$\sigma \quad=\quad$ normal stress
$v=$ Poisson's ratio
a $=$ distance between applied loads
$\mathrm{b}=$ width of member
$\mathrm{b}_{\mathrm{f}} \quad=\quad$ width of flange
$\mathrm{b}_{\mathrm{w}} \quad=\quad$ web thickness
c $=$ distance from outer fiber to centroidal axis
$\mathrm{d}=\quad$ joist depth
$\mathrm{E} \quad=\quad$ Young's modulus
$\mathrm{G}=$ shear modulus
GJ = $\quad$ torsional stiffness (rigidity)
$\mathrm{h}=$ height of member
$\mathrm{h}_{\mathrm{f}} \quad=\quad$ height of flange
$\mathrm{h}_{\mathrm{w}} \quad=\quad$ height of web
I $=$ moment of inertia
$\mathrm{k}_{1} \quad=\quad$ parameter used for torsion
L = $\quad$ span length, gauge length 


$\begin{array}{lll}1 & = & \text { length of measuring arm } \\ \mathrm{M} & = & \text { bending moment } \\ \mathrm{P} & = & \text { load } \\ \mathrm{r} & = & \text { length of moment arm } \\ \mathrm{T} & = & \text { torque }\end{array}$




\section{CHAPTER 1}

\section{INTRODUCTION AND LITERATURE REVIEW}

\subsection{Prefabricated I-Joists: An Overview}

A prefabricated I-joist is an engineered wood product designed for long span applications that consists of two main components. A relatively thin web which is sandwiched between two flanges forms an "I" shape cross-section, hence the name I-joist. This configuration allows for the positioning of materials to take best advantage of their properties, providing a high degree of structural efficiency. In general, the flanges are designed to provide all moment capacity while the web carries the shear forces. These products are manufactured at various lengths and depths, with a variety of flange dimensions and web thicknesses. These members are primarily used as floor joists, but are also used as roof support beams, garage door headers, and framing components, as well as for other various applications. Prefabricated I-joists are popular in both the residential and commercial construction industries and are the newest and fastest growing engineered wood product on the market (Forest Products Laboratory 1999).

\subsubsection{Development of Prefabricated I-Joists}

Wood composite I-beams are a relatively new product. In the 1920s I-sections were used in the construction of wooden aircraft. By the mid 1930s, Europeans were using composite I-beams 
with hardboard webs in building construction (Leichti et al. 1989). However, mass production of the I-joist did not begin until the late 1960s when the Trus Joist Corporation successfully introduced these beams into the North American construction market. Since then, the industry has grown and is now a significant supplier for both the residential and commercial construction markets. There was a high demand with homeowners for open floor plans in the late 60s and early 70s. This required long span members. Solid sawn lumber was an option; however, the dimensional lumber of these lengths was very expensive, often hard to find, and lacking in adequate strength to support increasingly longer spans. These high costs and performance issues brought about the need for composite products (Fisette 2000).

Over the past few decades, especially, there has been a serious decline in the availability of the high-quality and large dimensional lumber used for framing applications. However, there is high demand for long-span structural members in both the residential and commercial industries. The wood I-joist is designed to replace dimensional lumber in structural systems. When compared with solid sawn dimensional lumber, the wood I-joist offers several inherent advantages. These include a more efficient structural shape, better dimensional stability, higher strength-to-weight ratio, and lower variability of mechanical properties. In fact, I-joists require $50 \%$ less wood to manufacture than a solid beam with the same strength (Engineered Wood Products 2001). Also, the I-joists are lighter in weight, produce less waste, offer more design flexibility with increased span potential, and provide and ease of construction compared to dimensional lumber. Holes can also be predrilled for required electrical services, mechanical ductwork, and plumbing conveniently during manufacturing. 
I-joists have seen significant growth in all markets in the past few decades as the industry has become more familiar with the product's advantages. It is estimated that $50 \%$ of new residential floors built in North America now use this product (Chui et al. 2008). From 1990 to 1998 the number of wood I-joist plants operating in North America nearly doubled and their annual output increased more than 3 times (Forest Products Laboratory 2000). In 2000, 866 million linear feet of I-joists were produced in North America alone with estimated market share gains of about 5 to $10 \%$ per year for the next several years (Temperate Forest Foundation 2001). Prefabricated Ijoists are now manufactured by approximately 15 companies in the United States and Canada (Forest Products Laboratory 1999).

\subsubsection{Commercially Available I-Joists}

I-joists are most often distributed through building material suppliers. Each manufacturer has developed its own building code and provides catalogs with span tables and design information. However, over the last few decades there has been a gradual shift towards standardizing the industry with the development of ASTM D5055-05 (Standard Specification of Establishing and Monitoring Structural Capacities of Prefabricated Wood I-Joists) (Rancourt 2008). Sizes offered are standard throughout the industry. Lengths of up to 60 feet are available, with 48 footers being the most common size offered. Joist depths typically range from $9-1 / 2$ " to 16 " for residential applications, with some manufactures offering depths up to 32 " for commercial applications. Various flange geometries and web thickness are offered which are manufactured from a variety of materials and species. 


\subsubsection{Flange Materials and Influence}

The flanges of an I-joist are typical some type of structural composite lumber (SCL). Solid lumber is occasionally used as flange stock, but in recent years the industry has moved away from solid lumber flanges. Now, flanges are either laminated veneer lumber (LVL), laminated strand lumber (LSL), or parallel strand lumber (PSL). SCL is an engineered wood product formed by combining veneer sheets, strand, or other particles with an adhesive to form a composite product with the wood fibers oriented along the longitudinal axis of the beam.

The web generally has a relatively lower stiffness than the flanges. Therefore, the properties of the flanges are particularly important. The geometry of the joist is designed so that the flanges carry the majority of the tensile and compressive stress. Fergus (1979) found that moment critical beams were governed by flange strength and stiffness and the shear critical beams were also sensitive to flange stiffness. Stiffer flanges resist shape changes and carry greater shear loads after web buckling, increasing the ultimate load capacity of the I-beam (Hilson and Rodd 1979).

\subsubsection{Web Material and Influence}

Engineered wood composite panels are the most commonly used web materials. Plywood and oriented strand board (OSB) are most common web materials. However, particleboard, waferboard, and hardboard are also used. These panels are formed by orienting and laminating different layers of veneers sheets, strands, or flakes to create a panel characterized by high shear modulus and shear strengths. 
The web of the I-joist is designed to provide the shear resistance. In general the web material exhibits much lower bending strengths than the material used for the flanges, but have higher shear properties. The effect of the shear modulus of the web material on the deflection of the beam was investigated by Leichti and Tang (1983). It was shown that a lower shear modulus led to greater shear deflections, a major component of the total deflection.

\subsubsection{Influence of the Connections}

Various connection details are used to join the web along the length of the joist. To achieve the web-to-web connection producers most commonly use butt, scarf, tongue and groove, v-groove, or finger web joints. These connections, as well the flange-web connection are generally assembled using a phenolic based resin (either phenol-formaldehyde or phenol-resorcinol) Leichti (1986) found through experimental and theoretical analysis that the web joints did not cause a significant difference in the stiffness or load capacity of an I-beam. He did find, however, that this connection did affect differences in the failure characteristics of the beams.

The joint between the flange and the web is a critical part of joist integrity and is a typical source of patentability (Leichiti et al. 1990). Many different concepts have been developed to attain good shear performance and ease of fabrication and adhesion. Also efforts have been made to improve the ability to transfer concentrated loads without crushing and avoid splitting or cracking of the flange under either flange or web deformation. The most common type of joint used is the tongue and groove joint or a variation of it. Manufacturing a solid connection between the web and the flanges is essential, Voevodin and Kondratenko (1985) stated that I- 
beams do not perform well if the joints were not precisely machined and properly clamped during glue setting.

\subsection{Buckling of I-Joists}

Buckling is a serious concern associated with I-joists. Due to the high strength-to-stiffness ratio and thin-walled nature of the web of these structural members, buckling is the most likely mode of failure prior to material failure. Joists with large span-to-depth and depth-to-web thickness ratios are particularly prone to buckling. Wood I-joist can buckle in a variety of modes depending on the geometry of the cross section, the material properties of the flanges and the web, the boundary and support conditions, and the loading conditions.

\subsubsection{Local Web Buckling}

Joist under heavy concentrated loads or joists that are insufficiently braced can lead to local compressive or shear buckling of the web. Local buckling involves deformation of the component plate elements of a section. The effect of local buckling plays an important role in the design of slender section. When a section has undergone buckling it reduces the flexural rigidity of the section and, therefore, reduces the overall strength of the member. The greater the depth of the joist and the stronger the flanges, the more likely a joist is to experience buckling of the web (Zhu et al. 2005). Racher et al. (2007) found that as the depth of the joist increases the ultimate capacity of slender I-beams is governed by the plate behavior of the web, usually resulting in failure of the glued joint. However, through the use of web stiffeners local web buckling can be 
managed. Web stiffeners reduce the required bearing length and can transfer up to $90 \%$ of the reactions in deep I-beams (Maley 1987).

\subsubsection{Lateral-Torsional Buckling}

Lateral-torisonal buckling is the most common mode of buckling for an I-joist in flexure. When a long slender beam is subjected to bending loads about the strong axis, the beam may buckle by a combined lateral bending and twisting of the cross section. This then leads to significant out-ofplane bending and twisting instability. This phenomenon is known as flexural-torsional (or lateral) buckling.

Extensive research has been performed on the evaluation of the lateral-torsion buckling behavior of beams. Most of this research is focused on steel on Fiber-Reinforced Plastic (FRP) I-beams. An energy method was proposed by Hughes and Ma (1996) for analyzing the lateral-torsional buckling of monosymmetric steel I-beams under distributed vertical load and point load. The research on the flexural-torsional buckling behavior of FRP beams includes but is not limited to Pandey (1995) on flexural-torsional buckling of thin-walled FRP I-beams; Lin et al. (1995) on the stability of thin-walled FRP structural beams; Barbero and Raftoyiannis (1994) on the lateral and distortional buckling of FRP I-section beams; and Mottram (1992) on the flexural-torsion buckling behavior of pultruded E-glass FRP I-beams. In particular, Davalos and Qiao (1997) performed a combined analytical and experimental evaluation of flexural-torsional and lateraldistortional buckling of FRP composite wide-flange I-beams. Using nonlinear elastic theory, they derived the total potential energy equations for instability of the FRP sections based on the 
energy principle. These models were validated through experimental testing and finite element analysis.

There is very limited information on the buckling behavior of prefabricated wood I-joists, as stated by Zhu et al. (2005), "so far there are hardly any published studies on the buckling of wood I-joists, despite the fact that test evidence from this study showed clearly that buckling is indeed a prominent problem." This study addressed the buckling behavior of five joists. Hindman et al. (2005) did, however, test several prefabricated wood I-joists in order to develop a model for predicting lateral-torsional buckling loads. Saliklis and Mussen (2000) studied the buckling of oriented strand board panels both experimentally and numerically. The numerical modeling assumed OSB to be an elastic orthotropic material for eigenvalue buckling analysis, and it was modeled as a bilinear elasto-plastic material for nonlinear buckling analysis.

There are typically two ways to increase the buckling capacity of a wood composite I-joist. The first is to use high quality materials and increased cross-sectional dimensions. Secondly, improving the design of the joist, such as incorporating a corrugated web increases the resistance to buckling. As far as the author is aware, there are currently no available studies on the buckling behavior of wood I-joists with sinusoidal web.

\subsection{Corrugated Beams}


Engineers have long realized that profiling of the web of "I" shaped sections can enormously increase a beam's stability and can result in very economical designs. Corrugated beams are characterized by their high in-plane and out-of-plane geometrical stability. Corrugation of the web is essentially a universal stiffening of the beam in the transverse direction. Therefore, when compared to beams with flat webs, it can be found that corrugation enables the use of a thinner web and eliminates the need for stiffeners (Wang 2003). The profiling of the web provides generally avoids failure of the beam due to loss of stability before the plastic limit of the web is reached. Corrugated web beams may be used as roof or slab beams, or even as columns or frame columns.

Manufacturing of beams with corrugated webs began in Europe in the 1960s (Metwally 1998) for use in steel-framed buildings. The designs were adopted for highway bridges in Europe and Japan beginning in the 1980s (Abbas 2003). The profile of the corrugation was traditionally trapezoidal, but now beams are also manufactured with triangular, rectangular and sinusoidal shapes. The most commonly used profile for corrugated web steel girders is still the trapezoidal configuration (Sayed-Ahmed 2005). However, the sinusoidal configuration has the advantage over the others in that it eliminates the local buckling of the flat plate strips.

Extensive research has been conducted on I-beams with corrugated webs; however, this research is mainly limited to steel beams. Among others, Lindner (1990) studied the linear elastic inplane, torsional, and lateral-torsional behavior of corrugated web I-girders; Johnson and Cafolla (1997) studied the local flange buckling; and Sayed-Ahmed (2005) performed a numerical analysis of the lateral torsion-flexure buckling of steel girders with trapezoidal corrugated webs. 
He concluded that the girders with trapezoidal webs had a $12 \%$ to $37 \%$ higher resistance to lateral buckling than girders with traditional plane webs. Elgaaly et al. (1997) conducted experimental and analytical evaluations of the ultimate bending stress of corrugated web I-joists and Chan and Khalid (2002) studied the effect of web corrugation of the bending capacity of an I-beam using finite element analysis. Easley (1975) tested small-scale diaphragms to determine a formula for calculating shear strength; Smith (1992) determined that the connection between the flange and web is a critical element of shear strength; Hamilton (1993) found that dense corrugation profiles are more likely to result in global shear failure of the I-beam; and Luo and Edlund (1995) used finite element analysis to perform a parametric study on the depth of the corrugation and concluded that the depth only had a minor effect on shear capacity but did affect the degree of the localization of the buckling mode. It has been shown that corrugated web Igirders have improved stability than conventional I-girders with flat webs (Abbas 2003).

\subsection{Objectives and Scope}

This study is focused on the evaluation of composite I-joists with sinusoidal web geometry, both in terms of experimental investigation and finite element analysis. The study provides a comparison of joists manufactured with both flat and sinusoidal webs with equivalent volume at two different depths. The main goals of this study are to determine the effect of the profiling of the web and the depth of the joist on the overall strength and stability of the joist through finite element analysis and experimental testing. 
A new engineered wood composite web panel was developed at West Virginia University using discarded veneer-mill residues. An investigation into the physical and mechanical properties was performed in a preceding thesis (McGraw 2009). The results of this study showed that a very high quality composite can be produced from this waste material. The veneer strand composite proved to have higher bending, compression, tension, and shear properties than plywood and OSB, the most common web materials used in prefabricated I-joists.

Using these newly developed composite web panels, full scale I-joist samples were manufactured at two different depths with flat and sinusoidal web geometries. These joists were put through a series of rigorous tests to evaluate certain properties and behaviors. The specific individual objectives of this study on of the effect of web profiling and depth on these joists are as follows:

1. To study the effect of compression on the web. The goal was to observe the local buckling behavior of the web under in-plane compression.

2. To evaluate the lateral-torsional buckling response of the I-joists.

3. To determine the torsional stiffness of the joists.

4. To determine the strength and stiffness of the joists through a four-bending analysis as well as to study the modes of failure.

5. To develop a finite element model of these I-joists and to compare and correlate the experimental testing results with the finite element analysis. 


\subsection{Organization}

There are a total of seven chapters in this thesis. An introduction and literature review are presented in Chapter 1. Also, the objectives and scope of work and the organization of the thesis are given.

A description of the joist samples and finite element modeling procedure is given in Chapter 2. This includes the manufacturing and the geometry of the I-joist specimens as well as an overview of the production of the composite web panels and description of the web material. The naming conventions of the joist samples are described as well as a detailed description of the testing protocol. The basic principles of the finite element model used to is outlined and the equivalent properties of the joists are given.

An analysis of the I-joist web under compression is presented in Chapter 3. The experimental procedures as well and samples specific to this test are described. The results of the experimental evaluation and failure modes are presented. Also, the result of the finite element analysis as well as a comparison between the experimental testing is offered.

Chapter 4 describes the evaluation of the lateral-torsion buckling of composite I-joists. This was accomplished using a cantilever beam with tip loading. Details on the testing method and apparatuses developed for this test are given. The description and results of the finite element analysis are given as is a comparison with the experimental results. 
An experimental of the finite element analysis of the I-joists in torsion is presented in Chapter 5. A detailed description of the torsion machine and used an instrumentation of the samples for this testing is given. This chapter also discussed the calculation of the rotational stiffness via this testing method. Proof of concept is also offered by experimental testing of a beam with known shear modulus. A finite element analysis is also given, and once again verified through modeling of the sample with known shear properties. The results and discussion of the experimental evaluation and finite element analysis of the composite I-joist samples are shown.

A four-point bending analysis of the I-joist is described in Chapter 6. Detailed information on the testing setup as well as instrumentation of the samples is provided. An explanation of the resulting strains and description of how they were used in the calculation of the stiffness of the beams is given. The bending strength, stiffness, and critical loads are given for each sample. A finite element analysis on the critical loads of the beams is presented as well as a comparison with the experimental results. A detailed discussion on the failure modes observed in the samples is also provided.

Finally, in Chapter 7, the experimental results and finite element analysis of the I-joist with flat and sinusoidal webs evaluated at two different heights are summarized to draw significant conclusions and make recommendations for future studies. 


\section{CHAPTER 2}

\section{TEST SAMPLES AND FINITE ELEMENT}

\section{MODELING}

\subsection{Test Samples}

All I-joist samples used in this research were manufactured in-house. The composite web panels were manufactured using equipment owned by the Wood Science Department at West Virginia University. The veneer-mill clippings as well as the flange stock were donations.

\subsubsection{Composite Web Panels}

The composite web panels were manufactured from recycled veneer-mill clippings. All panels were produced from Black Cherry (Prunus Serotina) clippings which were donated by the Universal Veneer Company located in Newark, Ohio. The resin that was used in panel manufacture was donated by the Weyerhaeuser OSB mill in Heaters, WV.

Two types of clippings are produced from flat slicing, side clippings and end clippings. The vast majority of clippings used in panel manufacture were side clippings (Figure 2.1a). These 
clippings range any from approximately 3 to 13 feet in length and 1 to 2 inches in width with a thickness of 0.015 in.

The clippings trimmed and dried to moisture content of 5\%. Then, the individual strands were coated with a phenol formaldehyde resin, to a resin content of approximately $5 \%$ by weight, and a mat was formed by aligning all the strands in one direction. The mat was then placed in a 200ton hot press with 30" x 30" heated platens. Using a specific pressing schedule (McGraw 2009) the composite panels were produced. An aluminum template was manufacture to achieve the sine wave geometry. The geometry of the template is shown in Figure 2.1b.

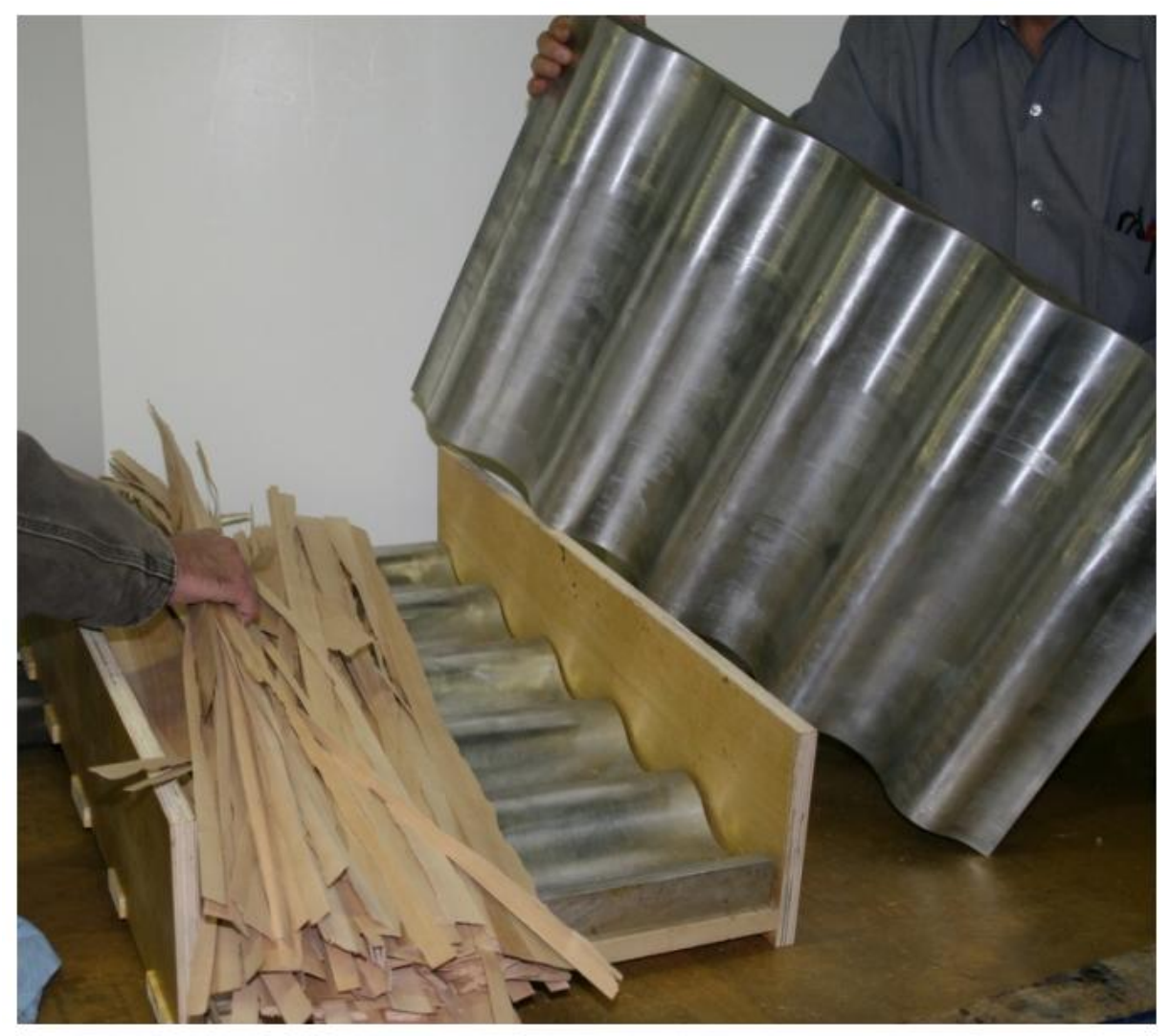

(a) Veneer-Mill Clippings and Template 


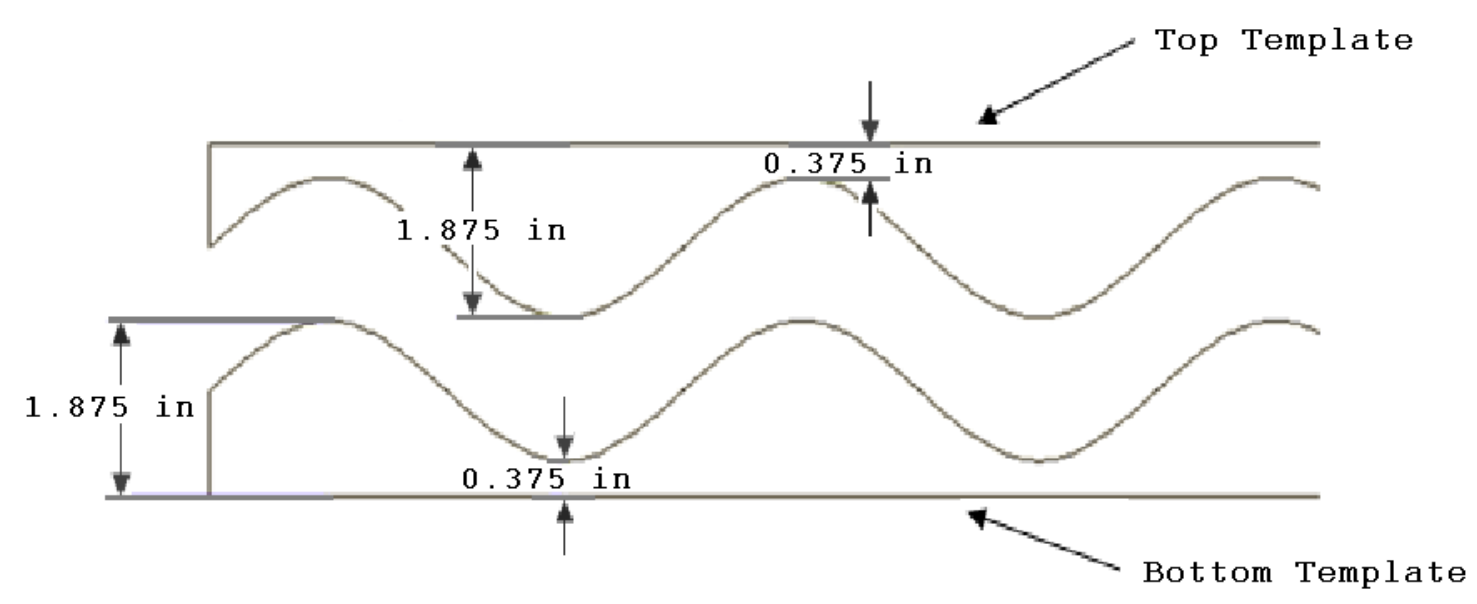

(b) Geometry of Sinusoidal Wave Template

Figure 2.1 Veneer-Mill Clippings and Sinusoidal Wave Template

The flat and sinusoidal web panels were manufacture with an equivalent volume. The flat panels were pressed to a thickness of 0.375 ". In the case the sinusoidal web panels; the templates maintained a constant vertical distance between one another during pressing. This produced panels in which the thickness varies slightly through the length of the curve. The templates were designed this way so that multiple panel geometries could be manufactured. To produce sine wave panels with equivalent volume, panels were manufactured with an average thickness of 0.329" where the thickness at the apex of the sine wave to 0.375 ". Finished flat and sinusoidal web panels are shown in Figure 2.2. 

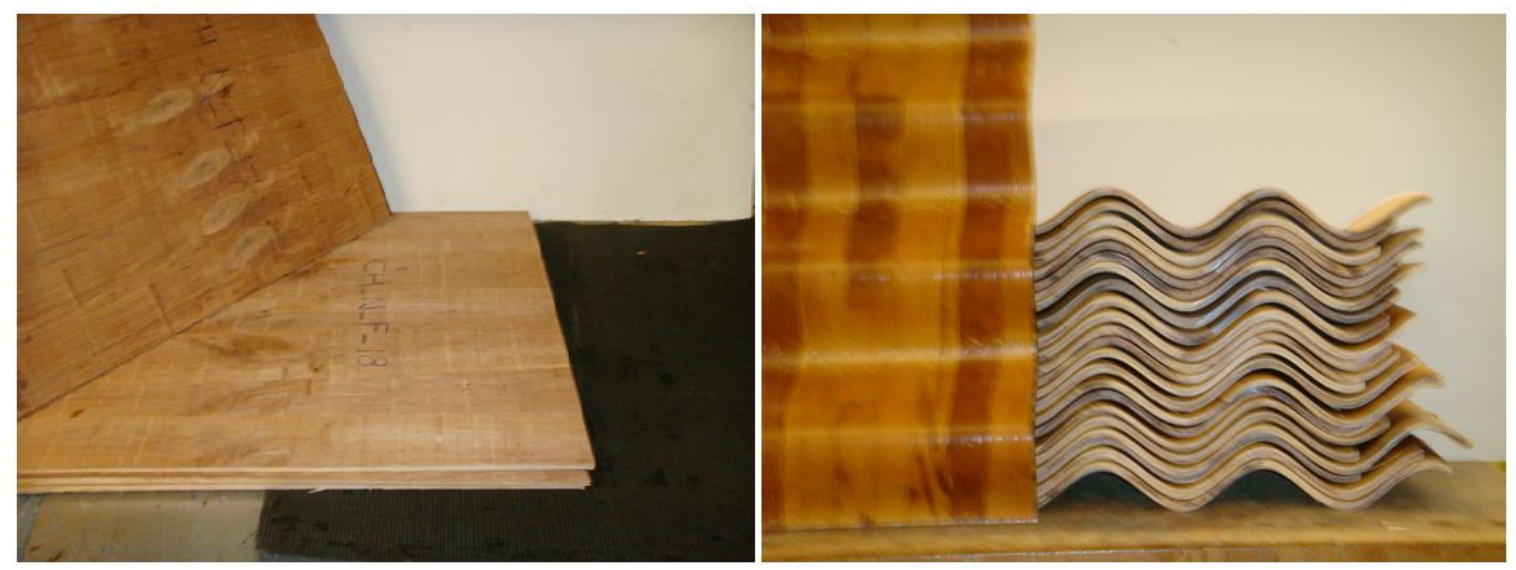

Figure 2.2 Finished Flat and Sinusoidal CompositeWeb Panels

Extensive testing has been performed to determine the physical and mechanical properties of these new composite panels. The testing and results are discussed in detail in a previous thesis (McGraw 2009). It was shown that these composite panels were superior in terms of bending strength and stiffness, tensile strength, compressive strength, and strength in rolling shear to panels commonly used as web material in prefabricated I-joist.

\subsubsection{Flange Material}

The flange stock used for the construction of these composite I-joists was laminated veneer lumber (LVL). The material was donated by the Weyerhaeuser Trus Joist Company in Buckhannon, WV. This is the most common flange stock used in the prefabricated I-joist industry. In this case all joists were constructed using 15-layer Yellow-poplar (Liriodendron Tulipifera) LVL. 


\subsubsection{Manufacture of Joist Specimens}

Four different geometries of I-joist were constructed for this research. Joists were manufactured at two different depths $(D), 10 "$ and 16", both with flat and sinusoidal web geometries. As mentioned in Section 2.1.1, flat panels were manufactured with a thickness of 0.375 " and the average thickness of the sinusoidal panels was 0.329 ". The LVL used for the flanges was 1.75 " in thickness and was cut into widths of $2.3125 \%$. The cross-sectional geometries of the joists are shown in Figure 2.3.
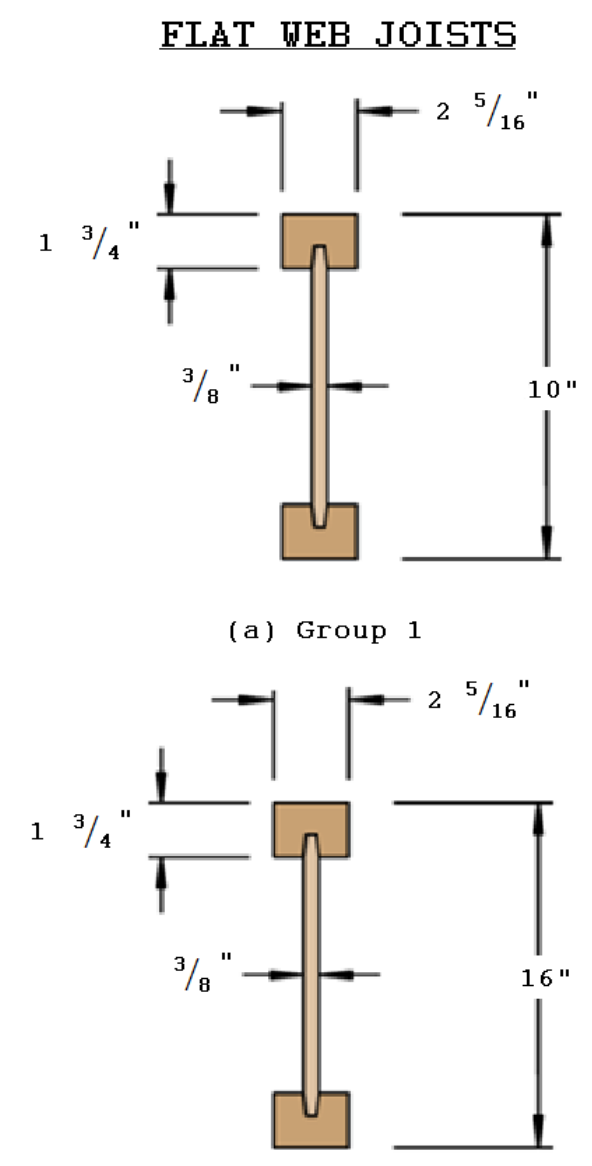

(c) Group 3
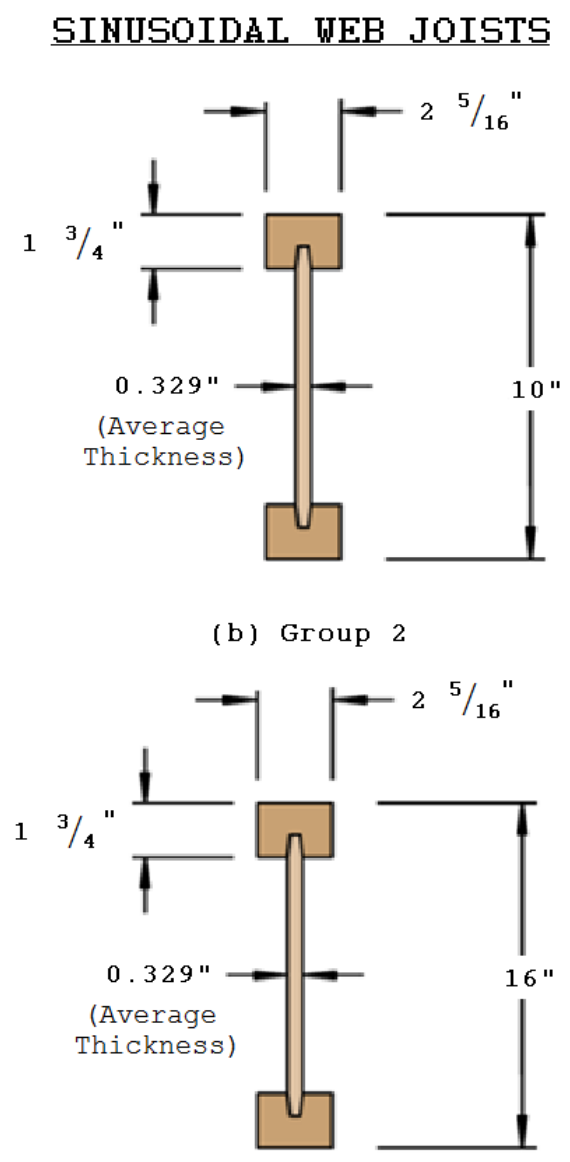

(d) Group 4

Figure 2.3 Cross-Sectional Geometries of the Four I-Joist Groups 
The flange-to-web connection was achieved using tongue and groove jointing. This joint is a critical part of the joist integrity (Leichiti et al. 1990). Using a hand router and template for the sinusoidal wave joists and a table saw with a specialized blade the groove was cut 0.375 " deep down the center of the LVL flanges. The edges of the web panels were sanded to fit snugly into the flanges.

Due to size limitations of the hot press, panels could only be manufactured at a maximum 30" in length. Therefore, a method for connecting the web panels had to be devised. It was decided that finger jointing was the best method (McGraw 2009). For the flat panels finger joints were cut along the width of the panels and offset for the next panel to create a smooth connection. The length of the joint was 0.375 ". To connect the sine wave panels the joints had to be cut at the apex of the wave to achieve a matching connection.

A cold setting phenol resorcinol formaldehyde liquid resin and hardener slurry were used to bond the flange-to-web and web-to-web connections. The resin and hardener were mixed and quickly spread evenly through the grooves on flanges and the finger joints on the web panels. The joist was then assembled, fixed with a series of clamps, and left to harden for at least 12 hours before the clamps were removed. The joists were manufactured at a length of 16 feet. They were shortened to 14 feet as that is the maximum length that the torsion machine (See Figure 5.1 in Chapter 5) would allow. The leftover sections were used for the evaluation of the I-joist web under compression. 


\subsubsection{Naming Convention}

As mention in the previous section, four different joist geometries were manufactured. There were also four samples within each group. The same joists were used for all tests. The joists were individually numbered by group (Figure 2.3) and sample number. The naming convention is shown in Figure 2.4.

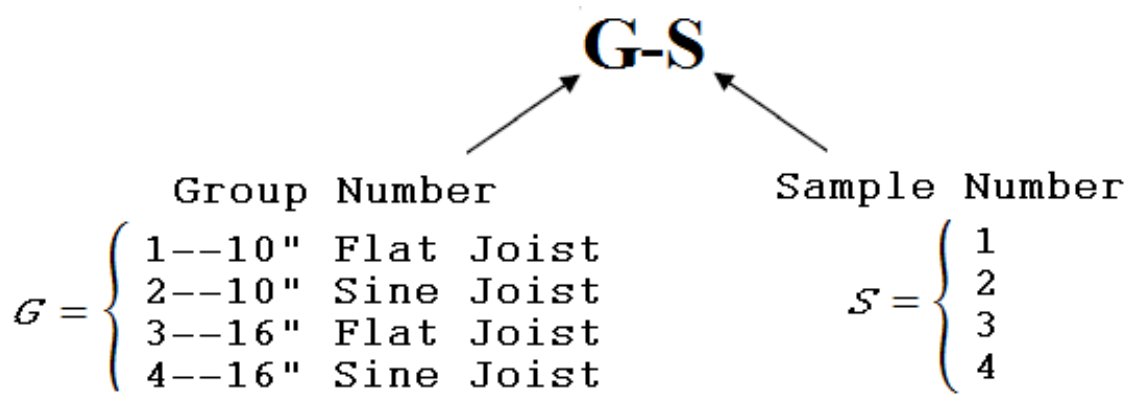

Figure 2.4 Joist Naming Convention

\subsection{Testing Protocol}

The same beam samples were used for all of the experimental evaluations. The lateral-torsional buckling and torsion tests were non-destructive and it was necessary that they be performed prior to the bending tests where all samples were loaded to failure. This section provides a background for the testing arrangements of the samples. 


\subsubsection{Compression}

There were a total of 16 samples used for the experimental evaluation of the web of the composite I-joists under compression. There were four samples tested from each group, each was a total of 6" in length. As in the case of the full sized joists, the flat and sinusoidal samples have equivalent volumes. The experimental procedure and results and given in Chapter 3.

\subsubsection{Lateral-Torsoinal Buckling}

A cantilever test method was used to evaluate the lateral-torsional buckling behavior of the joists. The testing and results are discussed in detail in Chapter 4. All 16 full joist samples were evaluated. This test did not destroy the samples and when the load was removed all the beams returned to their original configuration. A set of holes had to be drilled into the neutral axis at 3" and 6" from one end of the beam to accommodate for the hanger from which the load was applied. This does not interfere with the two final tests as this was outside of the area of the beam evaluated in torsion and the span of the four-point bending test.

\subsubsection{Torsion}

Many different approaches and configurations were first used for the torsion test. The final test involved 3 joists from each group 3 and 4 (the 16" deep joists). These joists were tested at the maximum length allowed in the torsion machine, $14 \mathrm{ft}$. To have a similar length to depth ratio, one joist from each group 1 and 2 (10" deep joists) were trimmed to 10 feet in length. Once again 
this is a non-destructive and the samples would be reused in the final test. The experimental procedures and results are presented in Chapter 5.

\subsubsection{Four-Point Bending}

The final test performed on the joists samples was an evaluation in four-point bending. All beams were loaded to failure to determine the stiffness and evaluate the failure modes. All 16 joists were tested, 3 from each group at a span of 160" and one from each group at a span of 112”. The experimental testing procedures and results are given in Chapter 6.

\subsection{Finite Element Modeling Procedure}

Finite element modeling is a very useful tool for providing verification and predictions of experimental responses. A background is presented on the formulation of the FE models used in this study. Finite element analysis was used to providence confidence in the data collected from the experimental studies. Each of the four experiments performed on the joists were supplemented with FE analysis. Further detail on each individual model is provided in the subsequent chapters.

The following sections describe the formulation of the geometric models used for the finite element analysis of both the flat and sinusoidal web joists. Also, details are given on the equivalent properties used for the modeling of both the flanges and the web. The commercial 
finite element program ABAQUS version 6.7 (2007) was used for the analysis, while FEMAP version 8.3 (2003) was used for pre- and post-processing.

\subsubsection{Formulation of the Geometric Model}

The purpose of generating the finite element model was to reproduce and simulate the beam samples as accurately as possible. The geometry of the I-joist consists of a top and bottom flange and a web with either flat or sinusoidal geometry. The geometry of the joists is described in Section 2.1.3.

Both the flanges and the web were modeled using 8-node shell elements, S8R. A convergence study was performed to determine the size of the mesh. It was determined that for the flanges and the flat web, a mesh size of 2 " $x 2$ " with a minimum of 4 elements across the depth of the web and width of the flange was to be used. The sinusoidal web was more challenging to model. The modeling of the sinusoidal curve was performed in AUTOCAD and exported into FEMAP. The curve was extruded and the web was model as a series of connected surfaces. For a comparable volume, the thickness of the sinusoidal web was modeled as the average thickness of 0.329 " as shown in Figure 2.3. A different mesh had to be created for a sinusoidal web, and an approximate mesh size of $0.425 " \mathrm{x} 0.95$ " was used. The final full scale models for the flat and sinusoidal joists are shown in Figures 2.5 and 2.6, respectively. 


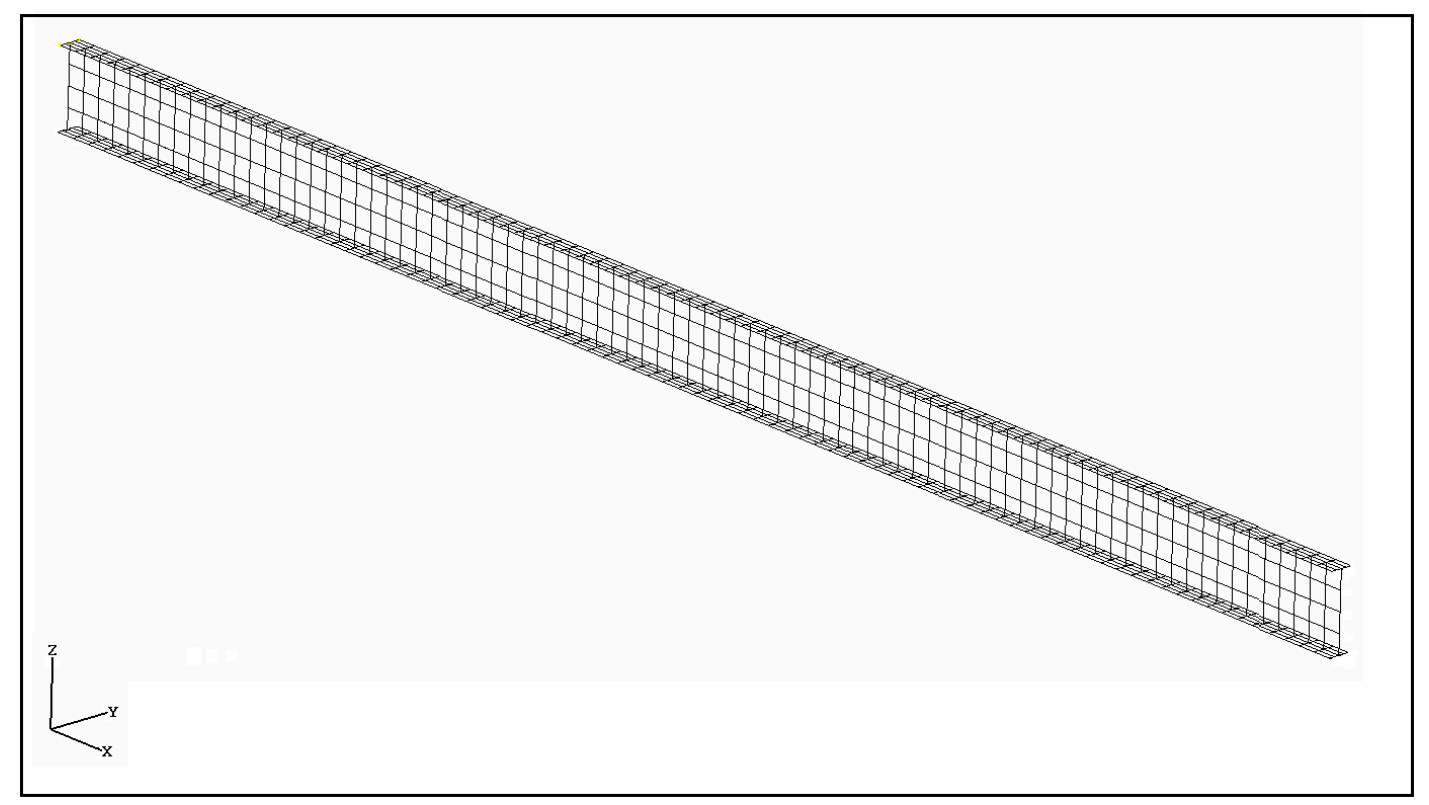

Figure 2.5 Finite Element Model of Composite I-Joist with Flat Web

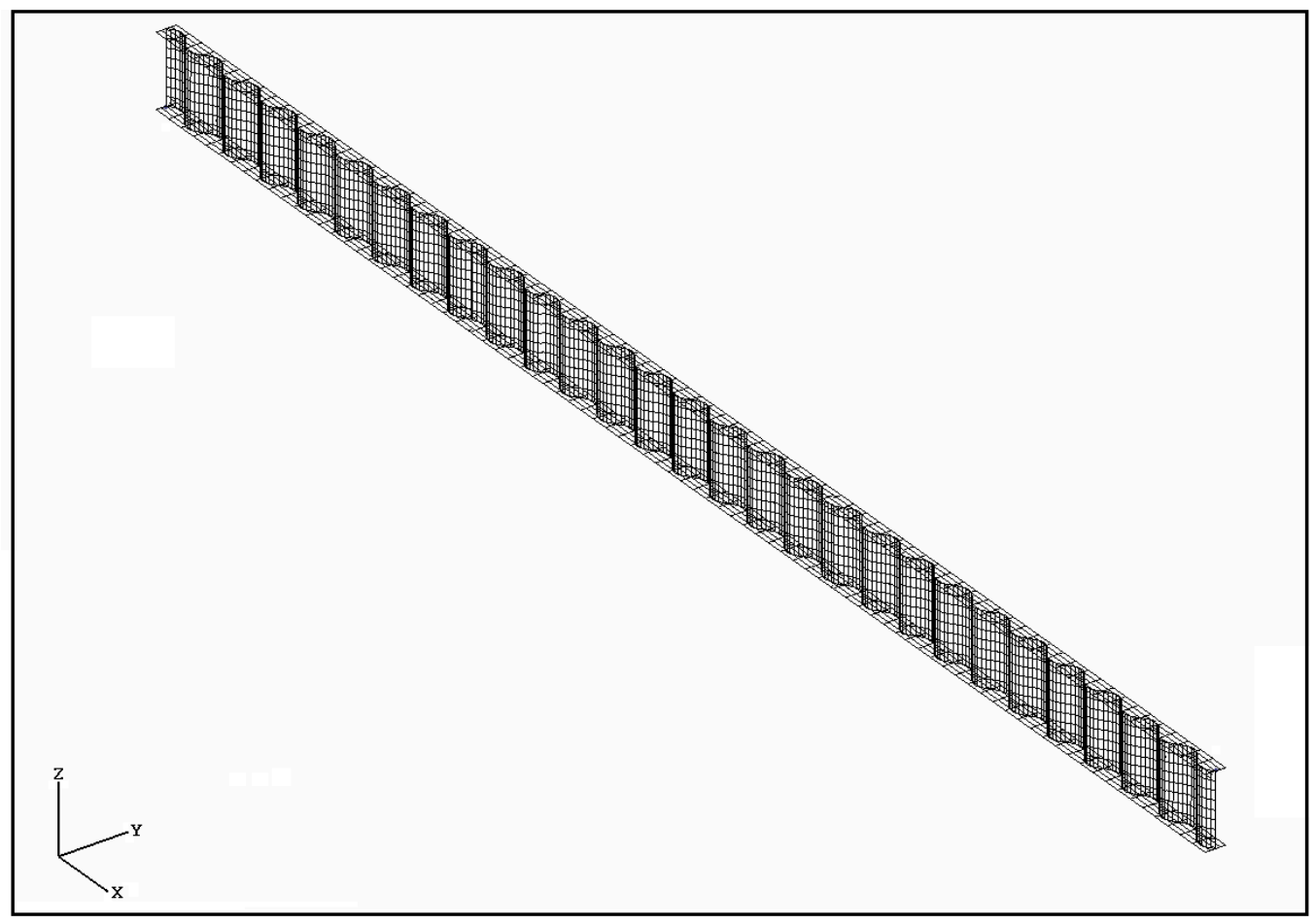

Figure 2.6 Finite Element Model of Composite I-Joist with Sinusoidal Web 


\subsubsection{Equivalent Properties}

The flanges and the web both were modeled as $2 \mathrm{D}$ orthotropic material properties. Therefore, 5 material constants had to be defined for each the flanges and the web: the modulus of elasticity in the principle direction, $\mathrm{E}_{1}$; the modulus of elasticity in the transverse direction, $\mathrm{E}_{2}$; the inplane shear modulus, $\mathrm{G}_{12}$; and the two out-of-plane shear moduli, $\mathrm{G}_{1 \mathrm{z}}$ and $\mathrm{G}_{2 \mathrm{z}}$ (or $\mathrm{G}_{13}$ and $\mathrm{G}_{23}$ ). These equivalent material properties are given in Table 2.1.

Table 2.1 Equivalent Material Properties

\begin{tabular}{lccccc}
\hline & $\mathbf{E}_{\mathbf{1}}$ (psi) & $\mathbf{E}_{\mathbf{2}}$ (psi) & $\mathbf{G}_{\mathbf{1 2}}$ (psi) & $\mathbf{G}_{\mathbf{1 z}}$ (psi) & $\mathbf{G}_{\mathbf{2 z}}$ (psi) \\
\hline Web & $2.26 \mathrm{E}+06^{1}$ & $1.80 \mathrm{E}+05^{1}$ & $1.52 \mathrm{E}+05^{3}$ & $1.48 \mathrm{E}+05^{3}$ & $1.48 \mathrm{E}+05^{3}$ \\
Flanges & $1.94 \mathrm{E}+06^{2}$ & $6.40 \mathrm{E}+04^{2}$ & $6.10 \mathrm{E}+04^{3}$ & $6.70 \mathrm{E}+04^{3}$ & $6.70 \mathrm{E}+04^{3}$ \\
\hline${ }^{1}$ McGraw (2009) & & & & \\
${ }^{2}$ Bejo (2001) \\
${ }^{3}$ Qaio and Davalos (2011)
\end{tabular}

Previous research done on the web material (McGraw 2009) defined $E_{1}$ and $E_{2}$ by means of small scale bending tests. Bejo (2001) performed an extensive evaluation on modeling the elastic properties of structural composites lumber. This study included the evaluation of Yellow-poplar LVL which was manufactured by the same plant where the flange material was procured. Bending tests were performed to determine $E_{1}$ and $E_{2}$. The shear moduli of these two materials was gathered from a paper in the process of being published concerning research performed at West Virginia University on the evaluation of the shear stiffness of wood and wood composites (Qiao and Davalos 2011). 


\section{CHAPTER 3}

\section{EVALUATION OF I-JOIST WEB IN}

\section{COMPRESSION}

\subsection{Introduction}

Local web buckling of the joist is an important issue that must be considered due to the relatively low stiffness and thin-walled nature of the web. Because of the thin-wall of the web these joists are likely to fail due to local compressive or shear buckling. An experimental evaluation of the Ijoists samples under compression is presented. The experimental results are supplemented by finite element analysis.

\subsection{Experimental Investigation}

Compression testing was carried out on I-joist samples to evaluate web local buckling behavior. Four joist samples were evaluated from each group, for a total of 16 tests. The specimens were cut from the full scale I-joists described in detail in Section 2.2.1. Both samples with flat and sinusoidal web geometries were cut to lengths of 6" to attain a representative sample of a full joist. 


\subsubsection{Test Setup and Instrumentation}

The compression testing was performed in a universal testing machine with an approximate 67,000 lb capacity. The universal testing machine was equipped with a self-aligning crosshead. A loading block was used to apply uniform load across the top flange of the joist. A 10-kip load cell was placed between the crosshead and a loading block. Two LVDTs were used, with one placed an equal distance from either side of the sample. Also, strain gages were bonded at mid height on either side of the sample to record compressive strains. The testing setup is shown in Figure 3.1.

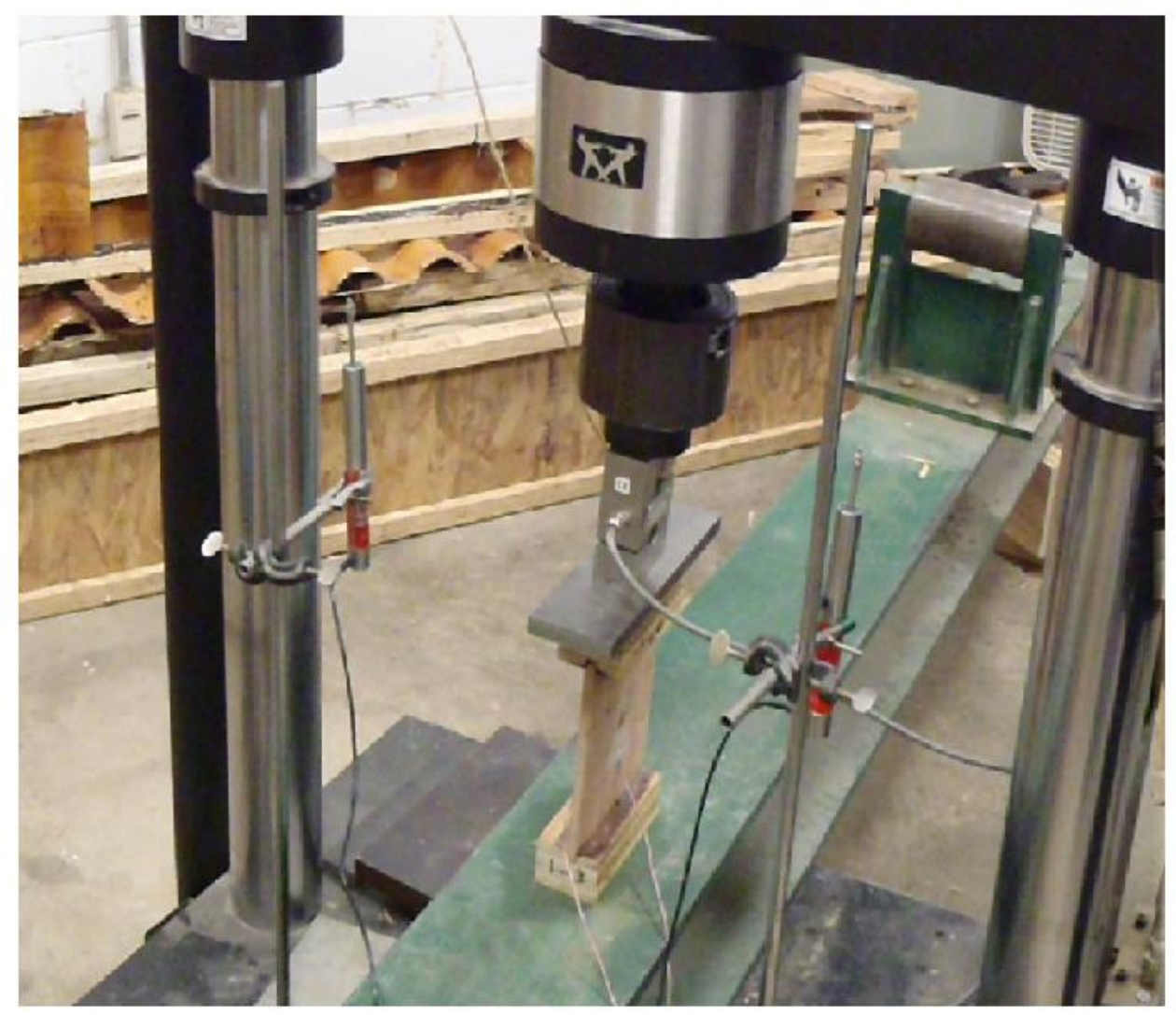

Figure 3.1 I-Joist Under Compression 


\subsubsection{Experimental Procedure}

Testing was carried out according to ASTM D5055-05 (2005) standards. Four specimens for each of the four different joist geometries were evaluated. It should be noted that the same section of the sinusoidal wave of the web was evaluated for each sample. The 6" specimen length was chosen because it incorporates two full sine waves. The loading rate was controlled such that each sample reached failure within 10 minutes. The load, deflections, and strains were recorded using an external data acquisition system.

\subsubsection{Test Results and Discussion}

Typical load-displacement and load-strain curves are shown in Figures 3.2 and 3.3. From these figures it can be seen that the specimens exhibit an approximate linear behavior. Also, the LVDTs which measured displacement of the crosshead on either side of the beam showed very similar displacements. Also, the strain gages placed at mid height on either side of the beam recorded similar compressive strains.

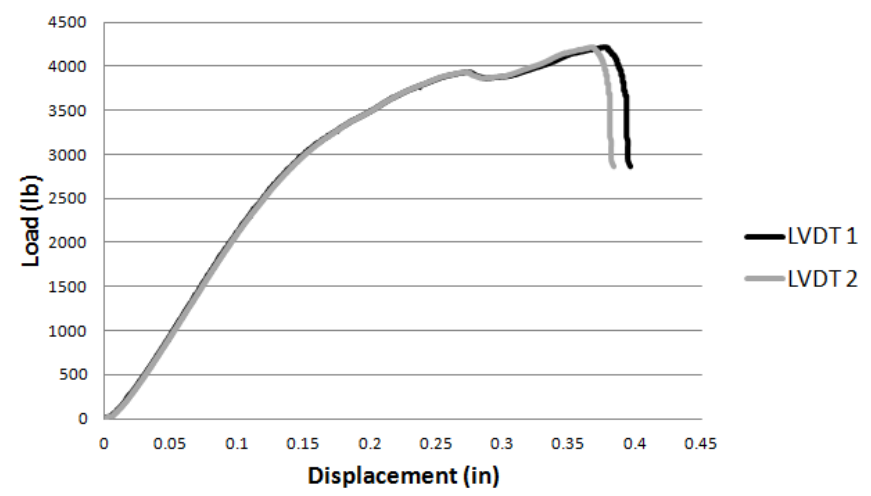

Figure 3.2 Load vs. Displacement Plot of Typical Joist Sample in Compression 


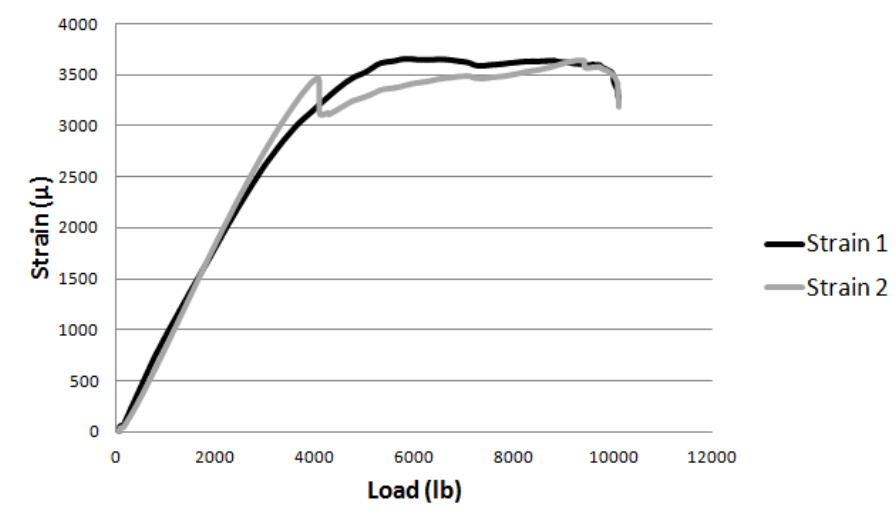

Figure 3.3 Strain vs. Load Plot of Typical Joist Sample in Compression

The results of the compression testing on the 10 " flat web joists samples are shown below in Table 3.1. Good agreement was shown between samples 1, 2, and 3. Sample number 4 had an uncharacteristically high critical load when compared to the other samples. Because of the average $50 \%$ difference between sample 4 and the rest of the group it will be removed from the final results shown in Table 3.5.

Table 3.1 Experimental Results of 10" Flat Web Joist Samples in Compression

\begin{tabular}{cc}
\hline $\begin{array}{c}\text { Sample } \\
\text { No. }\end{array}$ & P $_{\text {cr }}(\mathbf{l b})$ \\
\hline 1 & 1618 \\
2 & 1308 \\
3 & 1244 \\
4 & 2734 \\
\hline
\end{tabular}

Table 3.2 shows the critical loads of the four 10" sinusoidal web joist samples evaluated in compression. There is a wide range in the resulting critical load values. However, sample 1 was 
considerably low, with an average difference of $60 \%$ with the other 3 samples. This result was removed from the final group average value.

Table 3.2 Experimental Results of 10" Sinusoidal Web Joist Samples in Compression

\begin{tabular}{cc}
\hline $\begin{array}{c}\text { Sample } \\
\text { No. }\end{array}$ & P $_{\text {cr }}(\mathbf{l b})$ \\
\hline 1 & 1676 \\
2 & 3414 \\
3 & 5390 \\
4 & 4393 \\
\hline
\end{tabular}

The results of the compression testing of the 16" flat web joist samples are shown in Table 3.3. The critical loads of samples 1, 2, and 3 showed good correlation. The critical load of sample 4 has an average difference of $50 \%$ between the other samples. Thus, sample 4 will be excluded from the final results.

Table 3.3 Experimental Results of 16" Flat Web Joist Samples in Compression

\begin{tabular}{cc}
\hline $\begin{array}{c}\text { Sample } \\
\text { No. }\end{array}$ & $\mathbf{P}_{\text {cr }}(\mathbf{l b})$ \\
\hline 1 & 763 \\
2 & 1079 \\
3 & 790 \\
4 & 1709 \\
\hline
\end{tabular}

The final group evaluated in compression was the 16 " joist samples with sinusoidal web. The critical load values for all four samples are given below in Table 3.4. There was high variability 
between the critical loads of the four samples. Though, with no clear outliers, the average of all four samples will be used.

Table 3.4 Experimental Results of 16" Sinusoidal Web Joist Samples in Compression

\begin{tabular}{cc}
\hline $\begin{array}{c}\text { Sample } \\
\text { No. }\end{array}$ & $\mathbf{P}_{\text {cr }}(\mathbf{l b})$ \\
\hline 1 & 2866 \\
2 & 3924 \\
3 & 3068 \\
4 & 4217 \\
\hline
\end{tabular}

A summary of the results of the compression testing is given in Table 3.5. Certain values were excluded where mentioned above. The joist with sinusoidal web had significantly higher buckling resistance. In the case of the 10" joists, the critical load was nearly 3.2 times higher for the joists with sinusoidal web. For the 16 " joists, the critical load was over 4 times that of the flat web joists. With the increase in height, the critical load dropped by approximately $35 \%$ for the flat web joists and $20 \%$ for the sine web joists.

Table 3.5 Summary of Joist Samples in Compression

\begin{tabular}{lcccc}
\hline & \multicolumn{2}{c}{ Flat Web Joist } & \multicolumn{2}{c}{ Sinusoidal Web Joist } \\
Joist Height (in) & $\mathbf{1 0}$ & $\mathbf{1 6}$ & $\mathbf{1 0}$ & $\mathbf{1 6}$ \\
\hline Critical Load, $\mathbf{P}_{\text {cr }}$ (lb) & 1390 & 877 & 4399 & 3519 \\
\hline
\end{tabular}




\subsubsection{Failure Modes}

Two distinct failure modes were observed over the course of the web local buckling tests, failure in buckling and failure in shear. An example of failure due to web buckling is shown in Figure 3.4 and an example of failure due to shear is shown in Figure 3.5.

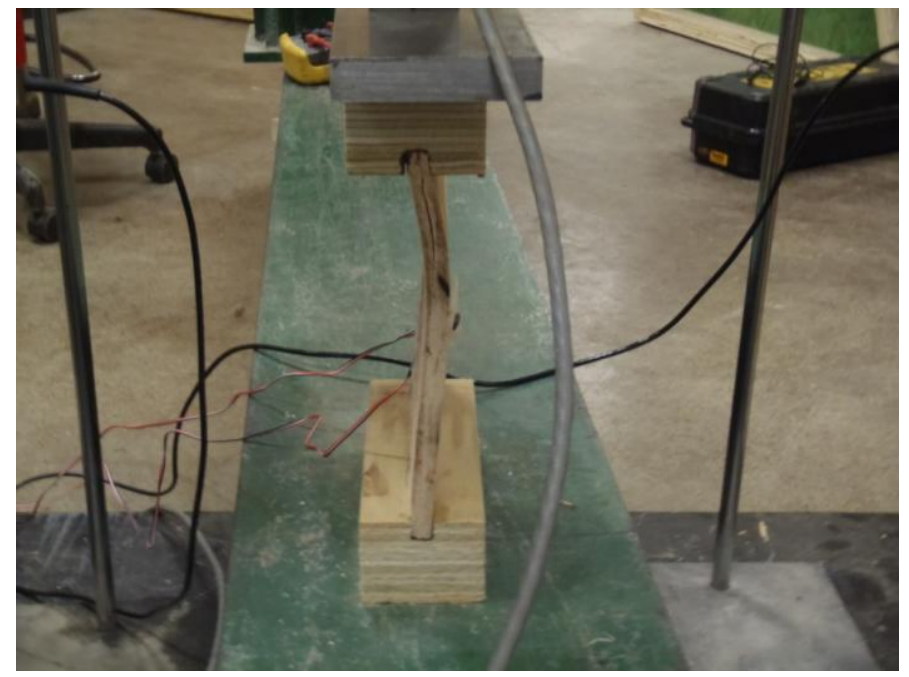

Figure 3.4 Web Local Buckling of I-Joist in Compression

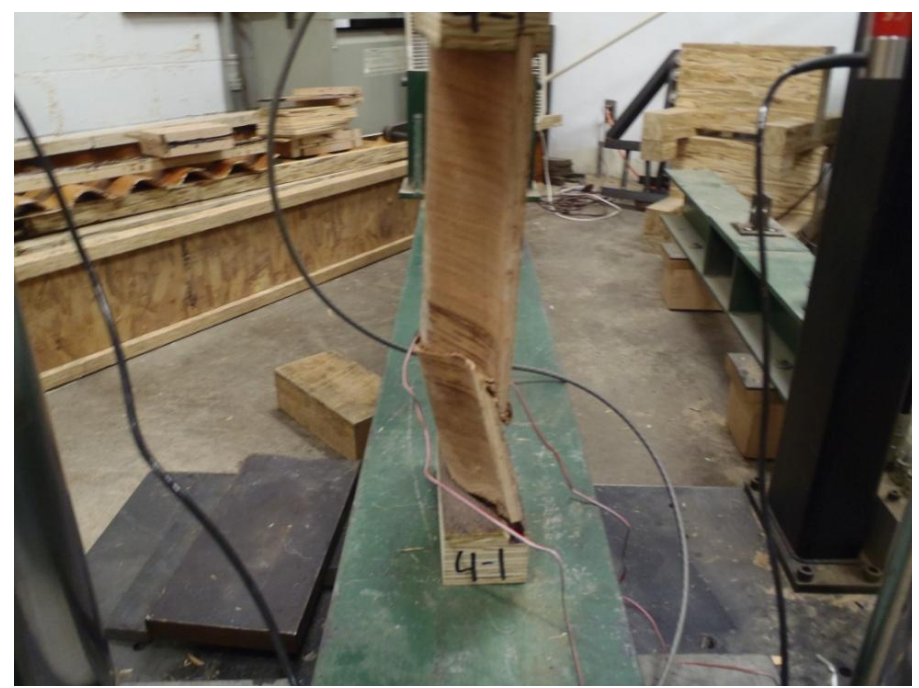

Figure 3.5 Shear Failure of I-Joist in Compression 
The majority of the joists with flat web experienced in due to web buckling. A few instances of shear failure were observed in the 10" deep joists. On the other hand, the sine wave joists tend to fail in shear. Only two cases of failure due to web buckling were observed for the sinusoidal web joists, one at 10" and one at 16".

\subsection{Finite Element Analysis}

A finite element study was performed on the I-joist webs under compression. Two different analyses were performed on each model. It is assumed that the flange-to-web connection is partially restrained. Therefore, an eigenvalue buckling analysis was performed on each model for hinged and clamped boundary conditions. If this assumption is true, the I-joist should buckle at a critical load between these two predicted values.

\subsubsection{Finite Element Model}

To achieve the hinged and clamped boundary conditions only the webs of the joist were used in the finite element model. The corresponding web height used for the FE models of the 10" joist was $6.5 "$, and for the 16 " joist the height of the web was 12.5 ". The boundary conditions were applied to the top and bottom of the web where the connection with the flange is made. The same mesh as described in Section 2.3.1 was used for the model of the webs. To apply the unit load, the nodes along the top of the web were tied together and the load was applied to the central node. The finite element models of the flat and sinusoidal webs are shown in Figures 3.6 and 3.7. 


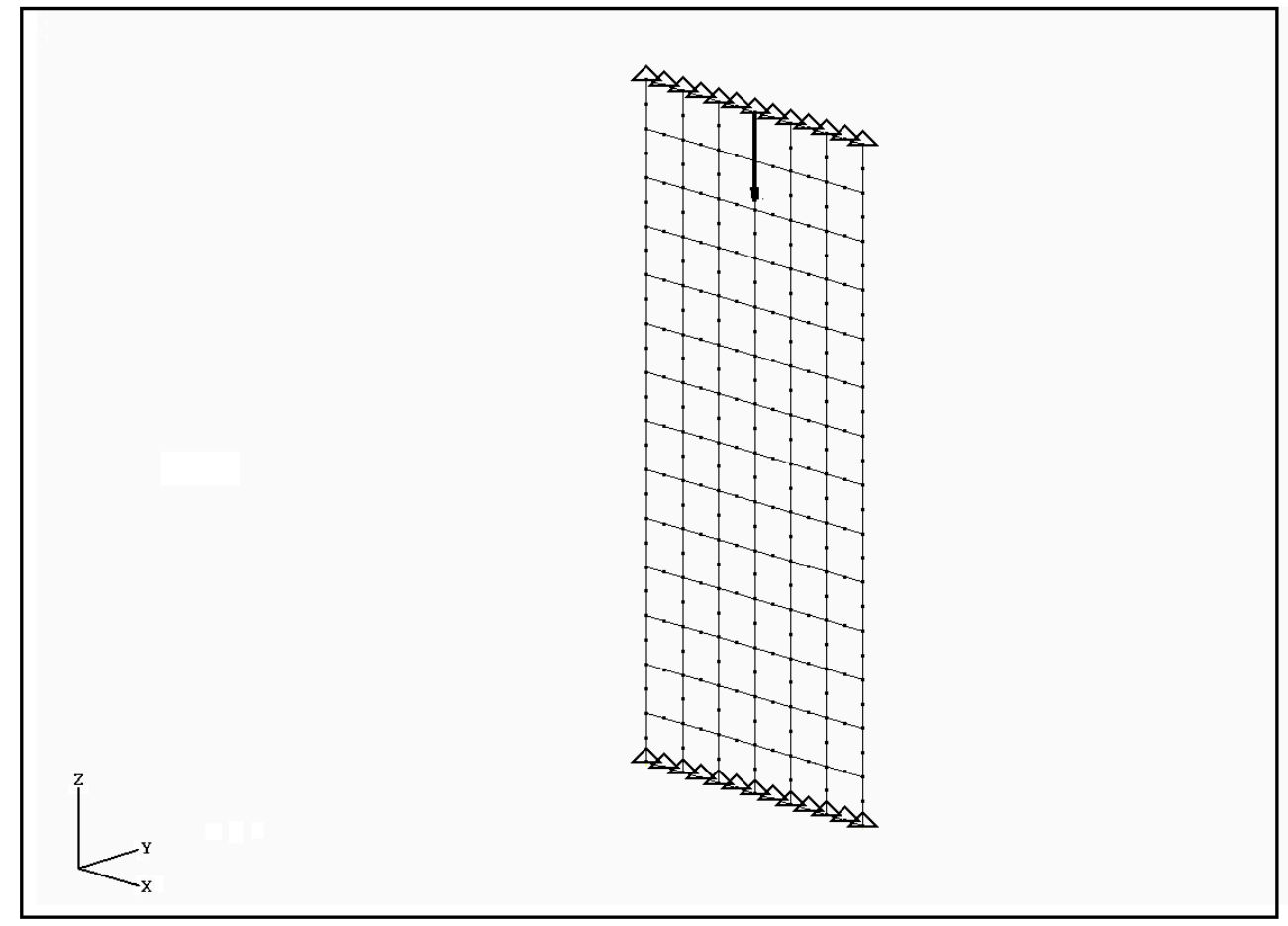

Figure 3.6 Finite Element Model of Flat Web in Compression

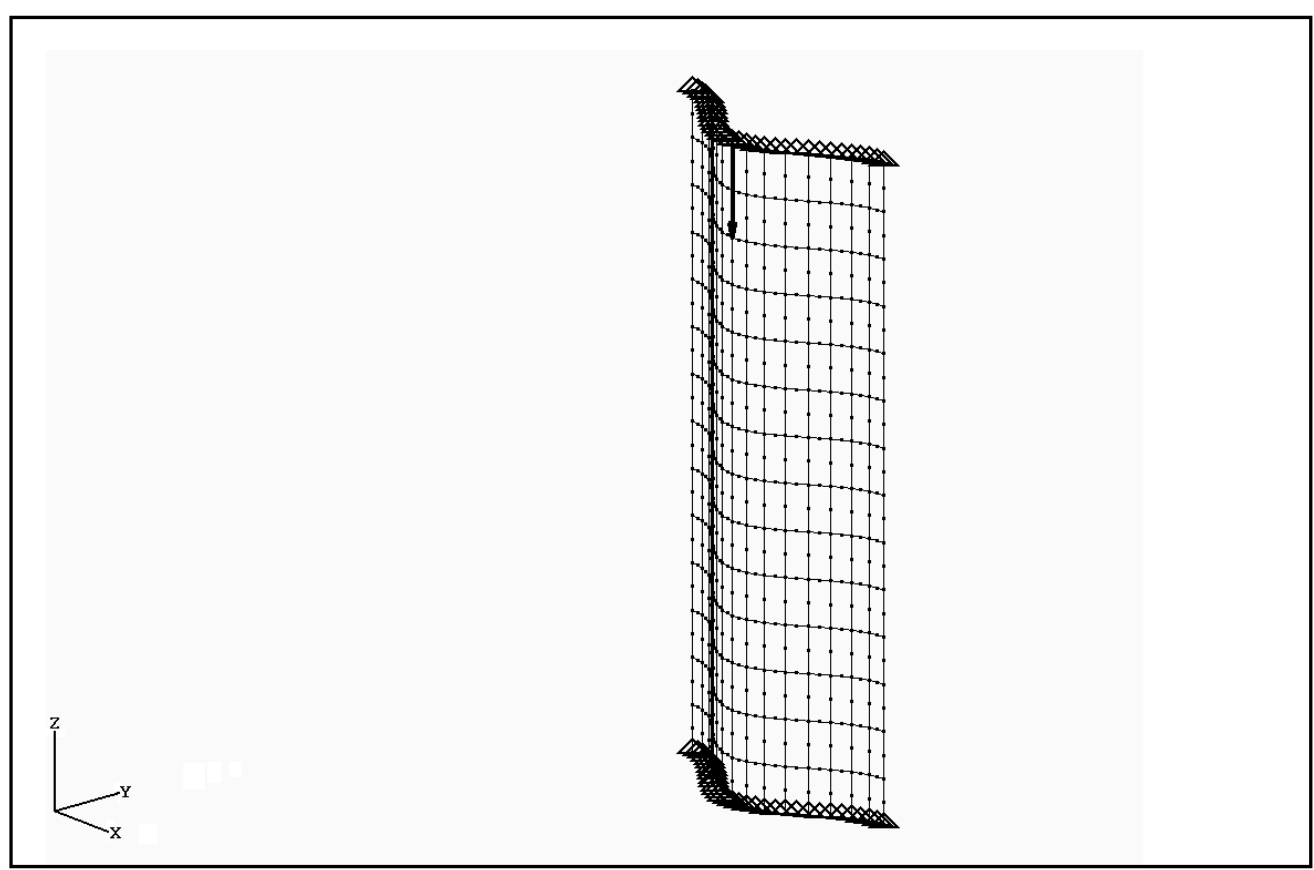

Figure 3.7 Finite Element Model of Sinusoidal Web in Compression 


\subsubsection{Results and Discussion}

The results of the finite element analysis of the web in compression are shown in Table 3.6. The deformed shapes and stress distributions of the buckled flat and sinusoidal webs are shown in Figures 3.8 and 3.9 respectively. Both the deformed shapes and stress distributions are very similar for both sets of boundary conditions.

Table 3.6 Web Compression Results from FE Analysis

\begin{tabular}{lcccc}
\hline & \multicolumn{2}{c}{ Flat Web } & \multicolumn{2}{c}{ Sinusoidal Web } \\
Joist Height (in) & $\mathbf{1 0}$ & $\mathbf{1 6}$ & $\mathbf{1 0}$ & $\mathbf{1 6}$ \\
\hline $\begin{array}{l}\text { Hinged Boundary } \\
\text { Condition, } \mathbf{P}_{\text {cr }}(\mathbf{l b})\end{array}$ & 701 & 238 & 4892 & 3700 \\
$\begin{array}{l}\text { Clamped Boundary } \\
\text { Condition, } \mathbf{P}_{\text {cr }}(\mathbf{l b})\end{array}$ & 2725 & 919 & 5636 & 3858 \\
\hline
\end{tabular}

It can be seen that the predicted critical buckling loads for the sinusoidal web than for the flat web. Also, the differences between the buckling loads for the hinged and clamped boundary conditions are less for the sinusoidal web than for the flat web (by a magnitude of one-third for the web of the 10 " and one-fourth for the web of the 16 " joist). This indicates that the effect of the flange-to-web connection is less critical for the joists with the sinusoidal web. 


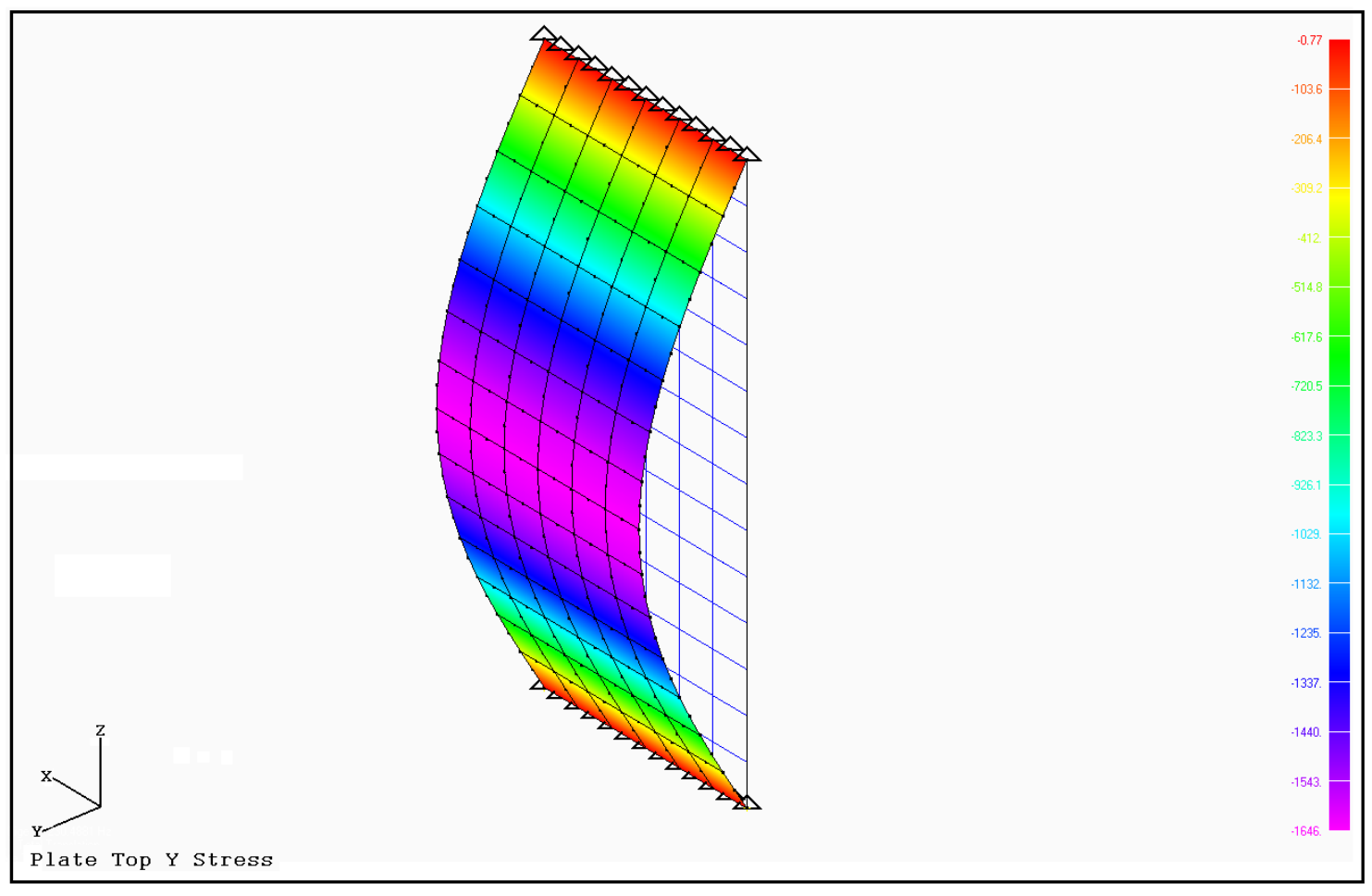

Figure 3.8 Compressive Buckling of Flat Web from FE Analysis

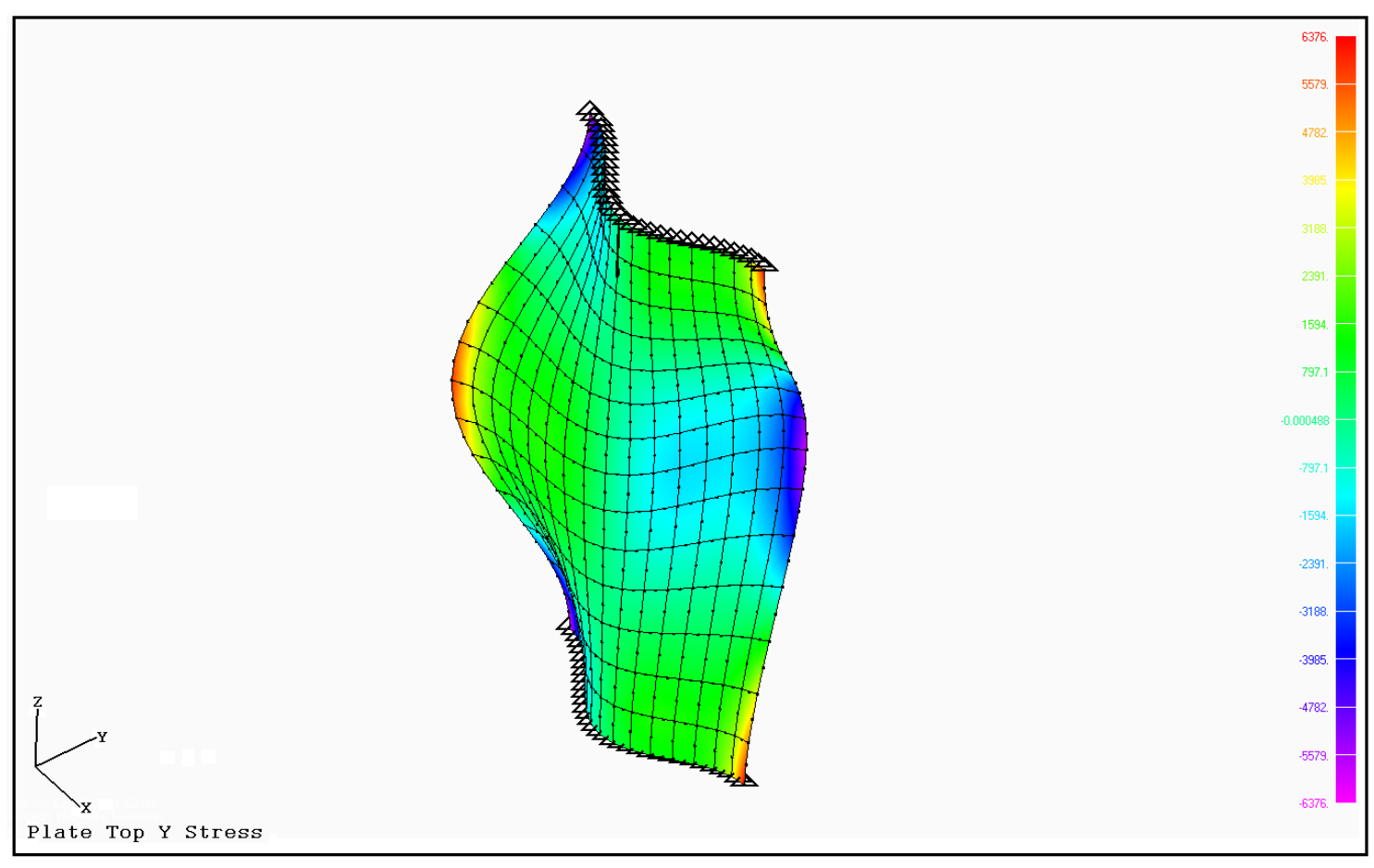

Figure 3.9 Compressive Buckling of Sinusoidal Web from FE Analysis 


\subsection{Comparison of FE and Experimental Results}

A comparison of the results of the finite element analysis and experimental testing is given in Table 3.7. It can be seen that the experimental results fall well within the range predicted by the finite element analysis. However, the experimental results of both the 10" and 16" sinusoidal joists are below the predicted range. But, the vast majority of the sinusoidal joists failed in shear and not buckling. Also, it should be noted that the critical load of two of both of the 10" and 16 " sinusoidal web joists fall within the predicted ranges. For the samples that failed in buckling, the load was within the predicted range.

Table 3.7 Comparison of the Experimental and FE Results of Joists in Compression

\begin{tabular}{lcccc}
\hline & \multicolumn{2}{c}{ Flat Web } & \multicolumn{2}{c}{ Sinusoidal Web } \\
Joist Height (in) & $\mathbf{1 0}$ & $\mathbf{1 6}$ & $\mathbf{1 0}$ & $\mathbf{1 6}$ \\
\hline $\begin{array}{l}\text { Hinged Boundary } \\
\text { Condition, } \mathbf{P}_{\text {cr }}(\mathbf{l b})\end{array}$ & 701 & 238 & 4892 & 3700 \\
$\begin{array}{l}\text { Experimental, } \mathbf{P}_{\text {cr }}(\mathbf{l b}) \\
\text { Clamped Boundary }\end{array}$ & 1390 & 877 & 4399 & 3519 \\
\begin{tabular}{l} 
Condition, $\mathbf{P}_{\text {cr }}(\mathbf{l b})$ \\
\hline
\end{tabular} & 2725 & 919 & 5636 & 3858 \\
\hline
\end{tabular}




\section{CHAPTER 4}

\section{LATERAL-TORSIONAL BUCKLING OF}

\section{COMPOSITE I-JOISTS}

\subsection{Introduction}

Prefabricated wood I-joists are structural members that consist of a thin web and usually exhibit large deformations and tend to buckling globally or locally. Lateral-torsional buckling is the most likely mode of failure before ultimate load is reached. A long slender beam under bending about the strong axis can often buckle by combined bending and lateral twisting.

In this chapter, an analysis of the lateral-torsional behavior of the cantilever I-joists is presented. Cantilever beams were tested under tip loads to evaluate their flexural-torsional response. A finite element analysis was also carried out to supplement the experimental results.

\subsection{Experimental Evaluation of I-Joists}

Testing followed a method previously carried out by Qiao et al. (2003). The four joist geometries that were evaluated are described in detail in Section 2.2.2. Four samples from each group were 
evaluated. To be certain of behavior and consistency, this experiment was repeated 3 to 4 times for each joist.

\subsubsection{Test Setup and Instrumentation}

The joist was clamped at one end to achieve a fixed boundary condition. To accomplish this boundary condition, two steel angles were attached to a vertical steel column. The joist was then placed between the two angles, along with proper lateral support, and the angles were tightly clamped around the joist (Figure 5.1). Each joist was evaluated at a cantilever length of $12 \mathrm{ft}$.

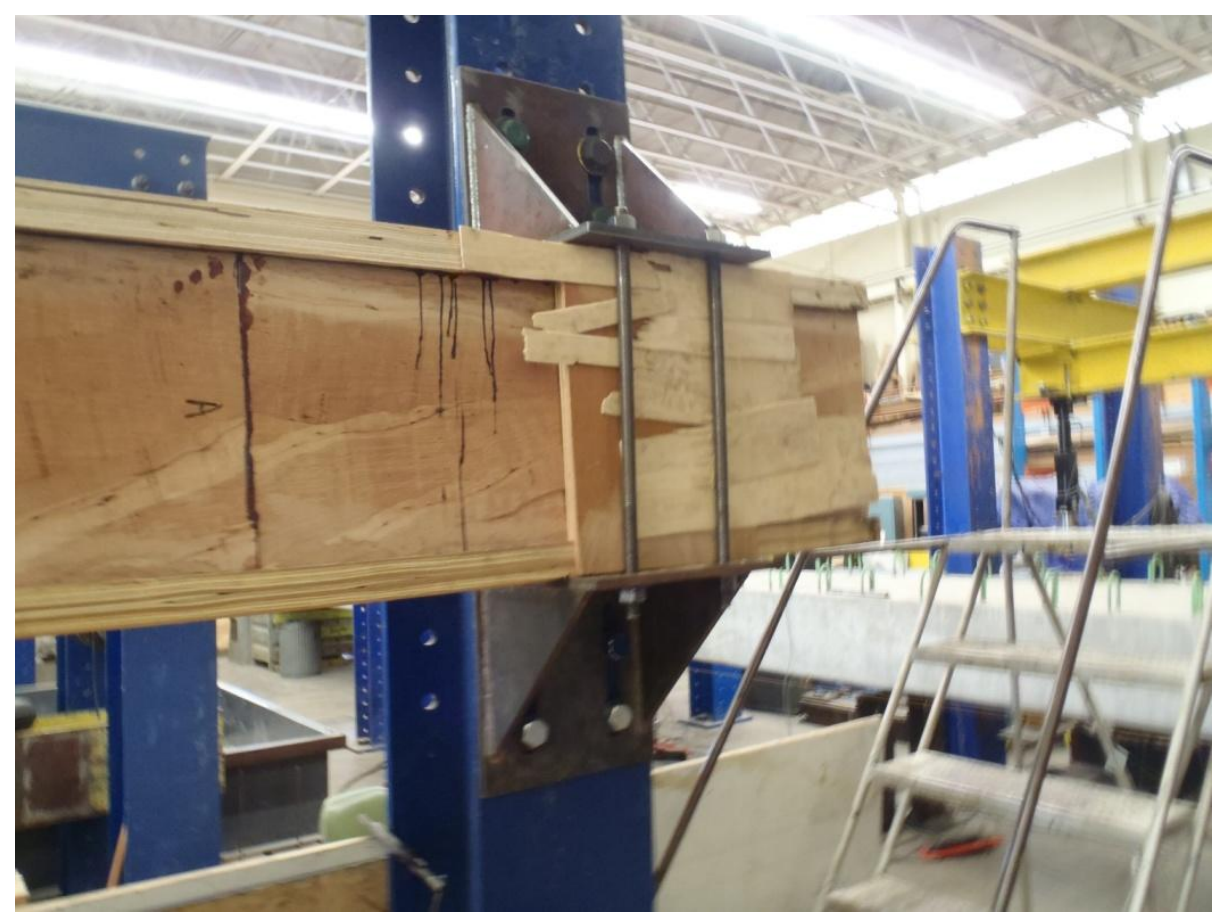

Figure 4.1 Cantilever Clamped-End Support

The load was applied to the tip of the joist by way of loading platform which was attached through the centroid of the cross-section by a series of chains. A steel hanger was bolted to the 
web along with two wooden templates to provide additional support. The steel hanger from which the load is suspended is shown in Figure 5.2.

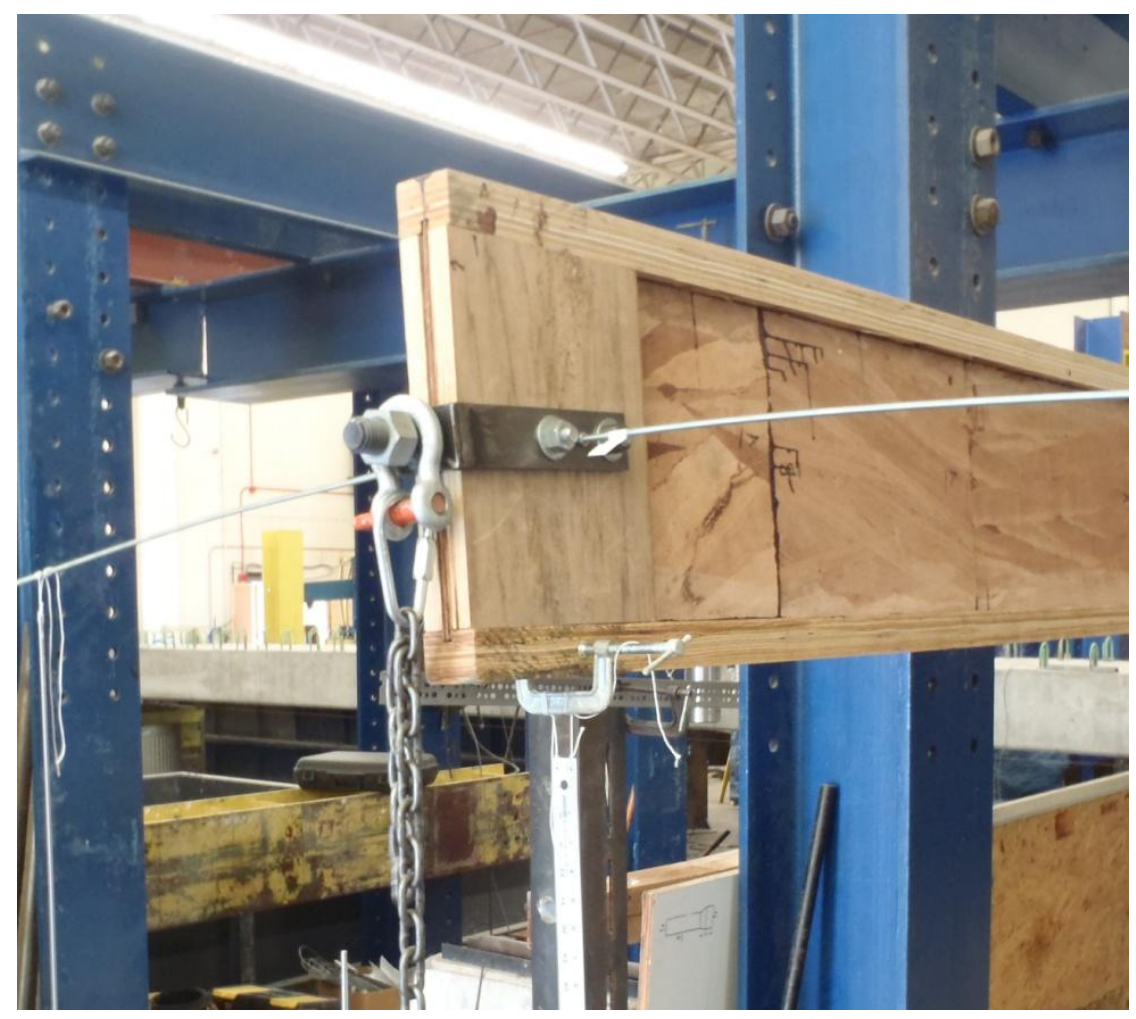

Figure 4.2 Steel Hanger for Load Applicaton

To measure the displacement of the beam, three rulers were used, each accurate within a sixteenth of an inch (Figure 4.3). One ruler was placed directly under the bottom flange of the beam to measure the vertical displacement $\left(\Delta_{3}\right)$. The other two rulers were suspended from a $3 \mathrm{ft}$ long arm attached to the hangar at the center of the cross-section. These were used to determine the vertical deflection $\left(\Delta_{1}\right.$ and $\left.\Delta_{2}\right)$ and corresponding rotation of the member. 


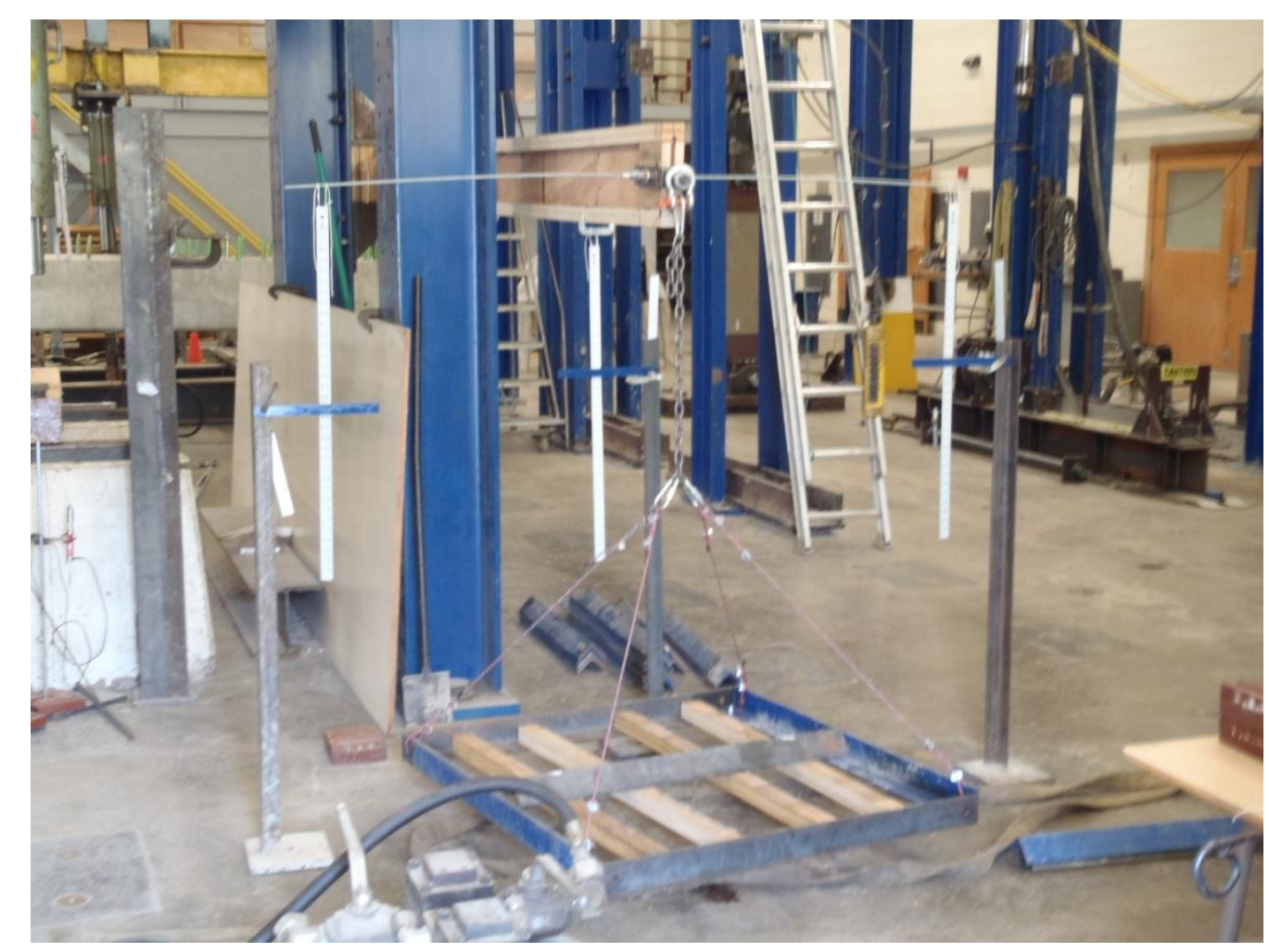

Figure 4.3 Measuring Devices and Loading Platform

\subsubsection{Experimental Procedure}

After the testing sample was fixed to the column, the loading platform (Figure 4.3) was attached to the hanger and initial displacements were recorded. Load was applied by sequentially adding steel angles of known weight to the loading platform. The weight of the angles ranged from 17.5 to 28 lbs. Load was distributed evenly across the platform. After each loading step, displacements were recorded from each of the three rulers. As the critical load was approached, smaller incremental weights of 5 and $10 \mathrm{lbs}$ were added until the beam buckled. The sudden sideways movement of the beam was directly observed when the critical load was reached and any small addition in load would cause a very large rotation and lateral displacement. Figure 4.4 shows an I-joist section which has reached the critical lateral buckling load. All load was then 
removed and the test was repeated 2 to 3 more times. The average value of these tests was taken to be the critical lateral-buckling load.



Figure 4.4 Buckled I-Joist Section

\subsubsection{Results}

A typical plot of load vs. displacement is shown in Figure 4.5. It can be seen that during the initial loading all three deflections increased in the same manner, i.e. the joist experienced vertical deflection with no rotation. As the critical load is approached the beam begins to rotate. The deflections on either side of the beam $\left(\Delta_{1}\right.$ and $\left.\Delta_{2}\right)$ are very large with small increments in load. While, the deflection increments underneath the bottom flange $\left(\Delta_{3}\right)$ remain small with 
increasing load. At this point the beam has undergone lateral-torsional buckling and any more addition of load would result in failure of the beam due to instability.

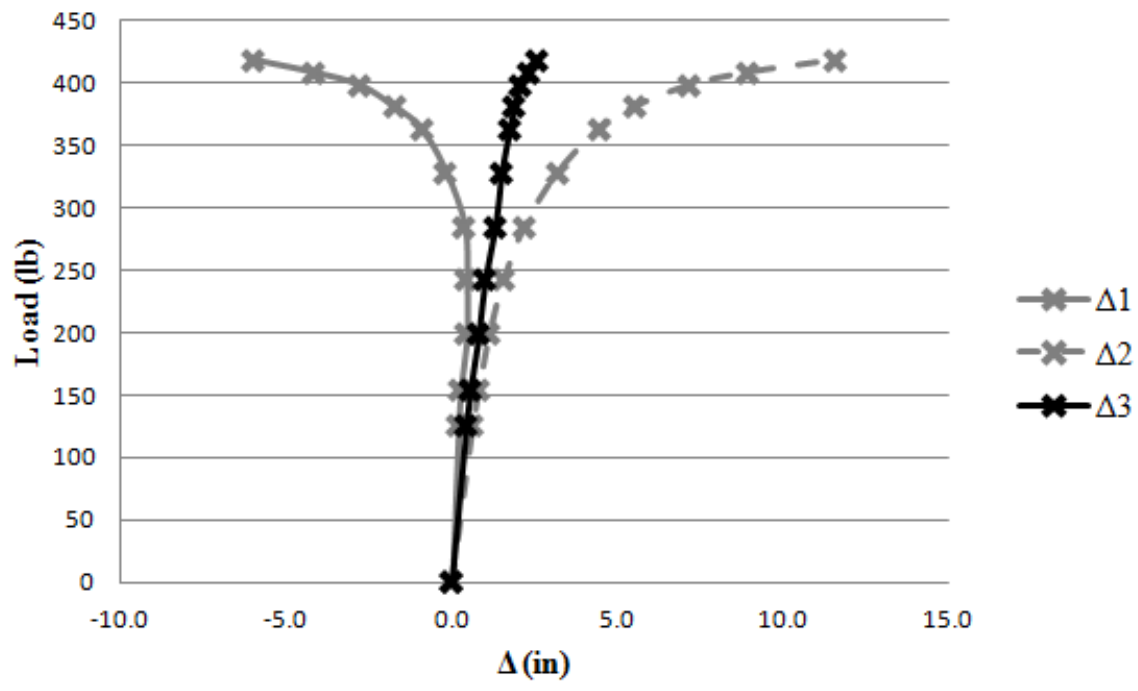

Figure 4.5 Typical Plot of Load vs. Deflection for Cantilever Beam Under Tip Loading

The experimental testing results for the 10" flat web I-joists are shown in Table 4.1. The critical load value from the four tests performed on each joist as well as the average is presented in the table. Results were consistent across the samples with the exception of joist 1-1, which yielded an uncharacteristically low critical load. This is most likely due to manufacturing issues. The results from this joist are removed from the final results presented in Table 4.5 of this thesis due to the high percent difference in critical lateral-torsional buckling load from the other three joists. 
Table 4.1 Experimental Results for 10" Flat Web Cantilever I-Joist

\begin{tabular}{lcccc}
\hline & \multicolumn{4}{c}{ Critical Load, $\mathbf{P}_{\text {cr }}(\mathbf{l b})$} \\
Specimen & $\mathbf{1 - 1}$ & $\mathbf{1 - 2}$ & $\mathbf{1 - 3}$ & $\mathbf{1 - 4}$ \\
\hline Test \#1 & 279.3 & 350.7 & 331.8 & 331.8 \\
Test \#2 & 289.3 & 350.7 & 345.9 & 341.8 \\
Test \#3 & 289.3 & 350.7 & 325.9 & 351.8 \\
Test \#4 & 289.3 & 350.7 & 333.4 & 341.8 \\
\hline Average & $\mathbf{2 8 6 . 8}$ & $\mathbf{3 5 0 . 7}$ & $\mathbf{3 3 4 . 3}$ & $\mathbf{3 4 1 . 8}$ \\
\hline
\end{tabular}

Upon completion of the testing of 10 " flat web joists the number of repetitions of the tests was reduced from 4 to 3 due to the consistency of the results among each individual joist. It can be seen that joist 2-1 was only evaluated once. When the critical load was reached there was damage to joist, mainly, separation of the flange-to-web connection that had to be repaired. This joist was not retested for fear of further damage and time constraints. Also, it was needed for other tests. Joist 2-1 was removed from the final results. Consistent results were seen among the other three joists in this group.

Table 4.2 Experimental Results for 10” Sinusoidal Web Cantilever I-Joist

\begin{tabular}{lcccc}
\hline & \multicolumn{4}{c}{ Critical Load, $\mathbf{P}_{\text {cr }}(\mathbf{l b})$} \\
Specimen & $\mathbf{2 - 1}$ & $\mathbf{2 - 2}$ & $\mathbf{2 - 3}$ & $\mathbf{2 - 4}$ \\
\hline Test \#1 & 296.8 & 344.3 & 371.8 & 328.2 \\
Test \#2 & & 345 & 353.4 & 331.8 \\
Test \#3 & & 350 & 353.4 & 331.8 \\
\hline Average & $\mathbf{2 9 6 . 8}$ & $\mathbf{3 4 6 . 4}$ & $\mathbf{3 5 9 . 5}$ & $\mathbf{3 3 0 . 6}$ \\
\hline
\end{tabular}


The lateral-torsional buckling testing results of the 16" flat web I-joist are presented in Table 4.3. High correlation is shown between joists 3-2, 3-3, and 3-4 with an average critical load. Joist 3-2 was more susceptible to lateral buckling than the other three, however, an approximate $9 \%$ difference between the critical load of this joist and the other three was not enough to warrant its exclusion from the final results. Once again the lower critical load for joist 3-2 is probably due to manufacturing issues.

Table 4.3 Experimental Results for 16" Flat Web Cantilever I-Joist

\begin{tabular}{lcccc}
\hline & \multicolumn{4}{c}{ Critical Load, $\mathbf{P}_{\text {cr }}(\mathbf{l b})$} \\
Specimen & $\mathbf{3 - 1}$ & $\mathbf{3 - 2}$ & $\mathbf{3 - 3}$ & $\mathbf{3 - 4}$ \\
\hline Test \#1 & 432.3 & 373.2 & 418.2 & 418.8 \\
Test \#2 & 393.2 & 390.7 & 418.2 & 428.2 \\
Test \#3 & 400.7 & 380.7 & 418.2 & 418.2 \\
\hline Average & $\mathbf{4 0 8 . 7}$ & $\mathbf{3 8 1 . 5}$ & $\mathbf{4 1 8 . 2}$ & $\mathbf{4 2 1 . 7}$ \\
\hline
\end{tabular}

Table 4.4 shows the experimental testing results for the 16 " sinusoidal web joist. The average critical load is fairly consistent across all four joist specimens. It can be seen that the critical load drops off after the first test of joist 4-2 which is most likely due to some minor separation of the flange-to-web connection which was repaired after the testing had concluded.

Table 4.4 Experimental Results for 16" Sinusoidal Web Cantilever I-Joist

\begin{tabular}{lcccc}
\hline & \multicolumn{4}{c}{ Critical Load, $\mathbf{P}_{\text {cr }}(\mathbf{l b})$} \\
Specimen & $\mathbf{4 - 1}$ & $\mathbf{4 - 2}$ & $\mathbf{4 - 3}$ & $\mathbf{4 - 4}$ \\
\hline Test \#1 & 418.2 & 448.2 & 398.2 & 418.2 \\
Test \#2 & 418.2 & 380.7 & 398.2 & 418.2 \\
Test \#3 & 418.2 & 398.2 & 398.2 & 418.2 \\
\hline Average & $\mathbf{4 1 8 . 2}$ & $\mathbf{4 0 9 . 0}$ & $\mathbf{3 9 8 . 2}$ & $\mathbf{4 1 8 . 2}$ \\
\hline
\end{tabular}


A summary of the experimental results is given in Table 4.5. A small difference can be observed in the flat and sinusoidal joists, with the average critical loads being slightly higher for the sinusoidal web joists. Also, for both the flat and sinusoidal web joist, the 16 " deep joist had an approximate $16 \%$ higher critical load than the 10 " joists.

Table 4.5 Summary of Lateral-Torsinal Buckling Results

\begin{tabular}{lcccc}
\hline & \multicolumn{2}{c}{ Flat Web Joist } & \multicolumn{2}{c}{ Sinusoidal Web Joist } \\
Joist Height (in) & $\mathbf{1 0}$ & $\mathbf{1 6}$ & $\mathbf{1 0}$ & $\mathbf{1 6}$ \\
\hline Critical Load, $\mathbf{P}_{\text {cr }}$ (lb) & 342.3 & 407.6 & 345.5 & 410.9 \\
\hline
\end{tabular}

\subsection{Finite Element Modeling of Cantilever I-Joists}

A finite element analysis was performed on the I-joists for comparison with the experimental results. Both flat web and sinusoidal web I-joists were evaluated in torsion.

\subsubsection{Finite Element Model}

The description of the finite element model of the beam is given in Section 2.3. For the cantilever model the full $14 \mathrm{ft}$ I-joist models were used. All nodes of the flange and web along one plane were prevented from deflecting and rotating in any direction to achieve the fixed boundary condition and a cantilever length of $12 \mathrm{ft}$. The unit load was applied to the tip of the joist at the location of the neutral axis. The finite element model is shown in Figure 5.6. 


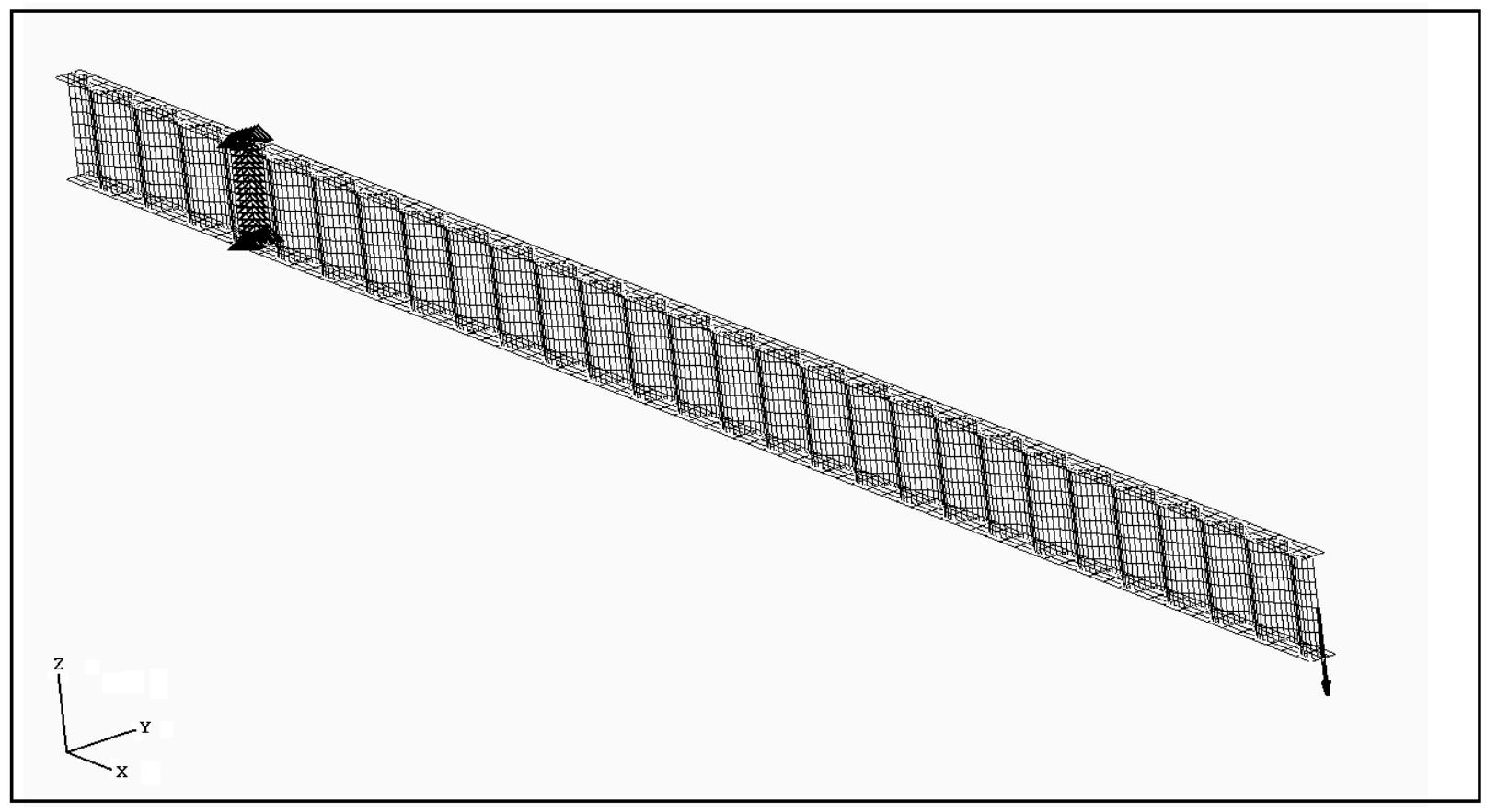

Figure 4.6 Finite Element Model of Cantilever I-Joist

An eigenvalue buckling analysis was performed and the corresponding critical loads were given for each joist. The results are given in the next section.

\subsubsection{Results and Discussion}

Figure 4.7 shows the deformed shape of a cantilever sinusoidal web joist under tip loading. A contour plot of the rotation of the joist about the longitudinal axis is also shown. Similar deformed shape was observed from the finite element analysis of the flat web joist. The resulting deformed shapes are very close to what was observed from the experimental testing. 


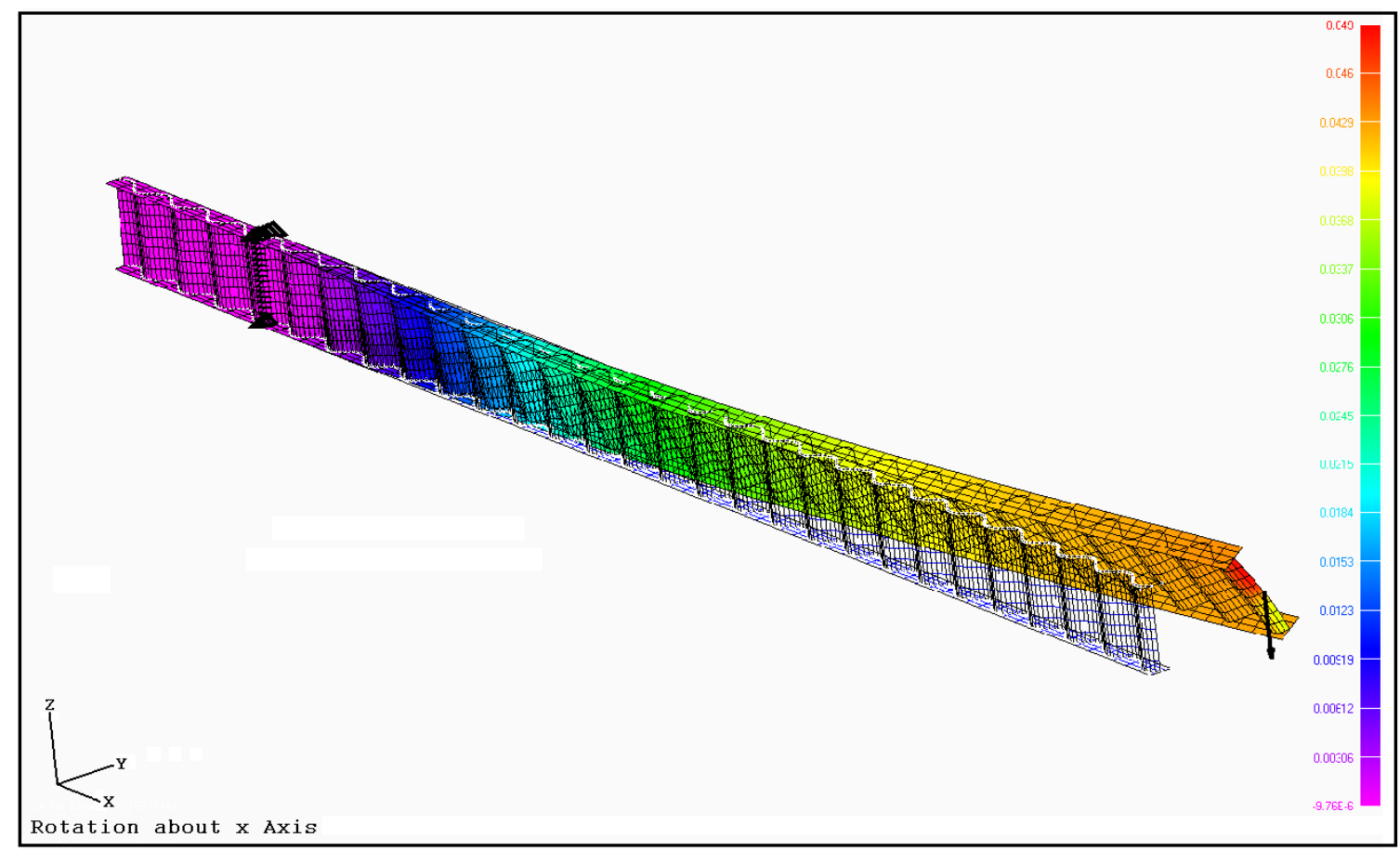

Figure 4.7 Lateral-Torsional Buckling of I-Joist from FE Analysis

The resulting critical loads from the finite element analysis are shown in Table 4.6. The results show an increase in buckling resistance from the flat to sinusoidal web joists. Also the percent difference in critical increases from $6 \%$ to $8 \%$ with increasing joist depth. The finite element analysis shows that the sinusoidal joist have a higher resistance to lateral-torsional buckling.

Table 4.6 Lateral-Torsional Buckling Results from Finite Element Analysis

\begin{tabular}{lccccc}
\hline & \multicolumn{2}{c}{ Flat Web Joist } & \multicolumn{2}{c}{ Sinusoidal Web Joist } \\
Joist Height (in) & $\mathbf{1 0}$ & $\mathbf{1 6}$ & $\mathbf{1 0}$ & $\mathbf{1 6}$ \\
\hline Critical Load, $\mathbf{P}_{\text {cr }}(\mathbf{l b})$ & 352.5 & 403.3 & 374.4 & 437.8 \\
\hline
\end{tabular}




\subsection{Comparison of FE and Experimental Results}

The experimental and finite element results are compared to determine the how well the correlation between the two sets of data. The comparison of the critical loads is shown in Table 4.7. The finite element results seem to accurately replicate the experimental results. The correlation is especially good for the joists with flat webs. The percent difference for the 10 " joists is $3 \%$ while the percent difference between the $16 \%$ joists is only $1 \%$. For the sinusoidal joists the difference is slightly higher. Once again, the correlation for the 16 " joists is better than for the 10 " joists which had a percent difference of $7.5 \%$.

Table 4.7 Comparison of Experimental and FE Results

\begin{tabular}{lcccc}
\hline & \multicolumn{2}{c}{ Flat Web Joist } & \multicolumn{2}{c}{ Sinusoidal Web Joist } \\
Joist Height (in) & $\mathbf{1 0}$ & $\mathbf{1 6}$ & $\mathbf{1 0}$ & $\mathbf{1 6}$ \\
\hline Experimental $\mathbf{P}_{\text {cr }}$ (lb) & 342.3 & 407.6 & 345.5 & 410.9 \\
Finite Element $\mathbf{P}_{\text {cr }}$ (lb) & 352.5 & 403.3 & 374.4 & 437.8 \\
\hline
\end{tabular}




\section{CHAPTER 5}

\section{EVALUATION OF I-JOISTS IN TORSION}

\subsection{Introduction}

In this chapter, an experimental method is developed to evaluate the response of the I-joist samples in torsion. A finite element analysis is performed to supplement the experimental results. To verify the precision of the torsion machine used in the experimental testing, calibration is first carried out using a beam sample with well-known material properties. The calibration of the torsion machine is discussed in Section 5.2. The experimental investigation and finite element study are presented in Section 5.3 and 5.4, respectively.

\subsection{Calibration of the Torsion Testing Machine}

To validate the accuracy of the experimental torsion setup, the machine was first calibrated using a sample with known shear modulus. This section describes the torsion machine and testing method. Also, an analytical, experimental, and finite element analysis of the torsional response of an aluminum bar is presented.

\subsubsection{Test Description}


The torsion machine used to evaluate samples was designed by a former graduate student, James Brokaw (1992), and has been used in earlier studies (Salim 1996, Robinson 2001). A diagram of the torsion testing machine is shown in Figure 5.1.

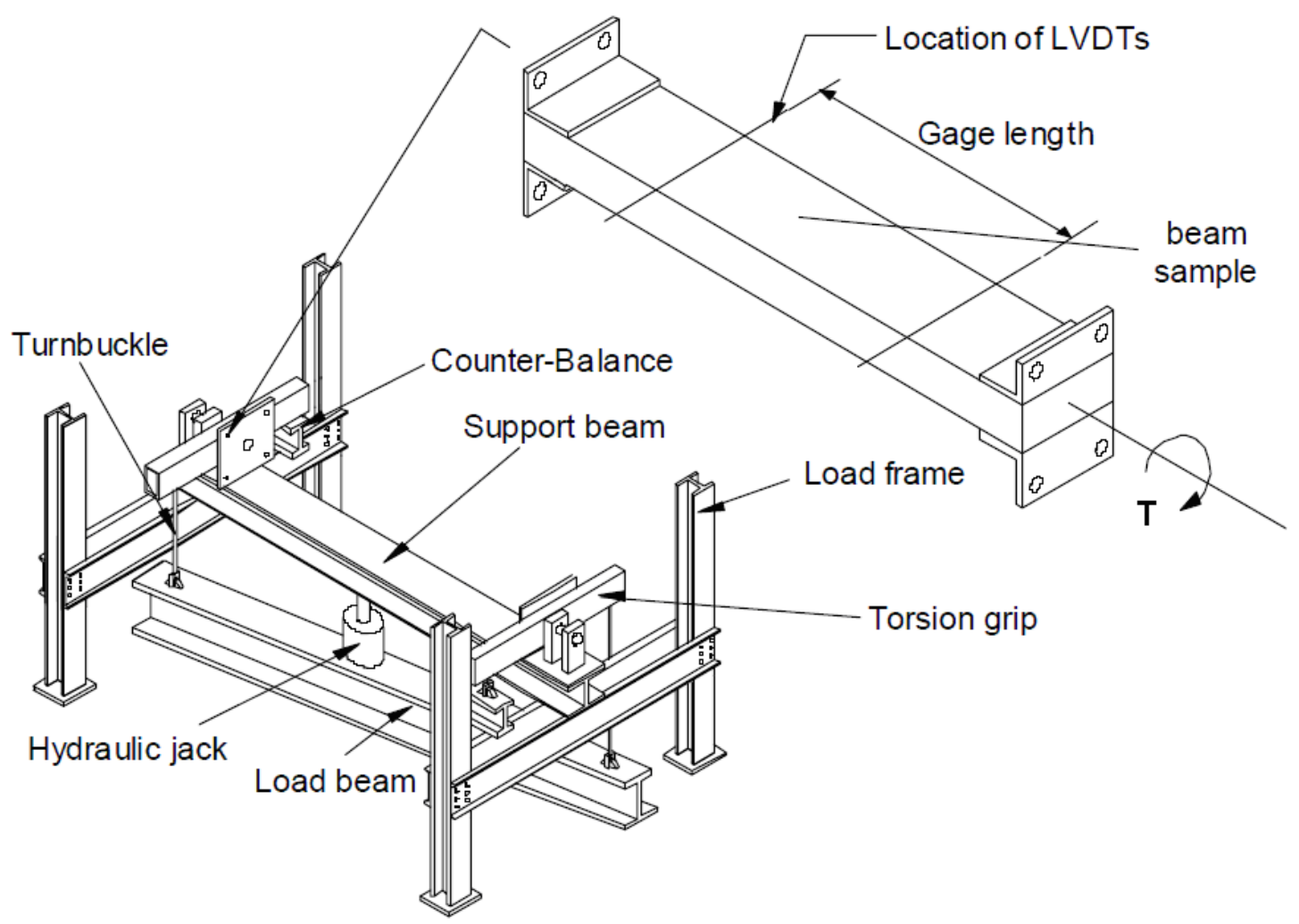

Figure 5.1 Torsion Machine

As shown in Figure 5.1, the test sample is placed between the two torsion grips, which hold the ends of the sample. Two counter-balances hang opposite one another off of the moment arms of the torsion grips on either side of the machine and are used to ensure that there is no rotation in the sample prior to testing. The load is applied vertically by a hydraulic jack to the loading beam which hangs diagonally from the other two moment arms. The load is applied at the center of the loading beam and is transferred through the turnbuckles to the torsion grips. Approximately one- 
half of the load is applied to either end of the sample and when multiplied by the length of the moment arm, torsion is produced. Both ends of the sample are subjected to equal and opposite rotations and the sample rotates with respect to its mid-length, which behaves as a fixed boundary condition. The machine allows for testing of samples up to 14 feet in length.

\subsubsection{Analytical Predictions for Aluminum Bar}

A 6061-T6 aluminum bar was used for the calibration process because of its well documented isotropic properties. The bar was 10 feet in length with cross-sectional dimensions of 6" x 1". Using the published shear modulus, geometric properties to find the angle of rotation, and maximum shear strain for a given torque, St. Venant's isotropic torsion solution can be used. Using the isotropic material properties, $\mathrm{E}=11,000 \mathrm{ksi}$ and $v=0.3$ (Robinson 2001), the shear modulus of the aluminum bar can be found using the following equations.

$$
G=\frac{E}{2(1+v)}=4,230 k s i
$$

The St. Venant's solution for an isotropic rectangular cross-section is (Boresi and Schmidt, 2003)

$\theta=\frac{T}{k_{1} G b h^{3}}$

where $\theta$ is the angle of rotation per unit length is radians. The value of $\mathrm{k}_{1}$ is based on the ratio of $\mathrm{b} / \mathrm{h}$. In this case, $\mathrm{k}_{1}=0.299$. The predicted value of $\theta$ at 36 " from the mid-span under a torque of 1 kip-in using St. Venant's solution is $0.00475 \mathrm{rad} / \mathrm{kip}$-in. 


\subsubsection{Experimental Results for Aluminum Bar}

The objective of the experimental testing was to measure the rotational response of the aluminum bar under torque. Load and deflections were collected and converted into applied torque and angles of rotation respectively. The shear modulus was then calculated using St. Venant's solution.

Four linear voltage differential transducers (LVDTs) were used to measure the displacements of the bar under an applied torque at specific locations. These displacements were used to calculate the angle of rotation of the sample. Each LVDT was suspended from an arm placed at 36" from the mid-span of the sample. The length of the attached arm was 33" from the mid-width of the aluminum bar. The instrumentation of the LVDTs on the aluminum bar is shown below in Figure 5.2 .

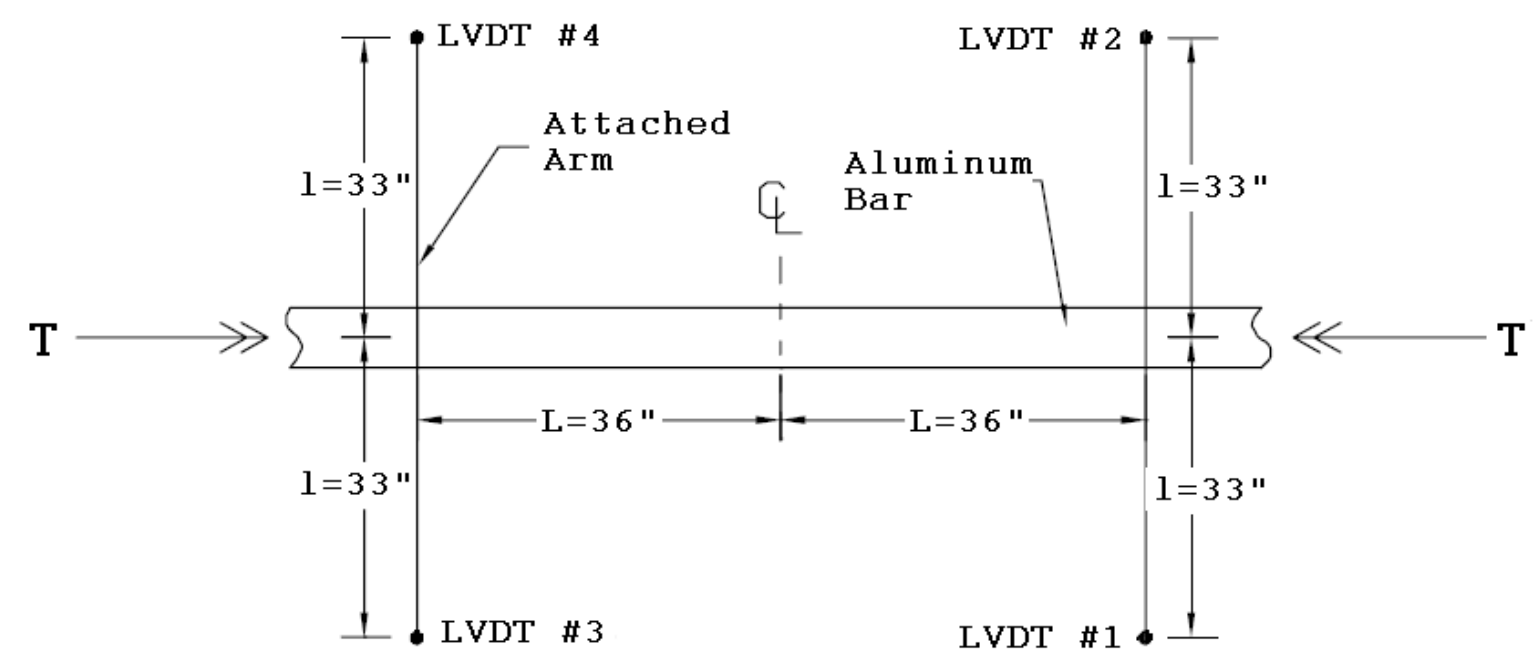

Figure 5.2 Instrumentation of Aluminum Bar 
For each LVDT, the angle of rotation was calculated using the small angle approximation, where the rotation is equal to the absolute value of the displacement divided by the arm length, L. The deformed and undeformed cross sections as well as the resultant displacements and rotations are shown in Figure 5.3. Theoretically, the absolute value of the displacement and the corresponding angle of rotation should be the same for all four positions. However, due to geometric variations and/or experimental error, slight variations are to be expected.

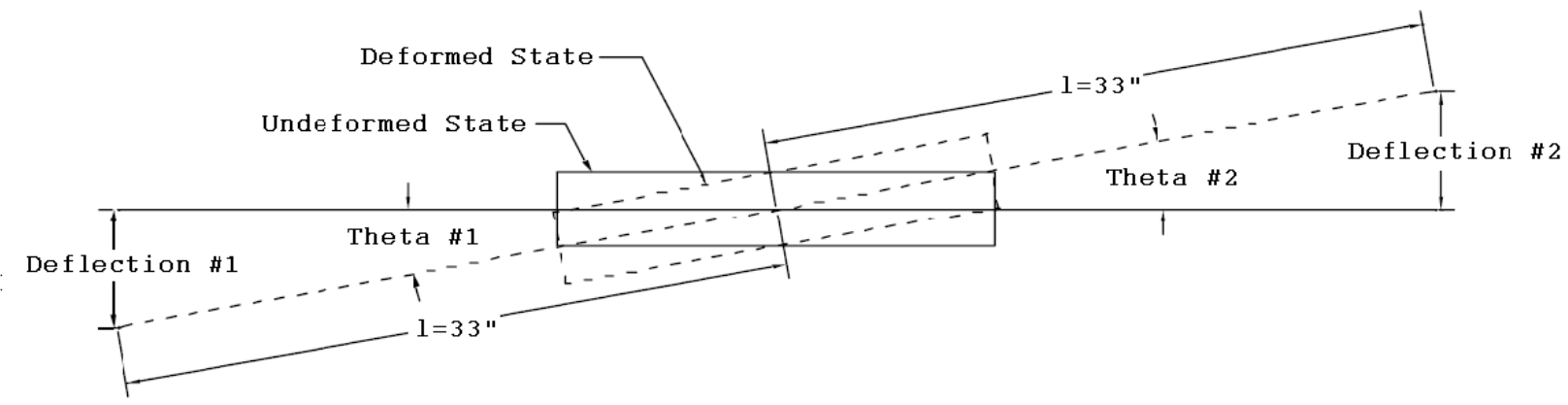

Figure 5.3 Deformed and Undeformed State of Aluminum Sample

The test is designed so that the mid-span undergoes no rotation and acts as a fixed boundary condition. This condition is not exactly met and it would be very tedious and disadvantageous to find the neutral axis along the bar. Thus, the angle of rotation is found by averaging the values for all four LVDTs. Therefore, a sample gauge length, L, of 36" can be used for analysis.

A 5-kip load cell was used to measure the force, $\mathrm{P}$, on the loading beam. The torque was calculated using the following equation:

$T=\frac{P}{2} \times r$

where $\mathrm{T}=$ applied torque (kip-in), $\mathrm{P}=$ load (kip), and $\mathrm{r}=$ length of moment arm (36 in). 
Using St. Venant's solution for an isotropic rectangular bar, the shear modulus can be found using the following equation:

$\frac{T}{\theta}=\frac{G b h^{3} k_{1}}{L}$

where $\mathrm{T}=$ applied torque (kip-in), $\theta=$ angle of twist (radians), $\mathrm{b}=$ width of bar (6in), $\mathrm{h}=$ height of bar ( $1 \mathrm{in}), \mathrm{k}_{1}=$ torsional constant based on geometry (0.299), and L = gauge length (36 in).

The experimental values for the shear modulus of the aluminum bar were found from four tests. The results are shown in Table 5.1 along with the percent differences with respect to the analytical prediction $(\mathrm{G}=4230 \mathrm{ksi})$.

Table 5.1 Experimental Results for Aluminum Bar in Torsion

\begin{tabular}{cccc}
\hline $\begin{array}{c}\text { Test } \\
\text { Number }\end{array}$ & $\begin{array}{c}\text { Average Angle } \\
\text { of Rotation } \\
\text { (rad/kip-in) }\end{array}$ & $\begin{array}{c}\text { Shear } \\
\text { Modulus } \\
\text { (ksi) }\end{array}$ & $\begin{array}{c}\text { Percent } \\
\text { Difference from } \\
\text { Theoretical Value }\end{array}$ \\
\hline Test \#1 & 0.004514 & 4462 & $5.5 \%$ \\
Test \#2 & 0.004495 & 4481 & $5.9 \%$ \\
Test \#3 & 0.004516 & 4426 & $4.6 \%$ \\
Test \#4 & 0.004493 & 4482 & $6.0 \%$ \\
\hline
\end{tabular}

An average percent difference between the experimental and analytical results of $5.5 \%$ was observed. This small difference verifies the accuracy of the test method and therefore this test can now be confidently used to test the torsional response of the I-joists. 


\subsubsection{Finite Element Modeling of Aluminum Bar}

A finite element analysis of the aluminum bar under torsion was performed to provide additional verification of the analytical and experimental results. The finite element modeling of the aluminum bar will also serve in developing the finite element model for the torsion of the composite wood I-joists. FEMAP v.8.3 (FEMAP User's Manual 2003) was adopted for pre- and post-processing and ABAQUS v.6.7 (ABAQUS User's Manual 2007) was used for analysis.

The mesh consisted of 8-node shell elements and using and aspect ratio of 1:1, each element was set to a size of 3" x 3". The cross-sectional geometry and isotropic material properties discussed in Section 5.2.2 are the same properties used in the FE analysis.

It was assumed that during the experimental testing that the mid-span of the bar acted as a fixed boundary condition and the equal and opposite torque was applied to each end of the bar. Also, the bar has symmetric material properties and geometry about the mid-span. Therefore, the aluminum bar may be modeled at a length of 36", which corresponds to the gauge length of the experimental testsing (see Figure 5.2). The resulting model consists of 24 elements, 12 along the length of the beam and 2 elements along the width.

The boundary conditions used in the FE model were as follows; the rotations and displacements were fixed at one end of the bar and free on the opposite end. The torque was applied to the free end of the bar by using a force couple, two equal and opposite concentrated loads placed on the 
edges of the model at the free end (Figure 5.4). The total applied torque was $1 \mathrm{kip}$-in. The finite element analysis yielded a result of $0.00455 \mathrm{rad} / \mathrm{kip}$-in of rotation.

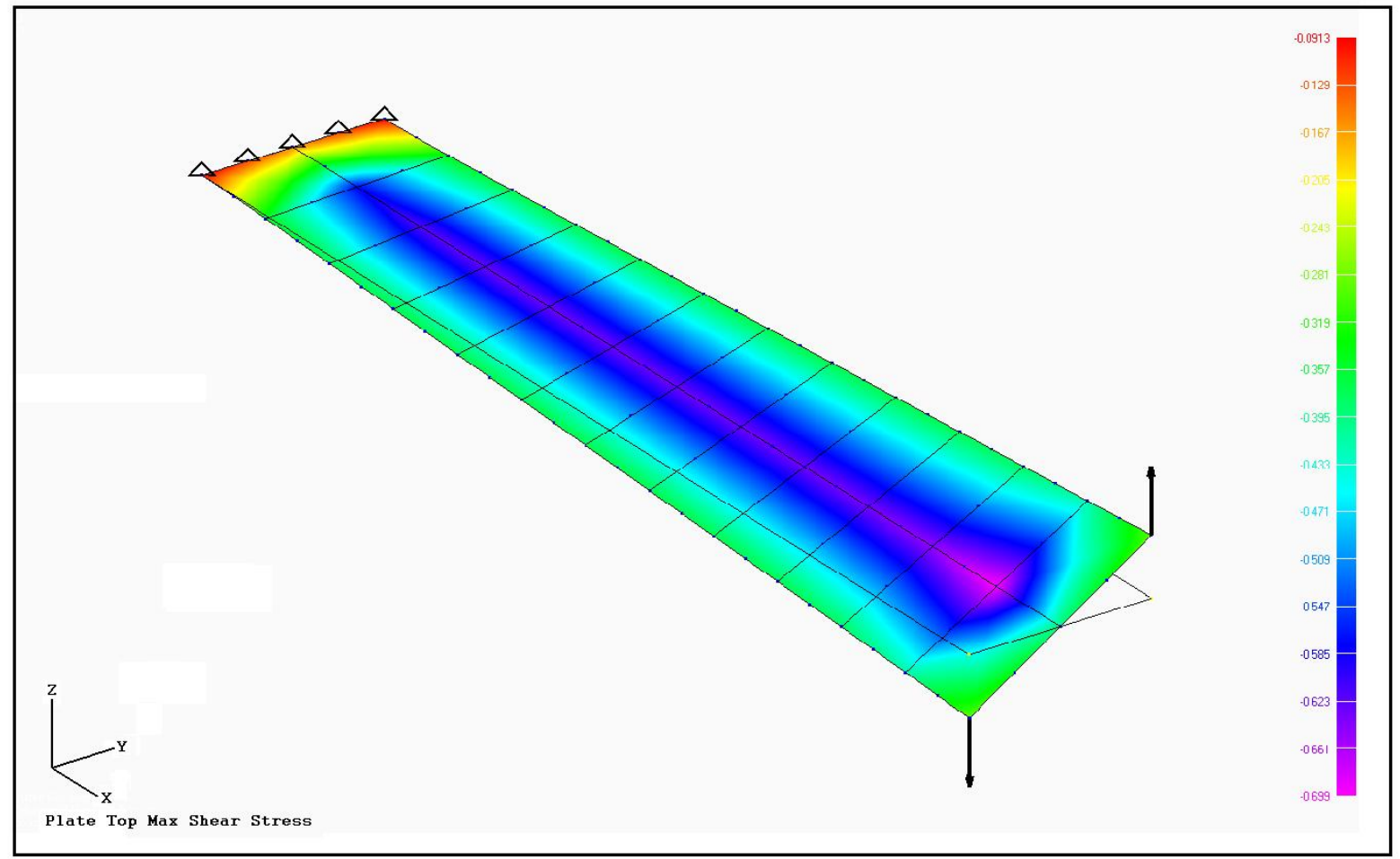

Figure 5.4 Finite Element Model of Aluminum Bar in Torsion

\subsubsection{Discussion of Calibration Results}

Three different methods of analyses of the aluminum bar in torsion were present in the previous sections. The resulting rotations at a gauge length of 36 " for all three methods of analyses are given in Table 5.4 . 
Table 5.2 Summary of Analyses of Aluminum Bar in Torsion

\begin{tabular}{cccc}
\hline & $\begin{array}{c}\text { Analytical } \\
\text { Prediction }\end{array}$ & $\begin{array}{c}\text { Finite Element } \\
\text { Prediction }\end{array}$ & $\begin{array}{c}\text { Experimental } \\
\text { Average }\end{array}$ \\
\hline $\begin{array}{c}\text { Angle of Rotation at Gauge } \\
\text { Length of 36" (rad/kip-in) }\end{array}$ & 0.00475 & 0.00455 & 0.00451 \\
\hline
\end{tabular}

From Table 5.4, the percent difference between the analytical prediction and the average experimental result is $5.1 \%$, and the percent difference between the finite element analysis and the average experimental result is only $0.9 \%$. These small differences provide confidence for both the finite element solution as well as the validity of the experimental method. Evaluation of the I-joists in torsion can now proceed.

\subsection{Experimental Evaluation of I-Joists}

In this section, an experimental torsion analysis and finite element method are used to characterize the rotational stiffness of the composite wood I-joists. This evaluation was performed using the calibrated torsion machine described in Section 5.2.1. The samples that were tested were previously described in Section 2.2.3. For the 16 " tall joists, a total of three samples for each the flat and sinusoidal web geometries were used. In the case of the 10 " joists, one specimen from each of the two web geometries was evaluated. In order to have a similar length to depth ratio, these two joists were shortened from 14 to 10 feet in length. The tests were repeated four times for each joist. 


\subsubsection{Test Description}

To measure the angle of rotation of the sample, four LVDTs were used. Two LVDTs were hung from an arm placed 36" from the mid-span on either side of the joist. Each arm was 30" in length. A diagram of the instrumentation of the samples is shown in Figure 5.5. In the case of the two shortened specimens a gauge length, L, of 24" was used.

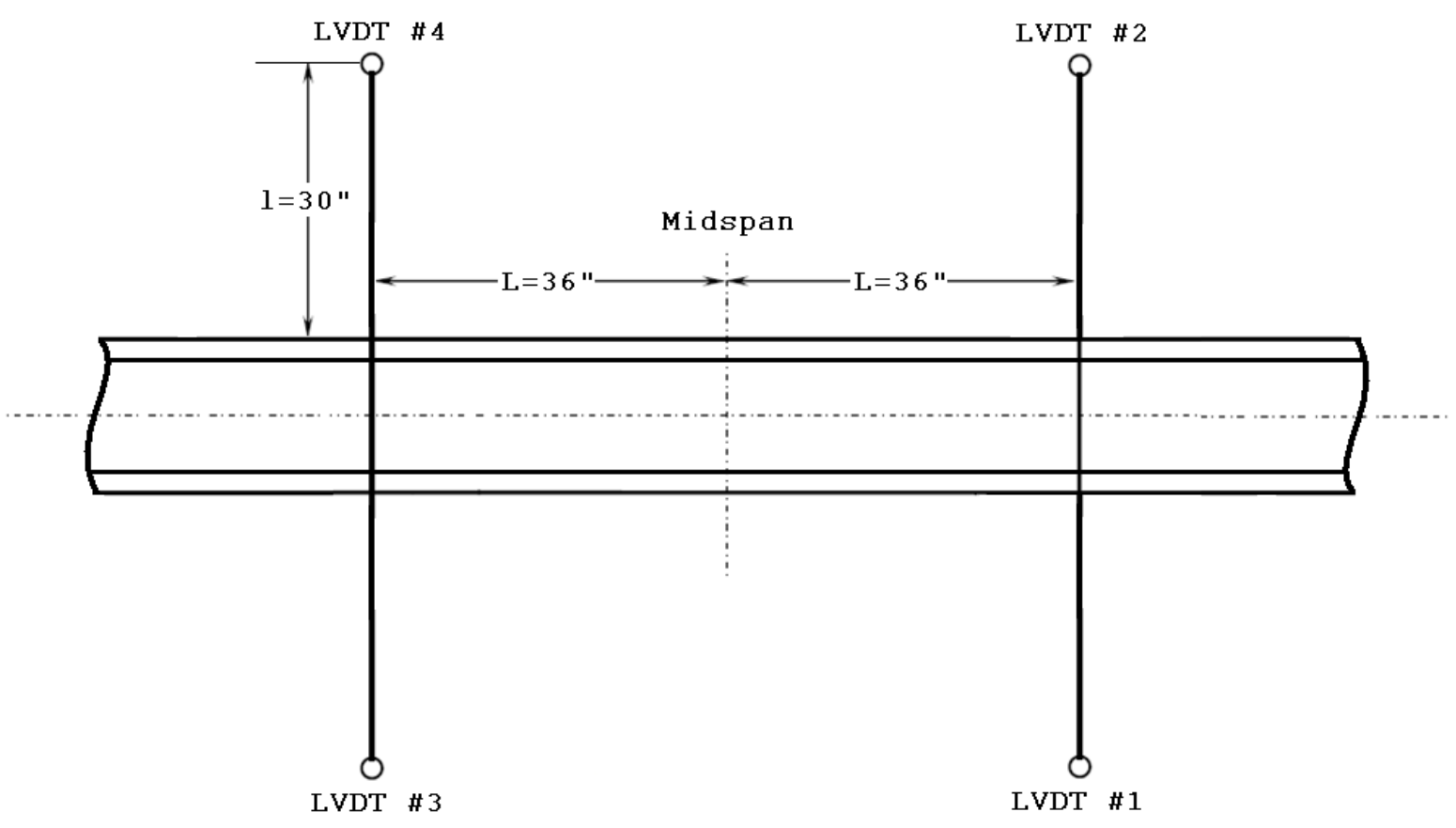

Figure 5.5 Instrumentation of the I-Joists

Each arm consists of a 30 " steel rod welded to a thin steel plate. These "arms" are attached to the sample using two long clamps (Figure 5.6). Each LVDT is hung from the end of the arm and records displacement during testing. The instrumentation and details of the test setup are shown in Figure 5.7. 


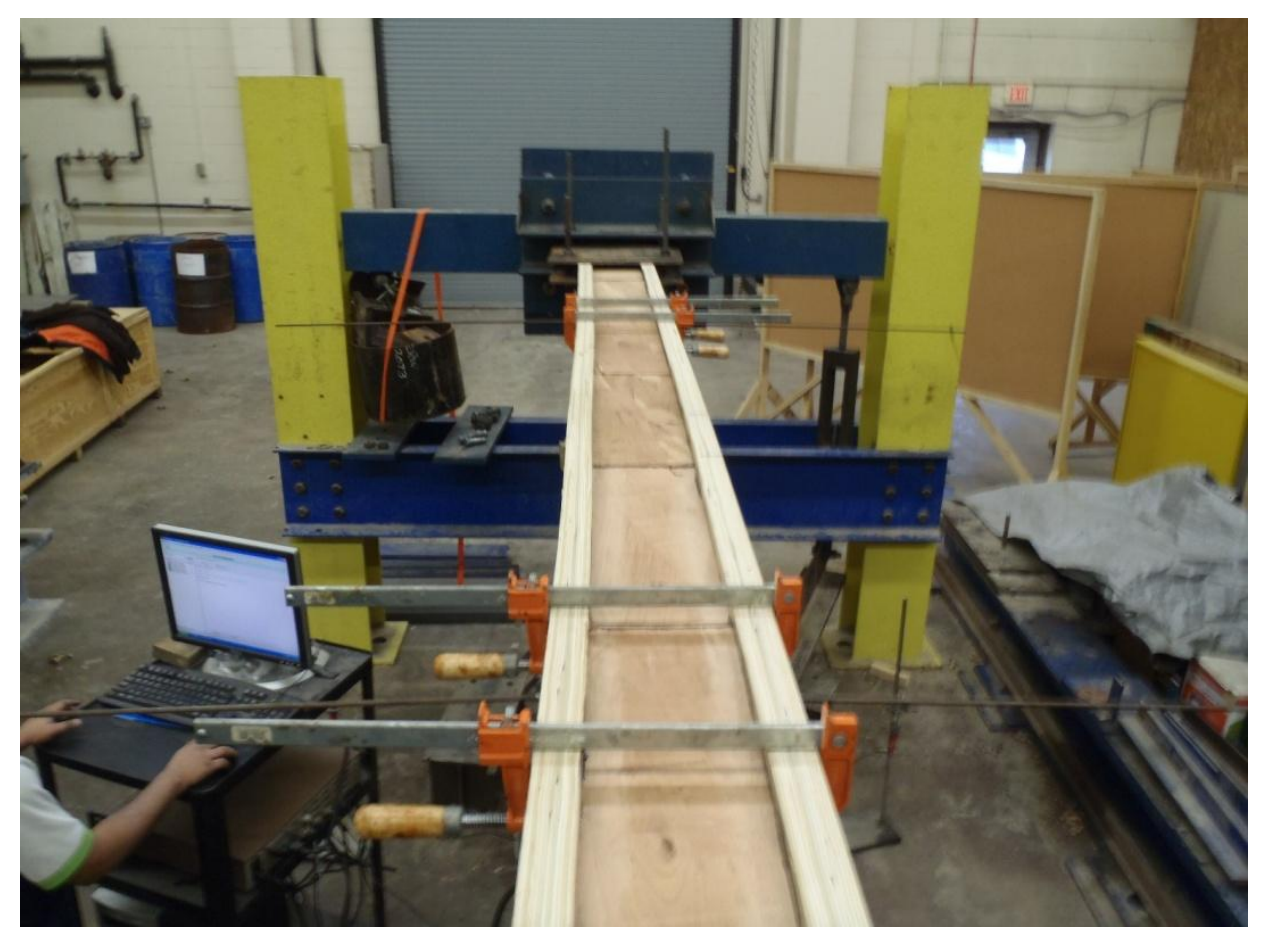

Figure 5.6 Sample Instrumented for Experimental Torsion Test

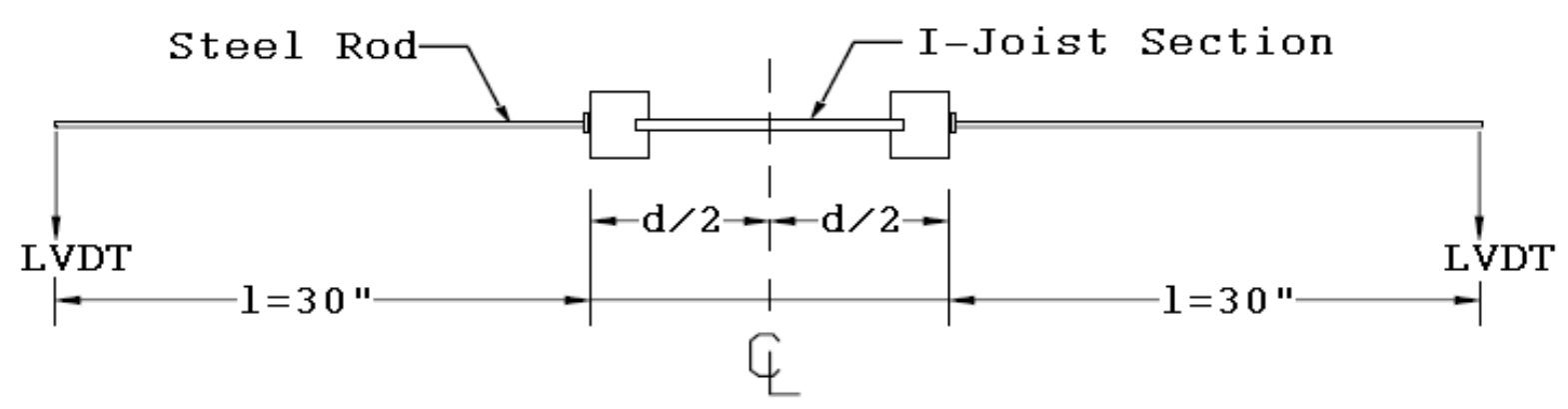

(a) Instrumentation of I-Joist 


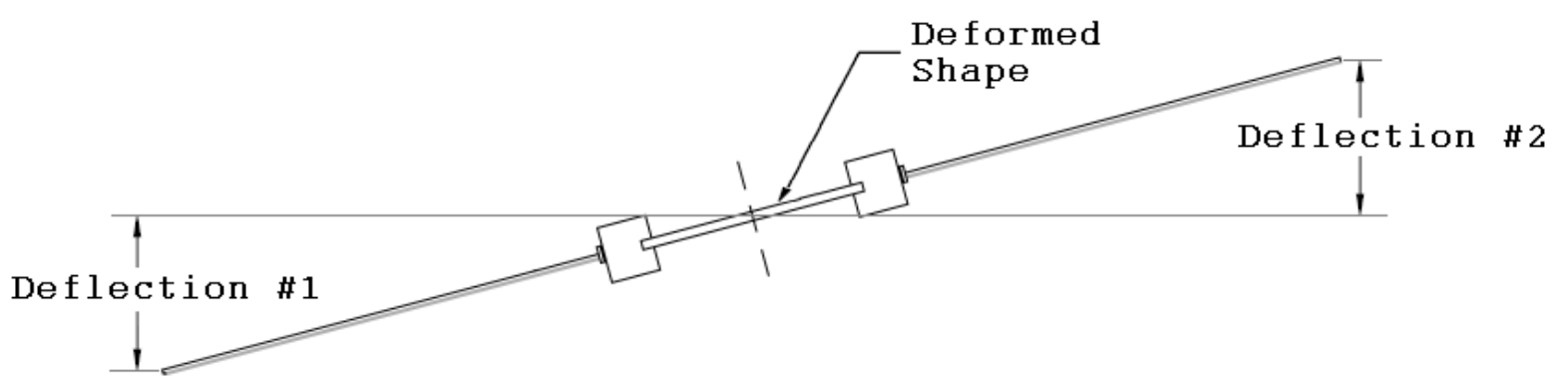

(b) Deformed Shape of I-Joist in Torsion

Figure 5.7 Cross Sectional View of I-Joist in Torsion

\subsubsection{Experimental Procedure}

Each sample was placed in the machine and a small torque was applied before the actual testing began. Minor adjustments were made to the counter weights as well as the position of the load cell. Small variations in this position can cause significant changes to the rotation as well as the location of the point of fixity along the sample. The goal was to place the load cell as close as possible to the mid-span and to have each LVDT reading the same displacement under this small load. When these conditions were satisfied, the testing began (Figure 5.8). Each beam was tested four times and load and displacement data was collected for analysis. The load was applied using a hydraulic ram. For each test, the load was applied at a constant rate up to a torque of 1 kip-in. 


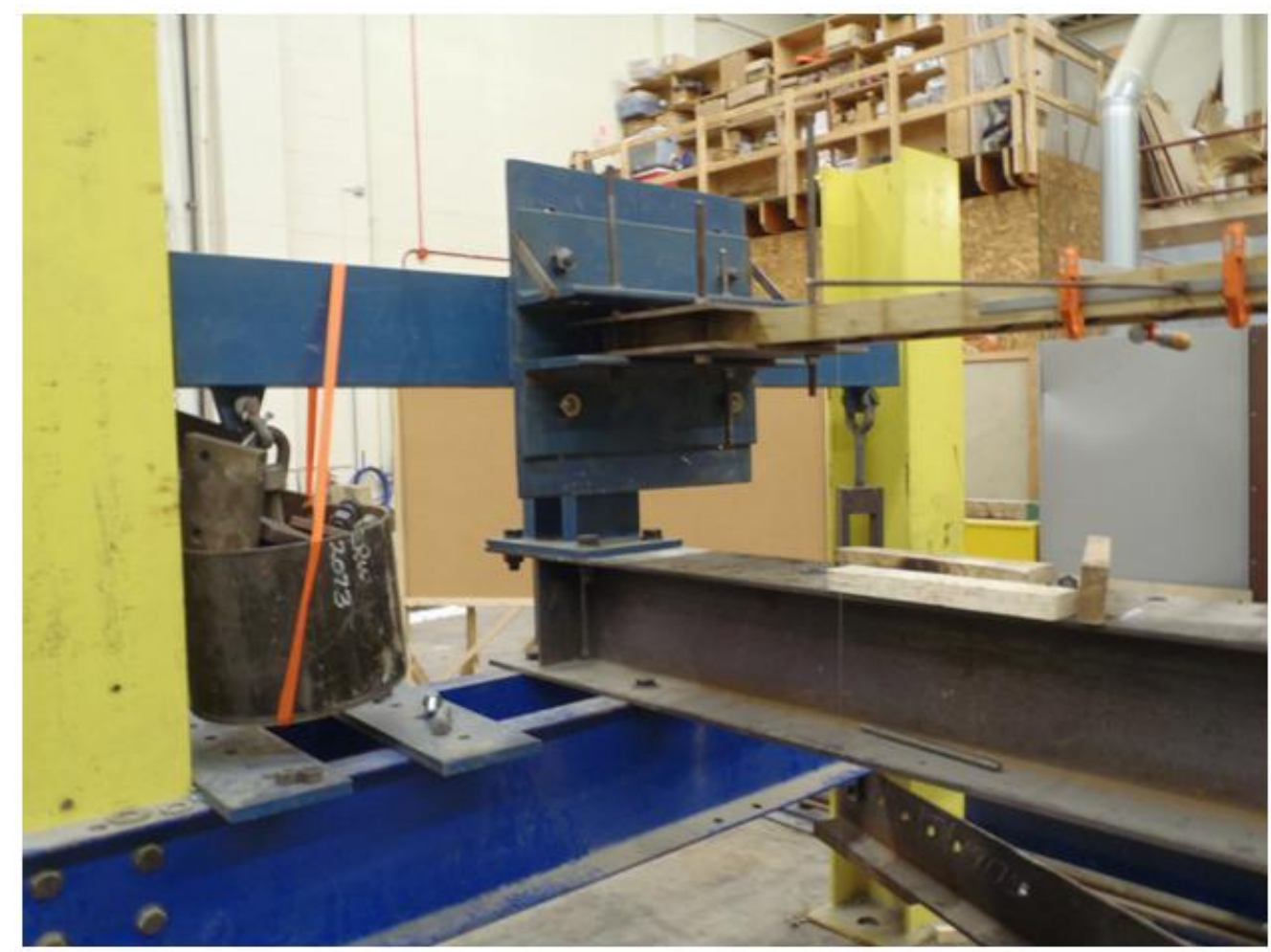

Figure 5.8 I-Joist Under Torsion

Each LVDT recorded displacement and the displacements were then converted into corresponding rotations. Using trigonometry and the small angle approximation, the rotation can be calculated using similar method as for the aluminum bar. The only difference being that the depths of the joist change and the length of the steel rod (30") must be added to half of the depth of the individual joist to calculate the rotation (Figure 5.7 a). The following formula was used to calculate the rotation for each LVDT:

$\theta=\frac{\left|\Delta_{1}\right|+\left|\Delta_{2}\right|}{l+(d / 2)}$

Where $\Delta_{1}=$ displacement at the end of the steel $\operatorname{rod}(\mathrm{in}), \Delta_{2}=$ displacement at the opposite end of the steel rod (in), $l=$ length of the steel $\operatorname{rod}(30$ "), and $d=$ depth of the joist (in). 
The rotations were then averaged. The loading data was collected using a 5-kip load cell and the same method as described in Section 5.2.3 was used to calculate the torque. The rotational stiffness can then be found using St. Venant's solution.

$G J=\frac{T}{\theta}$

where GJ is the torsional stiffness (rigidity) of the member.

\subsubsection{Results and Discussion}

The load versus the absolute value of displacement of the four LVDTs for a typical sample is shown in Figure 5.9. It can be seen that all four displacements are in agreement. The torque is also plotted against the average angle of rotation as seen in Figure 5.10.

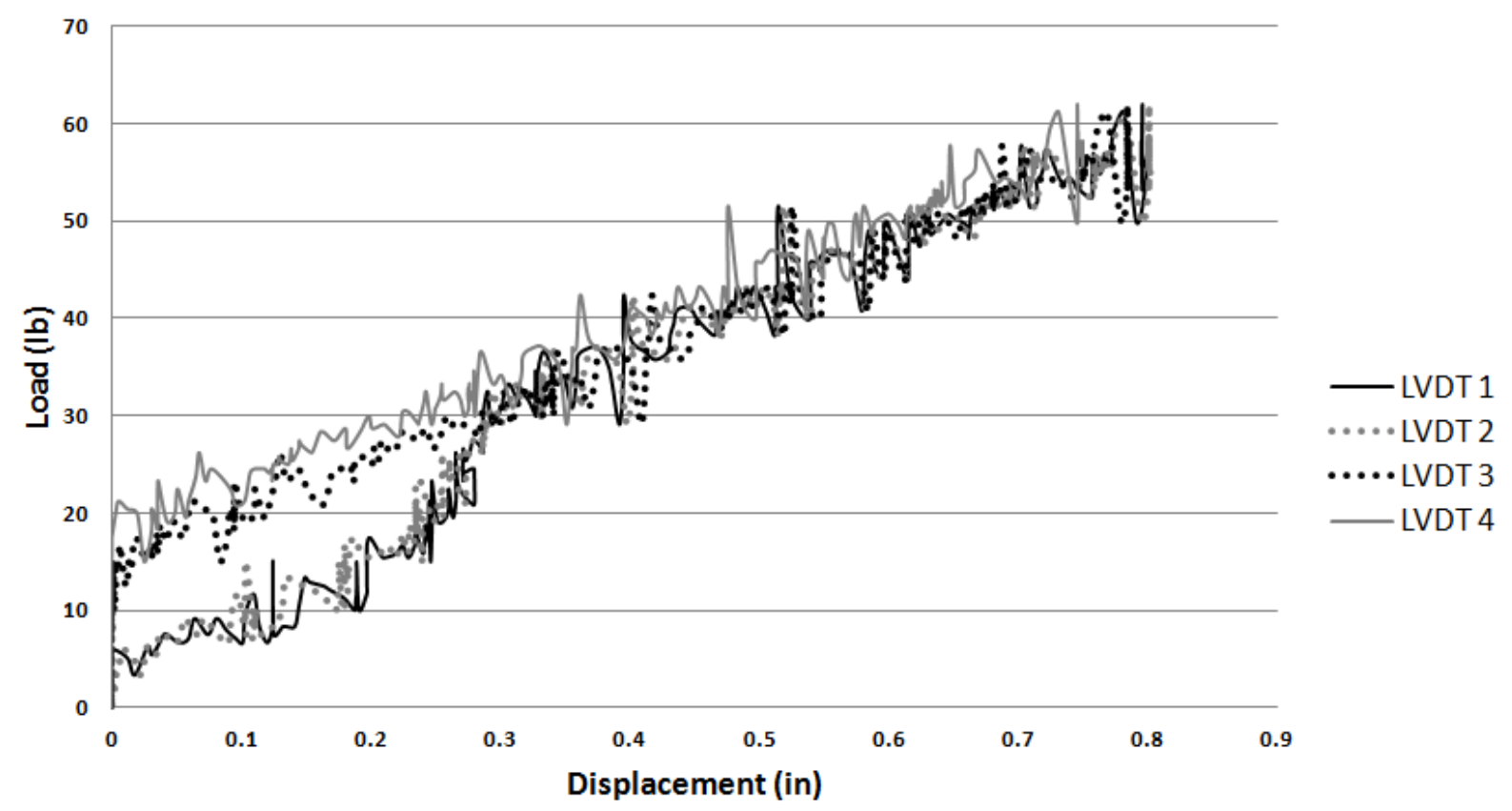

Figure 5.9 Typical Plot of Load vs. Displacement of I-Joist in Torsion 


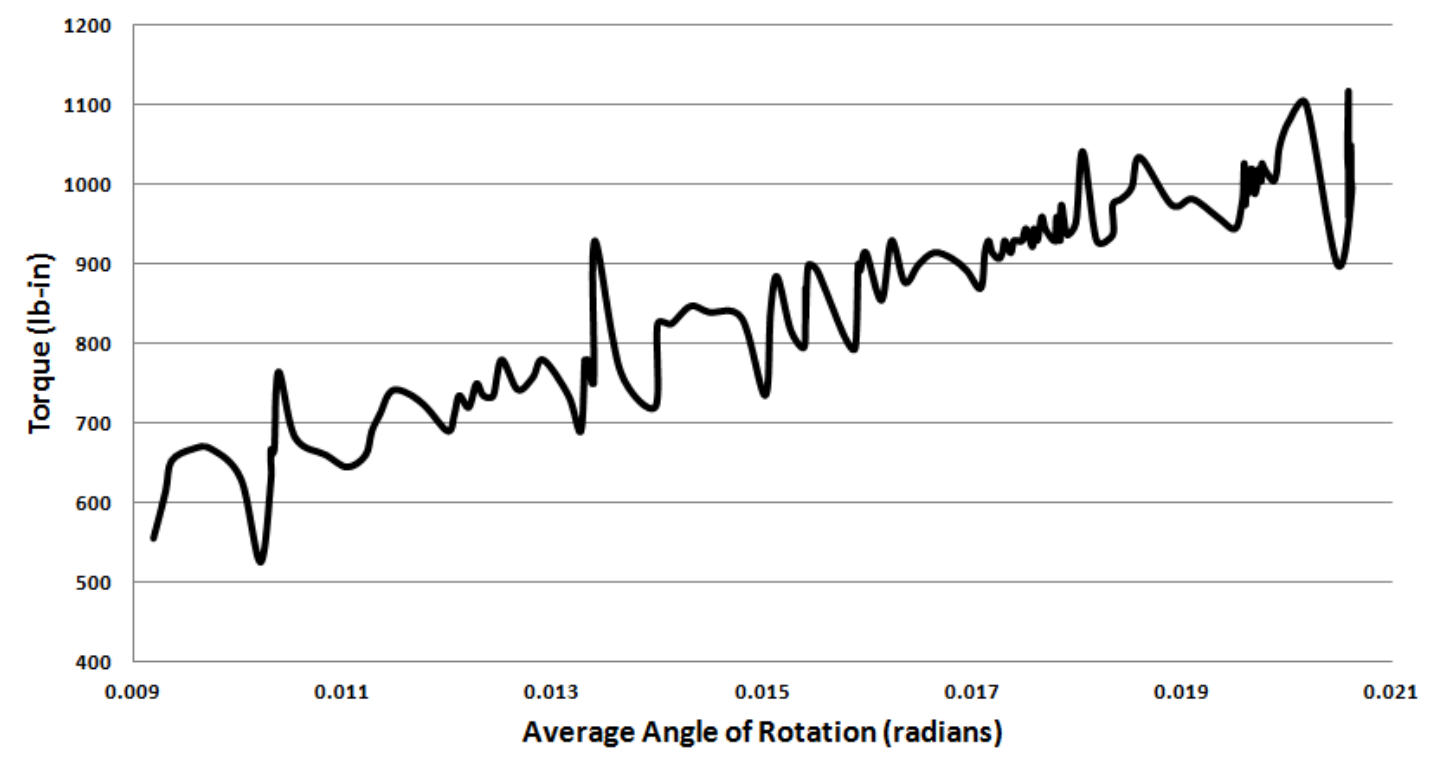

Figure 5.10 Typical Plot of Torque vs. Average Angle of Rotation of I-Joists in Torsion

The experimental results of the 10" flat web joist in torsion are shown in Table 5.3. Good correlation of the rotational stiffness is observed between all four tests. The resulting rotational stiffness values were all within $0.55 \mathrm{kip}$-in of one another with a maximum percent difference of $2.5 \%$ between all four tests.

Table 5.3 Experimental Results for 10" Flat Web I-Joist in Torsion

\begin{tabular}{lc}
\hline & GJ (kip-in) \\
Specimen & $\mathbf{1 - 3}$ \\
\hline Test \#1 & 21.88 \\
Test \#2 & 22.43 \\
Test \#3 & 22.10 \\
Test \#4 & 22.17 \\
\hline Average & $\mathbf{2 2 . 1 4}$ \\
\hline
\end{tabular}


The results from the torsion testing on the 10" sinusoidal web joist are shown in Table 5.4. Once again only one joist was tested because of the need to preserve the $14 \mathrm{ft}$ length of the other joists for later testing. The resulting GJ values from the four tests were very consistent. As in the case of the 10 " flat web joist the maximum percent difference in the four tests was only about $2.5 \%$.

Table 5.4 Experimental Results for 10" Sinusoidal Web I-Joist in Torsion

\begin{tabular}{lc}
\hline & GJ (kip-in) \\
Specimen & $\mathbf{2 - 1}$ \\
\hline Test \#1 & 30.55 \\
Test \#2 & 31.39 \\
Test \#3 & 31.24 \\
Test \#4 & 31.03 \\
\hline Average & $\mathbf{3 1 . 0 5}$ \\
\hline
\end{tabular}

Three 16" flat web joists were evaluated in torsion. The resulting torsional stiffness values are shown in Table 5.5. As in the case of the other joists, the results of the four tests between the individual joists are very consistent. The average torsional stiffness of the joists tested were within 3 kip-in of one another. A maximum percent difference of $11 \%$ is shown between joists 3 1 and $3-3$.

Table 5.5 Experimental Results for 16" Flat Web I-Joist in Torsion

\begin{tabular}{lccc}
\hline & \multicolumn{3}{c}{ GJ (kip-in) } \\
Specimen & $\mathbf{3 - 4}$ & $\mathbf{3 - 2}$ & $\mathbf{3 - 3}$ \\
\hline Test \#1 & 37.59 & 37.36 & 40.41 \\
Test \#2 & 38.54 & 37.47 & 41.34 \\
Test \#3 & 38.33 & 35.09 & 40.60 \\
Test \#4 & 35.91 & 35.20 & 40.71 \\
\hline Average & $\mathbf{3 7 . 5 9}$ & $\mathbf{3 6 . 2 8}$ & $\mathbf{4 0 . 7 7}$ \\
\hline
\end{tabular}


The results for the torsion testing on the 16 " sinusoidal web joists are shown in Table 5.6. The torsional rigidity of joists 4-1 and 4-3 are fairly close. However, the testing results from joist 4-4 yielded uncharacteristically low results. Because of the large percent difference, nearly $20 \%$, between joist 4-4 and joists 4-1 and 4-3, the testing results from 4-4 will be removed from the final results (Table 5.7).

Table 5.6 Experimental Results for 16" Sinusoidal Web I-Joist in Torsion

\begin{tabular}{lccc}
\hline & \multicolumn{3}{c}{ GJ (kip-in) } \\
Specimen & $\mathbf{4 - 1}$ & $\mathbf{4 - 3}$ & $\mathbf{4 - 4}$ \\
\hline Test \#1 & 39.77 & 38.32 & 32.02 \\
Test \#2 & 41.06 & 38.87 & 32.20 \\
Test \#3 & 42.61 & 37.77 & 32.72 \\
Test \#4 & 39.48 & 38.82 & 32.11 \\
\hline Average & $\mathbf{4 0 . 7 3}$ & $\mathbf{3 8 . 4 5}$ & $\mathbf{3 2 . 2 6}$ \\
\hline
\end{tabular}

The average torsional stiffness of the four different joist geometries are shown in Table 5.7. In the case of the 10 " joists, the joist with sinusoidal web exhibited a torsional stiffness nearly $30 \%$ higher than that of joists with flat web. However, for the 16 " joists the sinusoidal geometry only provided a $3.5 \%$ increase in stiffness. For the flat web joist, increasing the depth from 10 " to 16 " increased the torsional stiffness by $42 \%$ while the increase in depth only increased the stiffness of the sinusoidal web joist by $21 \%$. 
Table 5.7 Summary of the Experimental Results of I-Joists in Torsion

\begin{tabular}{lcccc}
\hline & \multicolumn{2}{c}{ Flat Web Joist } & \multicolumn{2}{c}{ Sinusoidal Web Joist } \\
Joist Height (in) & $\mathbf{1 0}$ & $\mathbf{1 6}$ & $\mathbf{1 0}$ & $\mathbf{1 6}$ \\
\hline GJ (kip-in) & 22.14 & 38.21 & 31.05 & 39.59 \\
\hline
\end{tabular}

\subsection{Finite Element Modeling of I-Joists in Torsion}

A finite element analysis was performed on the I-joists for comparison with the experimental results. The finite element method follows that same procedure as previously discussed in Section 5.2.4. Both flat web and sinusoidal web I-joists were evaluated in torsion.

\subsubsection{Finite Element Model}

The description of the finite element model is given in Section 2.3. For the torsion model a 36" in long beam is considered. The beam only needs to be modeled from the mid-span to the location of the gauges (L) as discussed in Section 5.2.4. A total of four FE models were produced, with one for each of the different joist configurations.

Once the model was finished, the boundary and loading conditions were applied (Figure5.11). The displacements and rotations were fixed at one end and the load was applied on the opposite end of the beam. The load was applied using a force couple, where the total applied torque was equal to $1 \mathrm{kip}$-in. Also, it was found that it was necessary to restrain the two nodes where the force couples were applied from rotations about the y and z-axes for these complex geometries. 


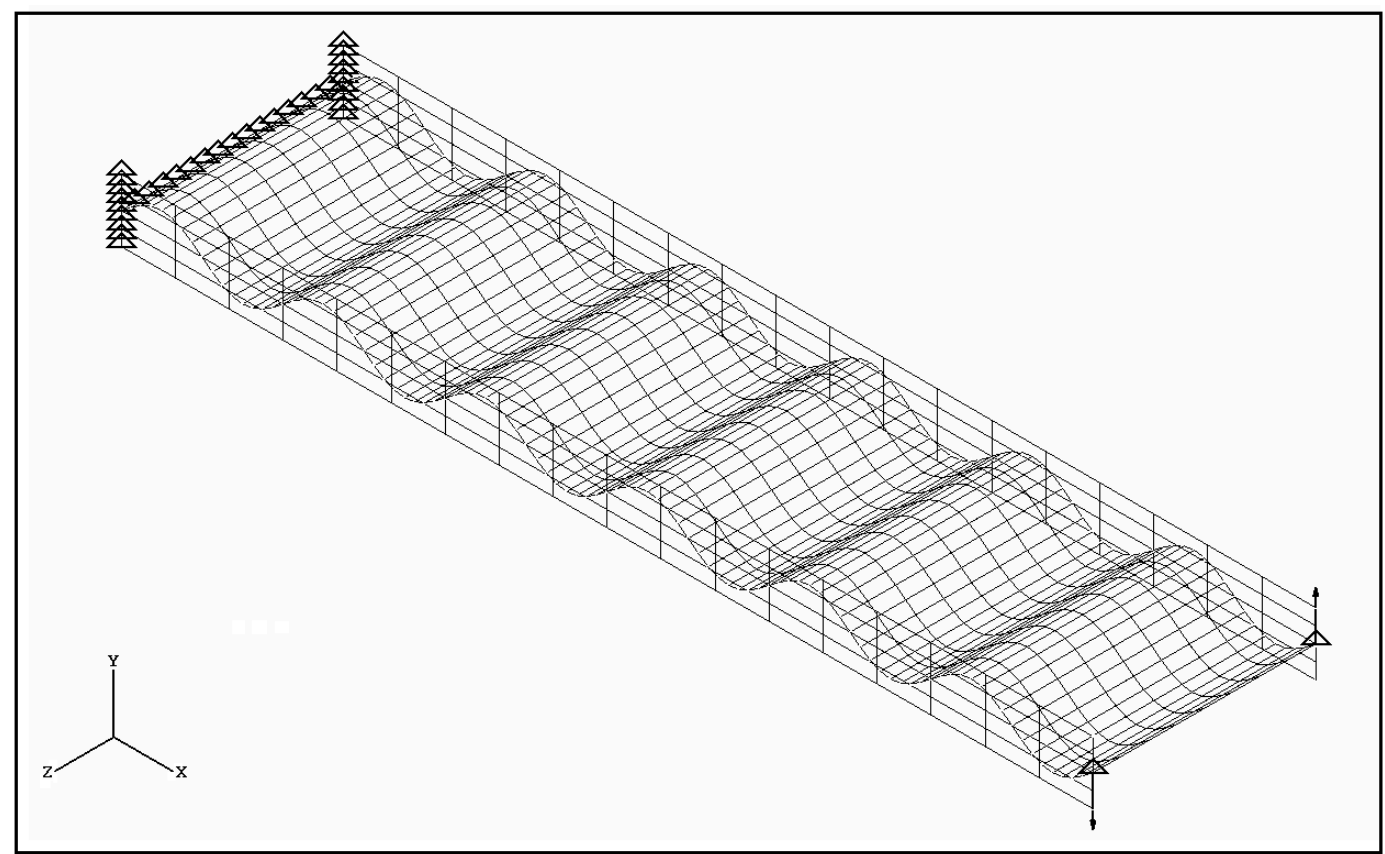

Figure 5.11 Finite Element Model of Sinusiodal Web I-Joist in Torsion

The two force couples, P, were applied to nodes on opposite edges at the end of the beam and were calculated using the following equation:

$P=\frac{T}{2(d / 2)}$

where $P=$ force couple (lb), $T=$ applied torque (1 kip-in), $d=$ depth of joist in FE model (in).

After the FE analysis was completed, the displacements of the nodes where the force couples were applied were found. The angle of rotation at the applied torque was equal to

$\theta=\frac{\Delta}{d / 2}$

where $\theta=$ angle of rotation (radians), $\Delta=$ displacement of node (in), $d=$ depth of joist in FE model (in). St. Venant's solution (Equation 5.6) was then used to calculate the rotational stiffness. 


\subsubsection{Results and Discussion}

The resulting deformed shape and contour plot of shear stress from the finite element analysis is shown in Figure 5.12. This result is typical of both the flat and sinusoidal web joists for both 10" and 16".

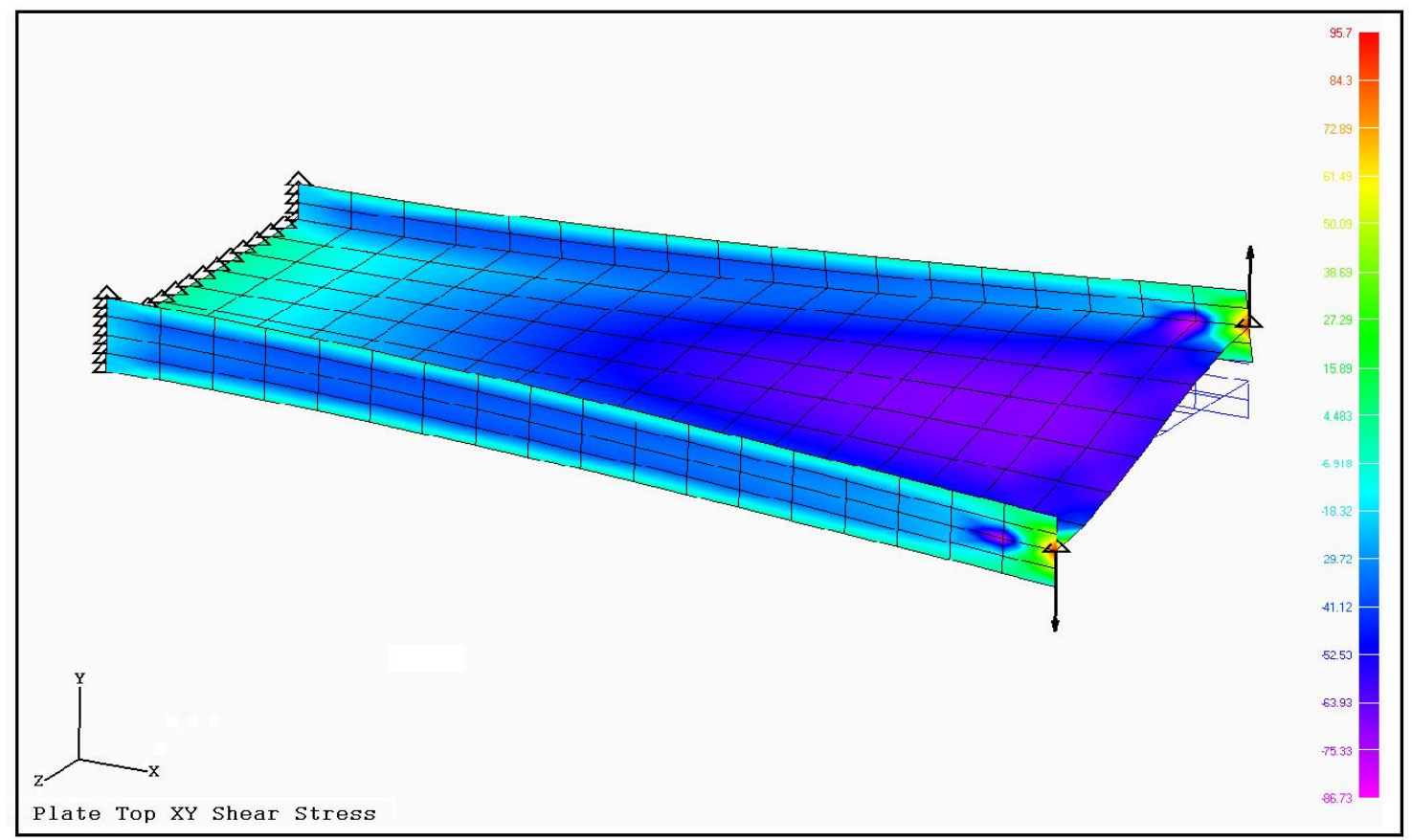

Figure 5.12 Deformed Shape of I-Joist Under Torsion form FE Analysis

As explained in the previous section, the torque applied the finite element model was known and the corresponding analysis yielded the angle of rotation. Using these two values and St. Venant's solution the rotational stiffness, or GJ value was calculated. These resulting values are displayed in Table 5.8. The increase in depth for both flat and sinusoidal joists increased the rotational stiffness by approximately $60 \%$. The results also show that the profiling of the web increases the 
stiffness by over $20 \%$, with the effect being magnified for the shorter joists where the stiffness was nearly $30 \%$ higher.

Table 5.8 Finite Element Results of I-Joists in Torsion

\begin{tabular}{lcccc}
\hline & \multicolumn{2}{c}{ Flat Web Joist } & \multicolumn{2}{c}{ Sinusoidal Web Joist } \\
Joist Height (in) & $\mathbf{1 0}$ & $\mathbf{1 6}$ & $\mathbf{1 0}$ & $\mathbf{1 6}$ \\
\hline GJ (kip-in) & 16.70 & 42.74 & 23.07 & 54.68 \\
\hline
\end{tabular}

\subsection{Comparison of FE and Experimental Results}

The results of the experimental investigation and FE simulation are summarized in Table 5.9. It can be seen that the FE simulation reflects the same behavior as seen in the experimental results in terms of web geometry and joist depth. However, the FE analysis does not agree closely with the experimental results. For the 10" deep joists the FE simulation underestimates the beam GJ value, while the opposite is true for the 16 " deep beams. A maximum difference of $38 \%$ is found for the $16 "$ sine joists and a minimum of $12 \%$ for the $16 "$ flat joists. The experimental and FE results differ by $25 \%$ for the 10 " joist of both web geometries.

Table 5.9 Comparison of FE and Experimental Results for I-Joists in Torsion

\begin{tabular}{lcccc}
\hline & \multicolumn{2}{c}{ Flat Web Joist } & \multicolumn{2}{c}{ Sinusoidal Web Joist } \\
Joist Height (in) & $\mathbf{1 0}$ & $\mathbf{1 6}$ & $\mathbf{1 0}$ & $\mathbf{1 6}$ \\
\hline Experimental GJ (kip-in) & 22.14 & 38.21 & 31.05 & 39.59 \\
Finite Element GJ (kip-in) & 16.70 & 42.74 & 23.07 & 54.68 \\
\hline
\end{tabular}




\section{CHAPTER 6}

\section{EVALUATION OF I-JOISTS IN FOUR-POINT BENDING}

\subsection{Introduction}

Characterizing the bending behavior of the composite I-joists is necessary for developing design guidelines. During the course of this research, beam samples with both flat and sinusoidal web configurations were tested under four-point bending. A finite element analysis is presented for comparison with the experimental results.

\subsection{Experimental Evaluation}

Experimental bending tests were performed using the beam samples described in Section 2.2.4. The bending tests were conducted using 4-point loading conditions and two different span lengths. Because certain samples were trimmed to $10 \mathrm{ft}$ to accommodate the torsion testing, one beam from each group was evaluated at a shortened span of 112 " while the other three were tested at a span of 160". This was the final test performed on the joists and all samples were loaded to full capacity to determine the bending stiffness and to investigate the failure modes. 


\subsubsection{Test Setup and Instrumentation}

All testing samples were instrumented with strain gages and LVDTs placed at chosen locations along the beams. These devices were placed at specified locations to best characterize the strain distribution and bending behavior of the joists. Lateral supports were used to prevent rotation of the beams during testing. The same universal testing machine was used for web local buckling was used for the bending evaluation.

The load was applied through the hydraulic ram of a universal testing machine. The load was transferred from the crosshead of the machine onto a spreader beam. This spreader beam then transferred the load equally through to loading blocks onto the test sample at $L / 3$ and $2 L / 3$, where $L$ is the span length (Figure 6.1). For the case of $14 \mathrm{ft}(168$ ") beams $L$ was equal to 160 ", and for $10 \mathrm{ft}$ (120") beams $L$ was 112". An external 10-kip load cell was placed between the ram and spreader beam to record load in real time. A photo of the test setup is shown in Figure 6.2.

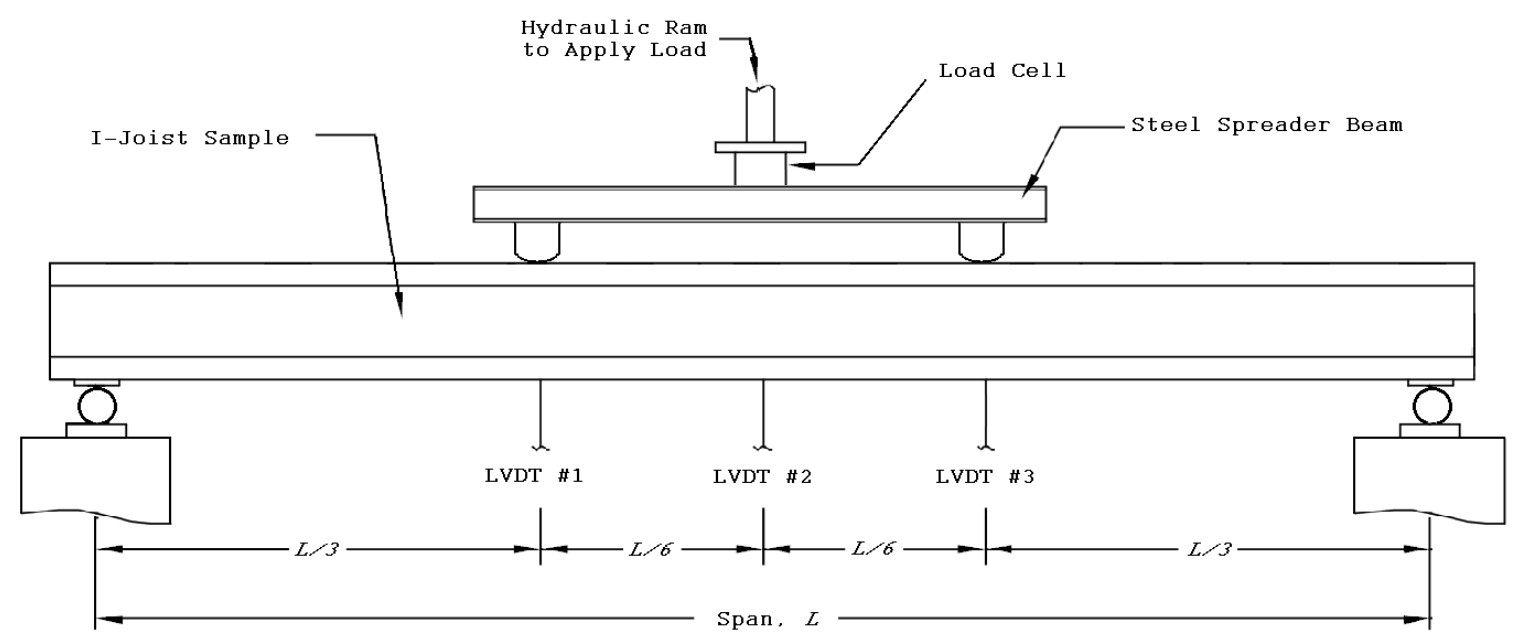




\section{Figure 6.1 Four-Point Bending Configuration}

Three LVDTs were used to monitor the displacement of the joists (Figure 6.1). The placement of the LVDTs was based on the span length. Two were placed at distances of $L / 3$ from the supports and one at the mid-span $(L / 2)$ of the beam. These were "floating" LVDTs that were hung directly from the bottom flange of the beam. A fastener was glued to the center of the bottom flange and a wire was strung from fastener. The core of the LVDT was then hung from the center of the wire in order to decrease localized effects.

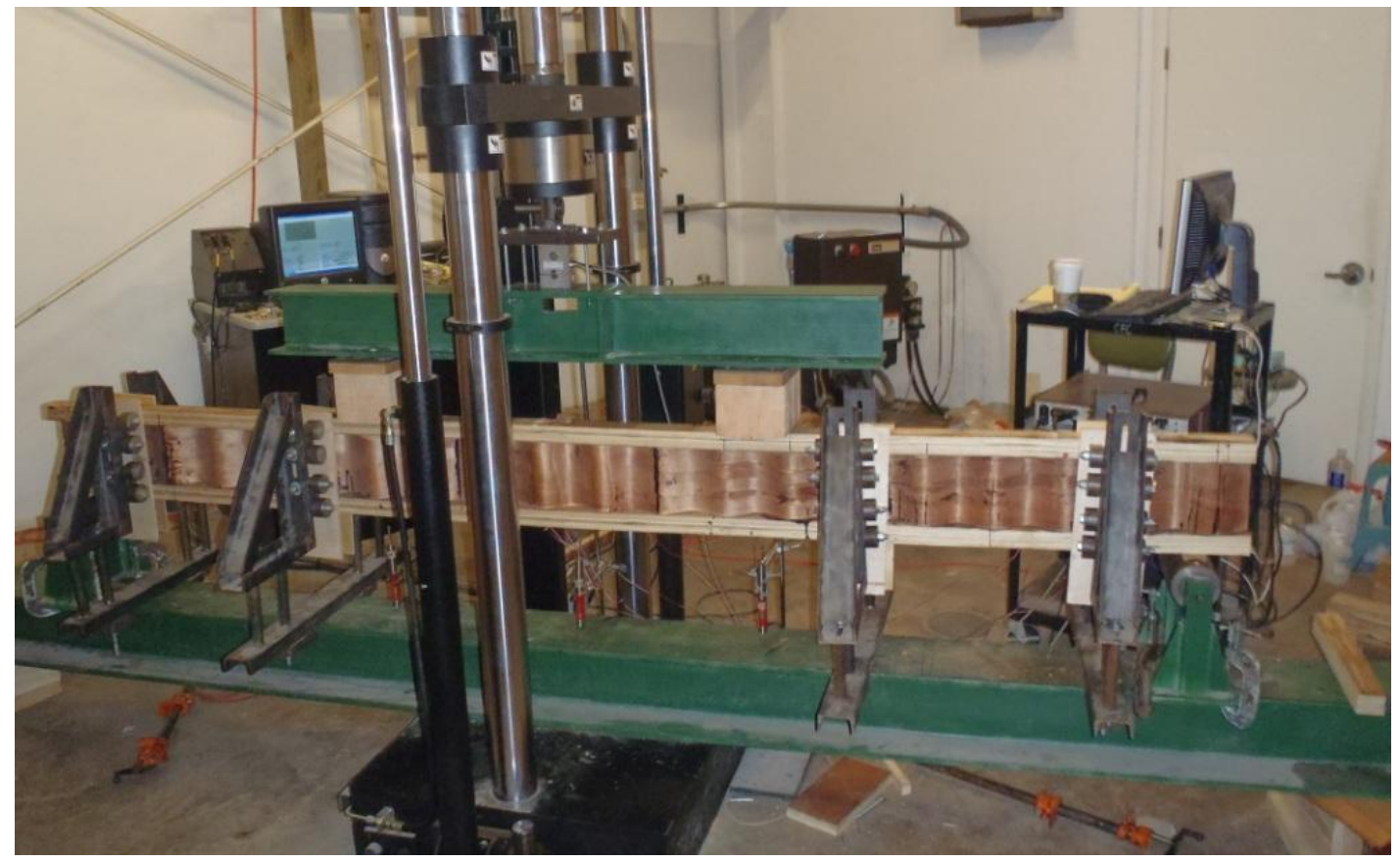

Figure 6.2 Photo of Bending Test Setup

Lateral supports were provided in specific locations to prevent rotation of the beams while under load. A diagram of the lateral support is shown in Figure 6.3. The lateral support was accomplished by a series of rollers which were fixed to the support beam. 3-layer ply was 
attached to the top flange of the testing beam and the rollers were secured around the plywood. This would not inhibit the vertical movement of the testing beam but would not allow any lateral deflection. The lateral supports were placed near the loading blocks and rollers. For the $14 \mathrm{ft}$ beams $L_{1}$ and $L_{2}$ were equal to 38 " and 8 " respectively. In the case of the $10 \mathrm{ft}$ samples, $L_{1}$ was equal to $22 "$ and $L_{2}$ remained at 8 ".

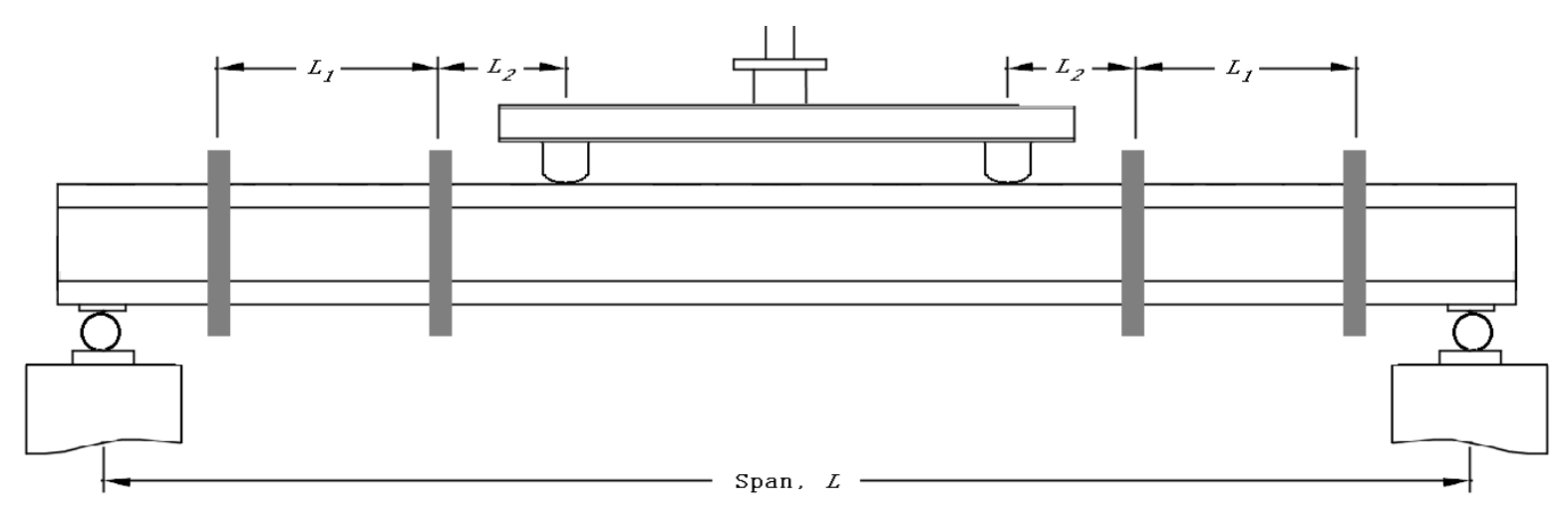

Figure 6.3 Lateral Supports Locations for Bending Test

The strain gages used in the bending tests were 1" 350-Ohm linear gages. There were five total gages placed on each sample in order to characterize the strain distribution through the depth of each joist. Each gage was oriented along the length of the sample to evaluate the strain longitudinally with respect to span length. One gage was placed on the top (compression) flange, two strain gages on the web of the beam, and two gages on the bottom (tension) flange. The locations of the strain gages are shown in Figure 6.3. The strain gage bonded to the top flange (Figure 6.3a) was placed a $w / 2$, where $w$ is the width of the flange. The strain gages on the bottom flange (Figure 6.3b) were each placed at a distance of 0.5 in from the edge of the flange. The two gages on the web (Figure 6.3c) were bonded at $d / 4$ and $3 d / 4$, where $d$ is the total depth of the beam. 


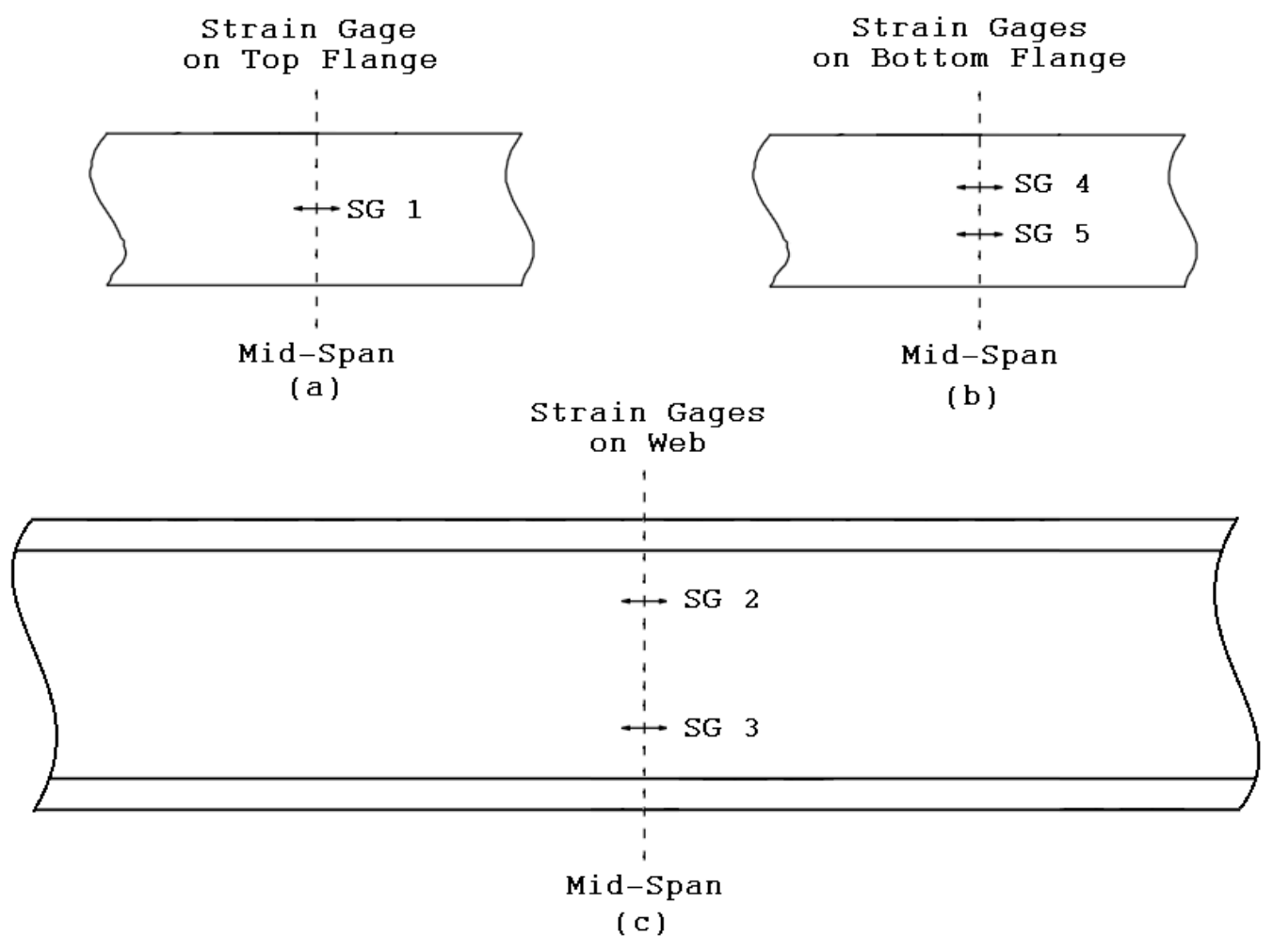

Figure 6.4 Strain Gage Placement for Bending Test

\subsubsection{Testing Procedure}

A constant load rate was applied to each sample. The load rate was controlled by deflection so that the sample would fail within 10 minutes. The LVDTs were removed from the sample before failure was reached so as they would not be damaged. The testing started with I-joist samples with 160" span. Once finish, the rollers and lateral supports were then moved inward and the final four $10 \mathrm{ft}$ beams were tested at a span of 112 ”.

To calculate the stiffness of the beams, the load and strain data was used. First, the load was plotted against the strain data (Figure 6.6). The linear elastic region of was found and the 
outlying data was removed. The stiffness was determined from the slope of the stress-strain curve in the linear elastic region. The following equations were used:

$M=\frac{P(L-a)}{8}$

where $M=$ bending moment (lb-in), $P=$ load (lb), $L=$ span (in), and $a=$ distance between the loading points (in).

$c=\frac{d}{2}$

where $c=$ distance from the outer fiber to the centroidal axis (in) and $d=$ depth of the joist (in).

$$
I=\frac{b_{w} h_{w}^{3}}{12}+2\left[\frac{b_{f} h_{f}^{3}}{12}+\left(b_{f} h_{f}\right)\left(\frac{d}{2}-\frac{h_{f}}{2}\right)^{2}\right]
$$

where $I=$ moment of inertia $\left(\mathrm{in}^{4}\right), b_{w}=$ width of the web (in), $h_{w}=$ height of the web (in), $b_{f}=$ width of the flange (in), $h_{f}=$ height of the flange (in), and $d=$ depth of the joist (in).

$\sigma=\frac{M c}{I}$

where $\sigma=$ stress (psi), $M=$ bending moment (lb-in), $c=$ distance from outer fiber to the centroidal axis (in), $I=$ moment of inertia $\left(\right.$ in $\left.^{4}\right)$.

$$
E=\frac{\sigma}{\varepsilon}
$$

where $E=$ stiffness (psi), $\sigma=$ stress (psi), and $\varepsilon=$ strain (microstrain). 
The strain was determined by taking the average value of the two strain gages located on the tension flange (Gages 4 and 5, see Figure 6.4b). The flexural strength was found using Equation 6.4 when the maximum bending moment occurred.

\subsubsection{Results}

The results of the testing of the individual joists are given in Tables 6.1 through 6.4. A summary of each group is given in Table 6.5. It should be noted that the joist marked with an asterisks $(*)$ denote those which were tested at the shorter span of 112". A description of the common failure modes is also provided.

A plot of load and displacement for joist 1-4 is shown in Figure 6.5. The linear elastic region can clearly be seen on the load-displacement curves. LVDTs 1 and 3 placed directly below the loading points observed approximately equal displacements while the LVDT at midspan recorded slightly higher deflections. This was expected, however, for many of the tests one or more of the LVDTs would behave erratically or record unusable data. The strain data proved to be much more consistent and reliable and therefore it was used to calculate the stiffness of each joist 


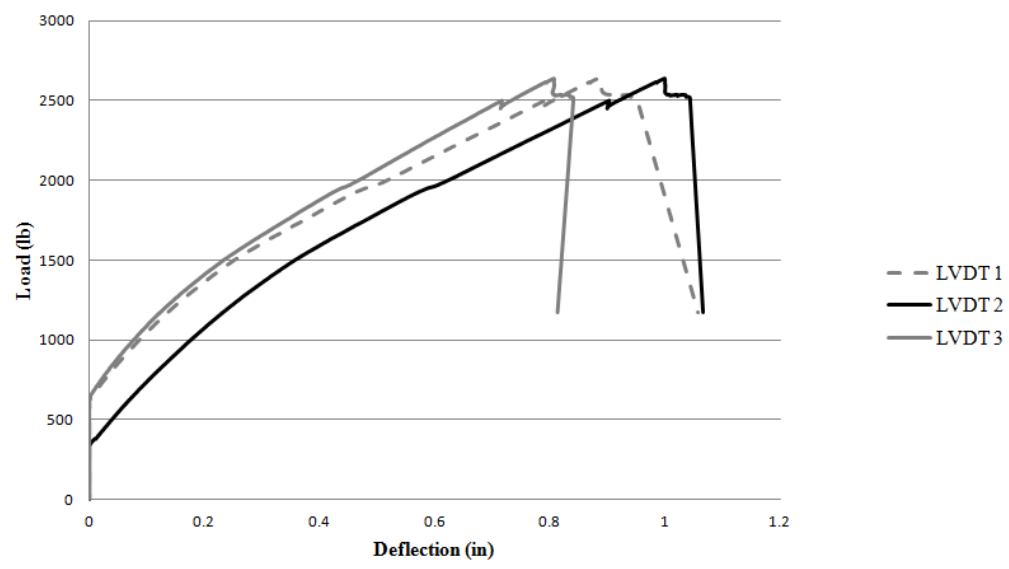

Figure 6.5 Typical Plot of Load vs. Deflection of Joist in Bending

A typical load and strain plot is shown in Figure 6.6. The absolute values of the strain are shown. Good correlation is shown between gages 1,4, and 5. Gage 1 was placed on the top flange (in compression) and gages 4 and 5 were placed on the bottom flange (in tension). All three gages show very similar strains which implies uniform strain distribution through the depth of the joist . Gages 2 and 3 placed at quarter depths on the web of the joist show approximately equal strains and good correlation with the other three gages. This result was typical for all joists.

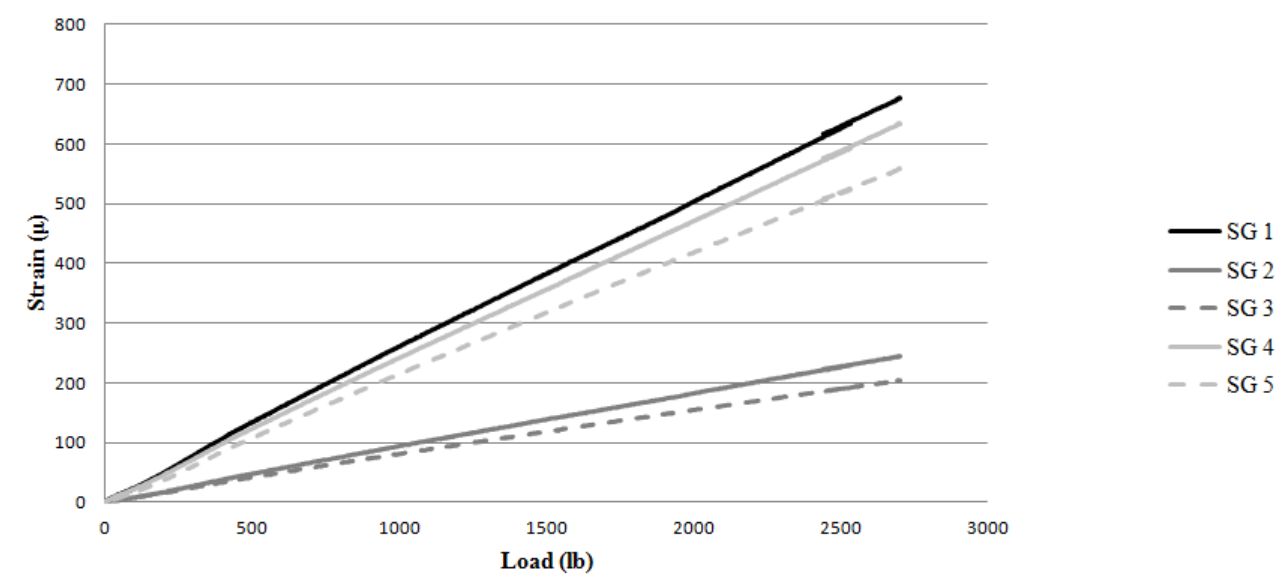

Figure 6.6 Typical Plot of Load vs. Strain of Joist in Bending 
The bending results are shown for the 10" flat web joists in Table 6.1. The critical loads and flexural strength values for the joists tested at a span of 160 " are consistent. The flexural strength for the $10 \mathrm{ft}$ joist is approximately $30 \%$ lower than for the $14 \mathrm{ft}$ joists, however, the critical load was in the same range. The range of the stiffness values over the four joists was fairly large with an average value of $1.370 \mathrm{E}+06 \mathrm{psi}$.

Table 6.1 Experimental Results for 10" Flat I-Joist in Bending

\begin{tabular}{lccc}
\hline Specimen & $\begin{array}{c}\text { Critical } \\
\text { Load (lb) }\end{array}$ & $\begin{array}{c}\text { Flexural } \\
\text { Strength }\end{array}$ & Stiffness (psi) \\
\hline $1-1$ & 2417 & 1090 & $1.240 \mathrm{E}+06$ \\
$1-2$ & 2267 & 1044 & $1.787 \mathrm{E}+06$ \\
$1-3^{*}$ & 2383 & 776 & $1.003 \mathrm{E}+06$ \\
$1-4$ & 2635 & 1191 & $1.450 \mathrm{E}+06$ \\
\hline
\end{tabular}

The results of each of the 10" sinusoidal joists evaluated in four-point bending are shown in Table 6.2. The critical load and flexural strength values are fairly consistent among the $14 \mathrm{ft}$ joists. Once again, the critical load of the shortened specimen was in the same range as the $14 \mathrm{ft}$ foot specimens with an approximately $20 \%$ lower critical strength. The stiffness of the joists is quite consistent with an average value of $1.035 \mathrm{E}+06 \mathrm{psi}$.

Table 6.2 Experimental Results for 10" Sinusoidal I-Joist in Bending

\begin{tabular}{lccc}
\hline Specimen & $\begin{array}{c}\text { Critical } \\
\text { Load (lb) }\end{array}$ & $\begin{array}{c}\text { Flexural } \\
\text { Strength }\end{array}$ & Stiffness (psi) \\
\hline $2-1^{*}$ & 2019 & 650 & $1.140 \mathrm{E}+06$ \\
$2-2$ & 1558 & 709 & $9.913 \mathrm{E}+05$ \\
$2-3$ & 1784 & 807 & $8.032 \mathrm{E}+05$ \\
$2-4$ & 2030 & 932 & $1.207 \mathrm{E}+06$ \\
\hline
\end{tabular}


Table 6.3 shows the bending results of group 3, the 16" flat web joists. Good consistency is again observed between the long span joists. In this case, the critical load for the shortened specimen is quite higher than the other three joists as should be expected and the flexural strength is in the upper range of the group. The stiffness values among the four joists show good correlation.

Table 6.3 Experimental Results for 16" Flat I-Joist in Bending

\begin{tabular}{lccc}
\hline Specimen & $\begin{array}{c}\text { Critical } \\
\text { Load (lb) }\end{array}$ & $\begin{array}{c}\text { Flexural } \\
\text { Strength }\end{array}$ & Stiffness (psi) \\
\hline $3-1$ & 2326 & 532 & $1.083 \mathrm{E}+06$ \\
$3-2$ & 2486 & 558 & $1.140 \mathrm{E}+06$ \\
$3-3$ & 2702 & 617 & $1.040 \mathrm{E}+06$ \\
$3-4^{*}$ & 4475 & 698 & $1.221 \mathrm{E}+06$ \\
\hline
\end{tabular}

The bending results for the final group, the 16" sinusoidal web joists, are presented in Table 6.4. As with group 3, the critical loads and flexural strengths among the $14 \mathrm{ft}$ joists are consistent while the shortened specimen shows higher load. The stiffness values show good correlation and an average of $1.109 \mathrm{E}+06 \mathrm{psi}$.

Table 6.4 Experimental Results for 16" Sinusoidal I-Joist in Bending

\begin{tabular}{lccc}
\hline Specimen & $\begin{array}{c}\text { Critical } \\
\text { Load (lb) }\end{array}$ & $\begin{array}{c}\text { Flexural } \\
\text { Strength }\end{array}$ & Stiffness (psi) \\
\hline $4-1^{*}$ & 3027 & 477 & $8.279 \mathrm{E}+05$ \\
$4-2$ & 1826 & 420 & $1.060 \mathrm{E}+06$ \\
$4-3$ & 1923 & 441 & $1.379 \mathrm{E}+06$ \\
$4-4$ & 1736 & 393 & $1.171 \mathrm{E}+06$ \\
\hline
\end{tabular}


A summary of the calculated stiffness of all four joists geometries is given in Table 6.5. These average values include all four joist samples in all four groups. The 10 " flat web joist shows an approximate $30 \%$ increase in stiffness over the joist with sinusoidal web while the difference in the stiffness of the 16 " joists is minute. Also, the stiffness decreases by nearly $20 \%$ for the increase in depth of the flat web joist while a slight increase in stiffness is observed from the 10" to 16 " sinusoidal joists. The improved performance of the flat web joists is most likely due to manufacturing defects present in the sinusoidal web joists. The sinusoidal web joists were much more challenging to produce in a laboratory setting than joists with flat webs. Manufacturing a solid flange-to-web connection was very difficult and of critical importance to the overall bending performance of the joists, i.e. critical load, flexural strength, and stiffness.

Table 6.5 Summary of I-Joist Bending Experimental Results

\begin{tabular}{lcccc}
\hline & \multicolumn{2}{c}{ Flat Web Joist } & \multicolumn{2}{c}{ Sinusoidal Web Joist } \\
Joist Height (in) & $\mathbf{1 0}$ & $\mathbf{1 6}$ & $\mathbf{1 0}$ & $\mathbf{1 6}$ \\
\hline Stiffness (psi) & $1.370 \mathrm{E}+06$ & $1.121 \mathrm{E}+06$ & $1.035 \mathrm{E}+06$ & $1.109 \mathrm{E}+06$ \\
\hline
\end{tabular}

\subsubsection{Failure Modes}

Failure in shear was the main cause of failure for all joist specimens. This came in two specific forms, shear through the web itself or shear through the flange-to-web connection. These failures always began between outside of the shear-free zone between the loading points and usually close to the bending supports or just outside of the load points. Separation of the web-web connection under bending as well as instances of web crushing occurred. 
Shear could occur at the interface between the top flange and the web, the bottom flange and the web, or in some instances shear through both the top and bottom flange web connection was observed. Shear directly through the interface would occur and in some instances there would be a combination of separation of the connection and shear. Figure 6.7 and Figure 6.8 show typical examples of shear failure through the flange-web interface for both the sinusoidal and flat web joists.

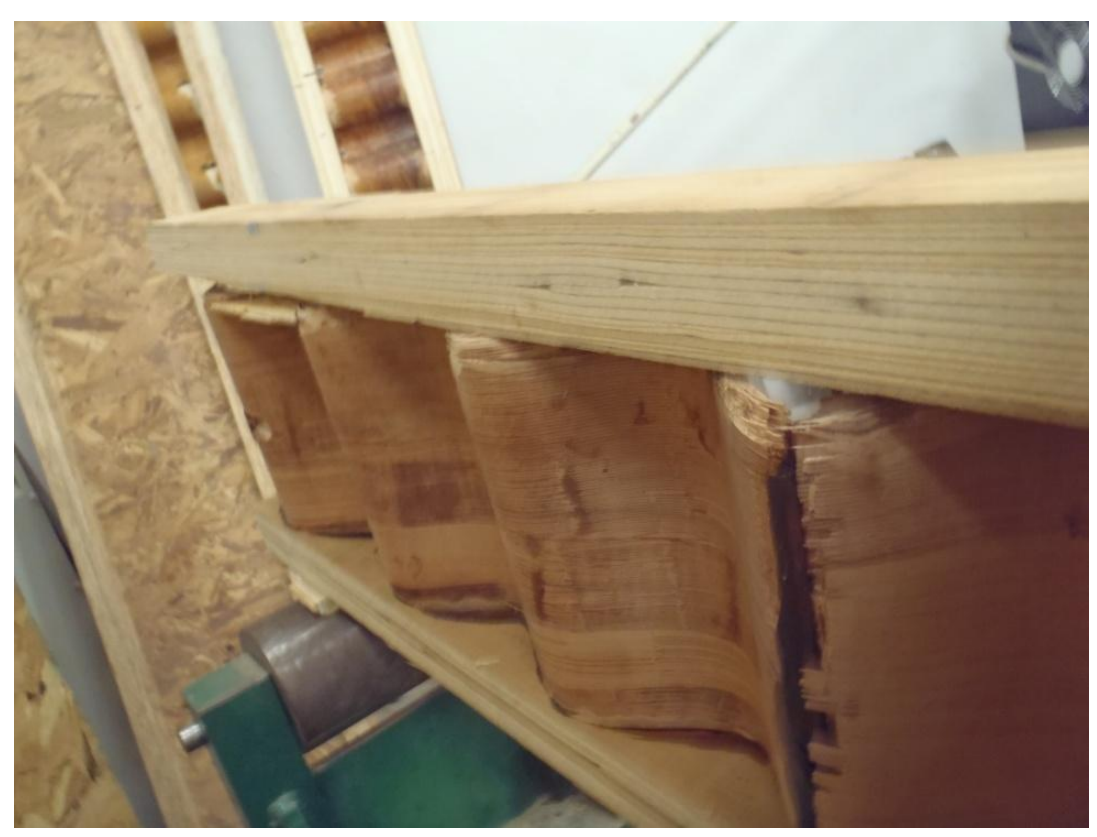

Figure 6.7 Shear Through the Flange-to-Web Connection of Sinusoidal Web Joist 


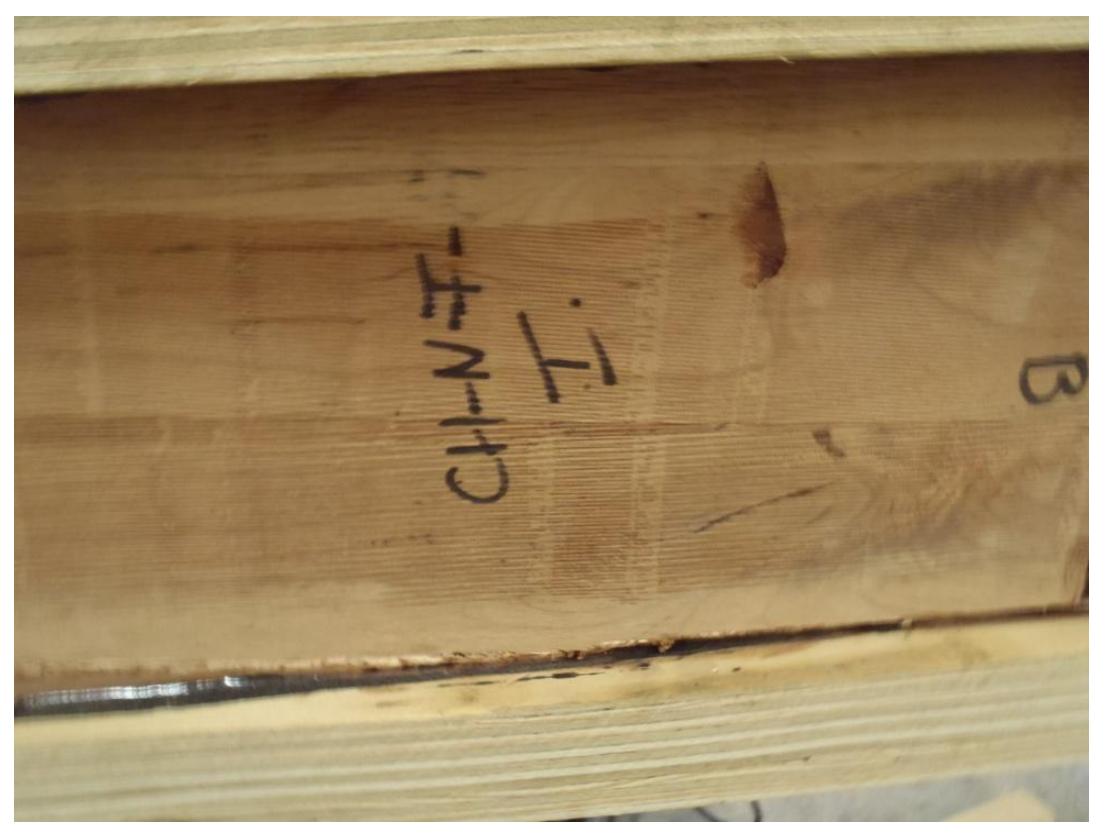

Figure 6.8 Shear Through the Flange-to-Web Connection of Flat Web Joist

Shear directly through the web was also a very common occurrence. This was observed in nearly all the 10 " joists that were evaluated and in two of the sinusoidal 16" deep joists. For half of all the sinusoidal web joists this is where the failure began. Figures 6.9 and 6.10 show shearing through the webs of the sinusoidal and flat web joists, respectively.

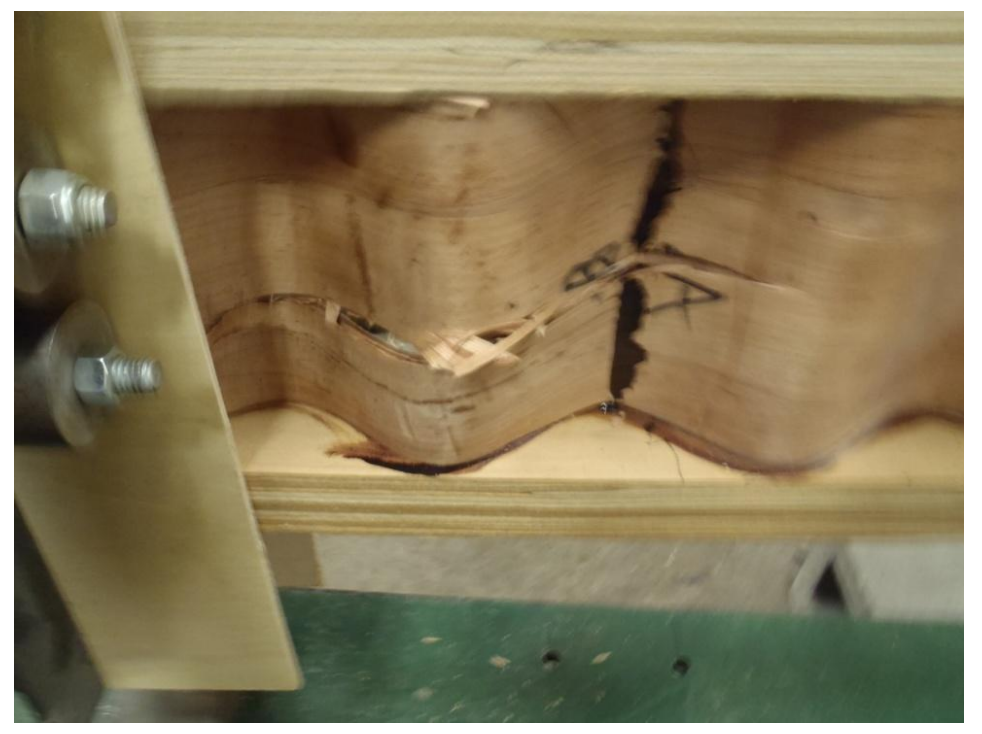

Figure 6.9 Shear Through the Web of a Sinusoidal Web Joist 


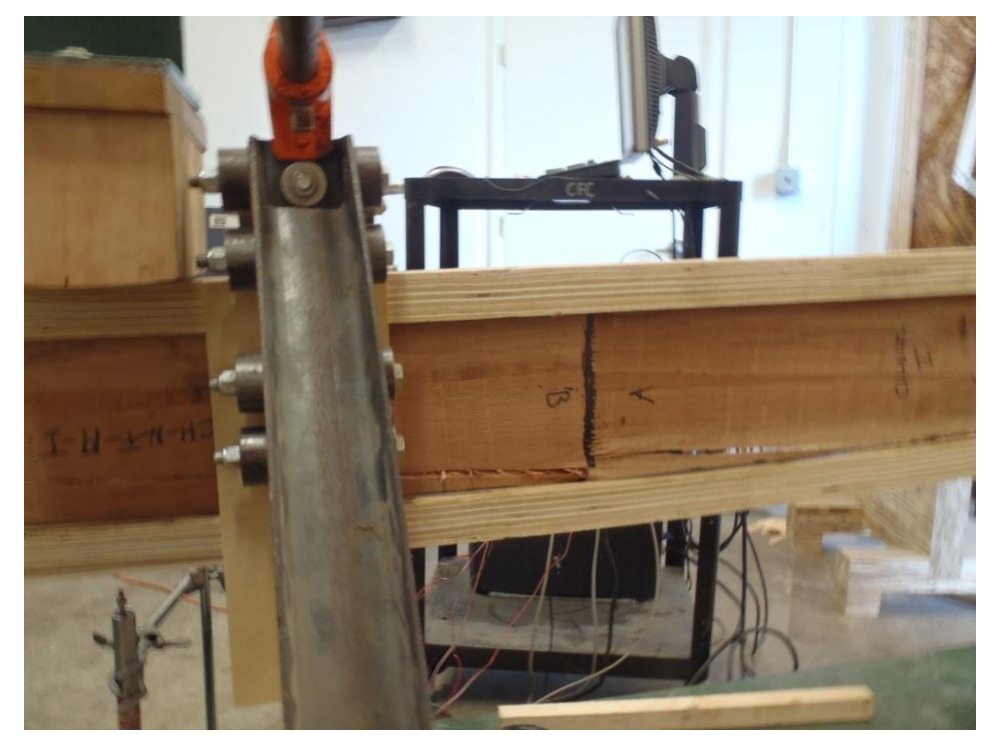

Figure 6.10 Shear Through the Web of a Flat Web Joist

It was common for shear occur in the both the web and flange-to-web connection being joined by a separation of the web-to-web connection (Figure 6.11). It was more common in the sinusoidal web joist for the failure to begin in the web panel itself and move to the flange-to-web connection. For the joists web it was more common for failure to begin at the flange-web interface. Though, instances of the shear beginning at the interface or beginning in web were seen in both flat and sinusoidal web joists. There were also instances of the shear through both the top and bottom flange-web interfaces connected by separation of the web to web connection (Figure 6.12) 


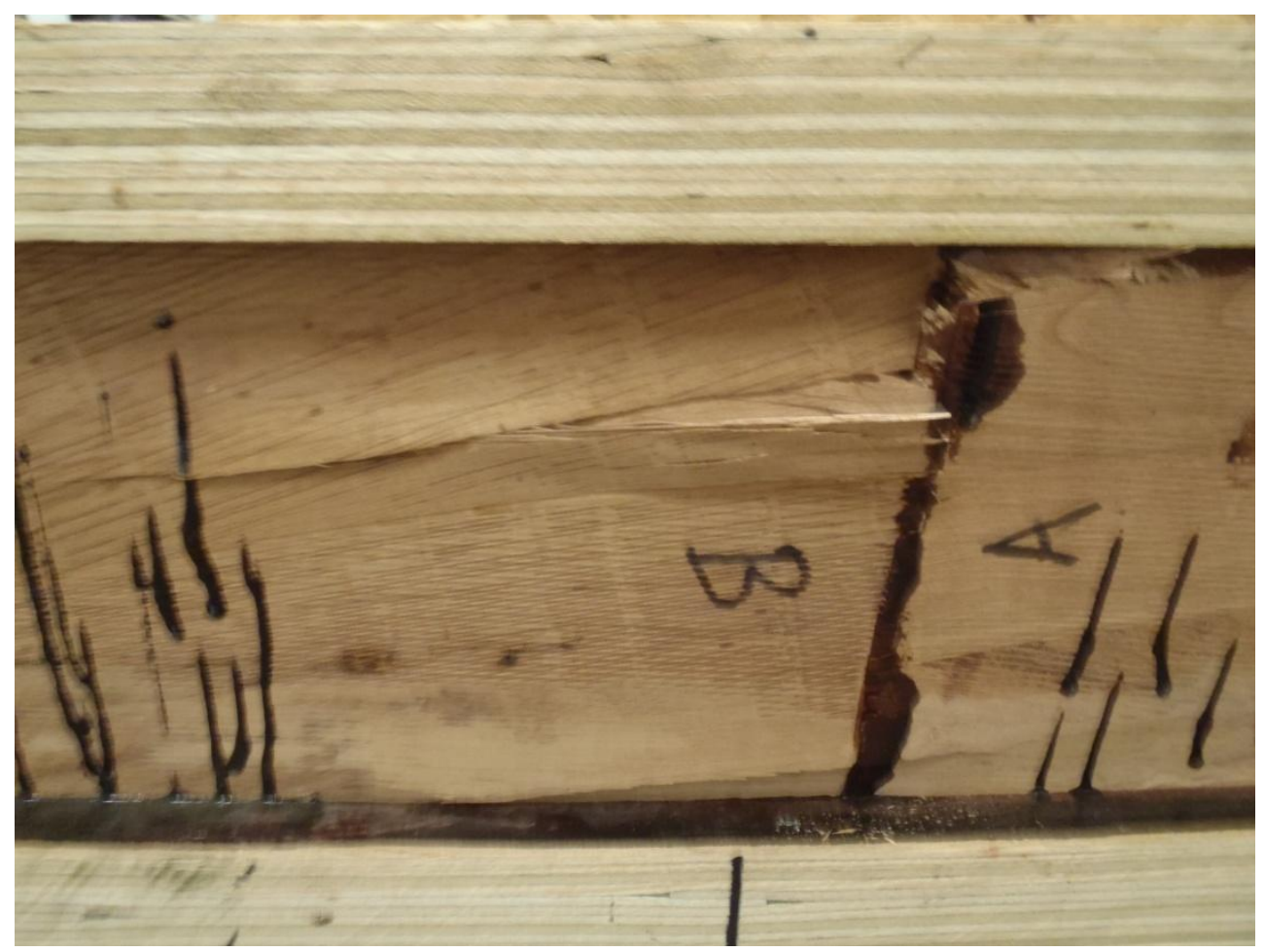

Figure 6.11 Common Path of Shear Failure

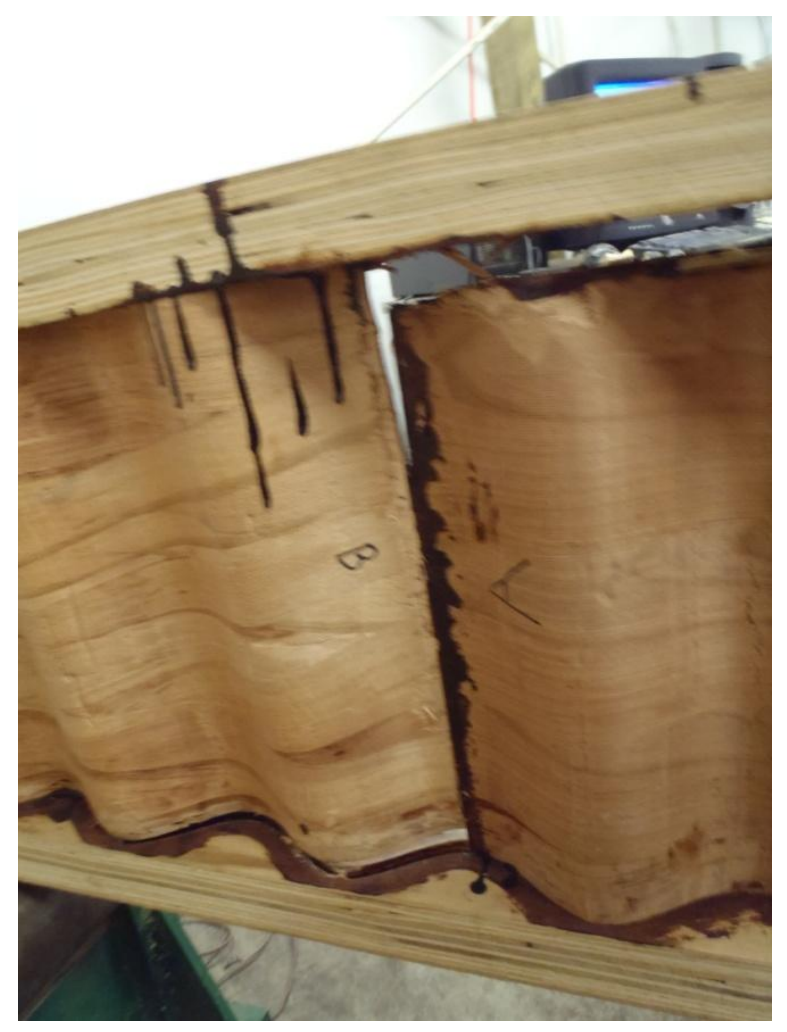


Figure 6.12 Simultaneous Shear of Top and Bottom Flange-Web Connections

Web crushing, or compression failure, occurred in a few samples. This was generally observed at the ends or very near the ends of the beams. This was much more common for the flat web joists and was only observed once for the sine wave samples. Three of the four 16 " flat web joists underwent some form of web crushing. Only one joist failed from web compression alone. All other instance of web compression were joined by some sort of shear failure as well. An example of web crushing under compression is shown in Figure 6.13.

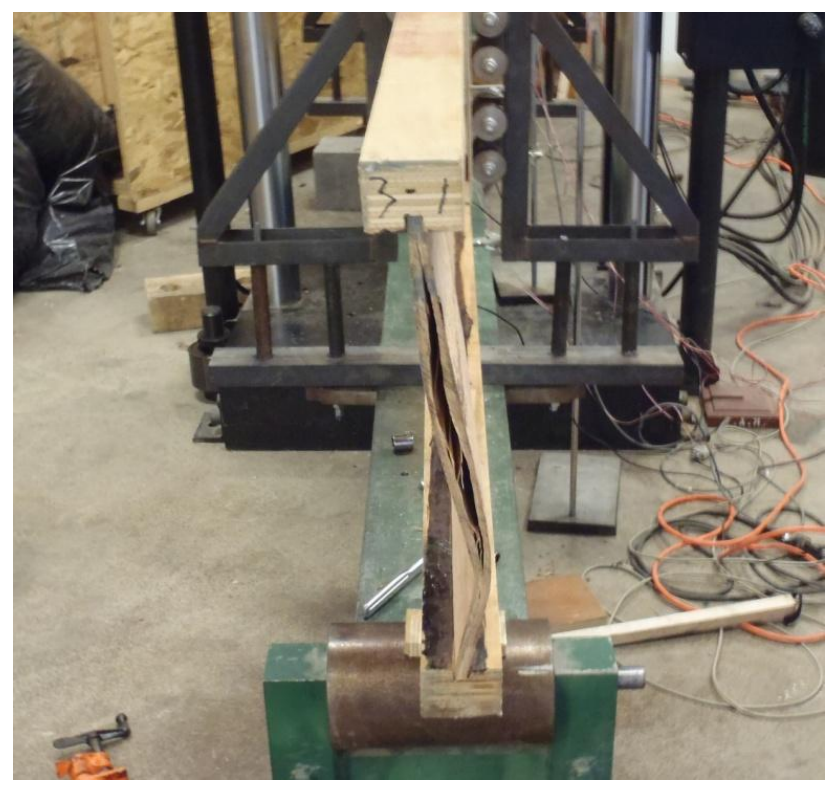

Figure 6.13 Web Failure in Compression.

\subsection{Finite Element Analysis}

Finite element analysis was performed as a check on the experimental results. Upper and lower limits on the critical loads were determined by imposing two different sets of boundary 
conditions on the beams. First, the beam was left unrestrained and therefore the beam buckled when the critical load was reached. Secondly, the upper limit was defined by the critical load at which the material strength was reached.

\subsubsection{Finite Element Model}

For the first case, the lower limit of critical load, an eigenvalue buckling analysis was performed. A simply supported beam simulated, placing the supports at the same locations as the experimental evaluations (160" span). The unit load was applied on all the nodes along the width of the top flange at the location of the two loading points. Figure 6.13 shows an example of one of the models used for the finite element analysis with loads and boundary conditions applied.

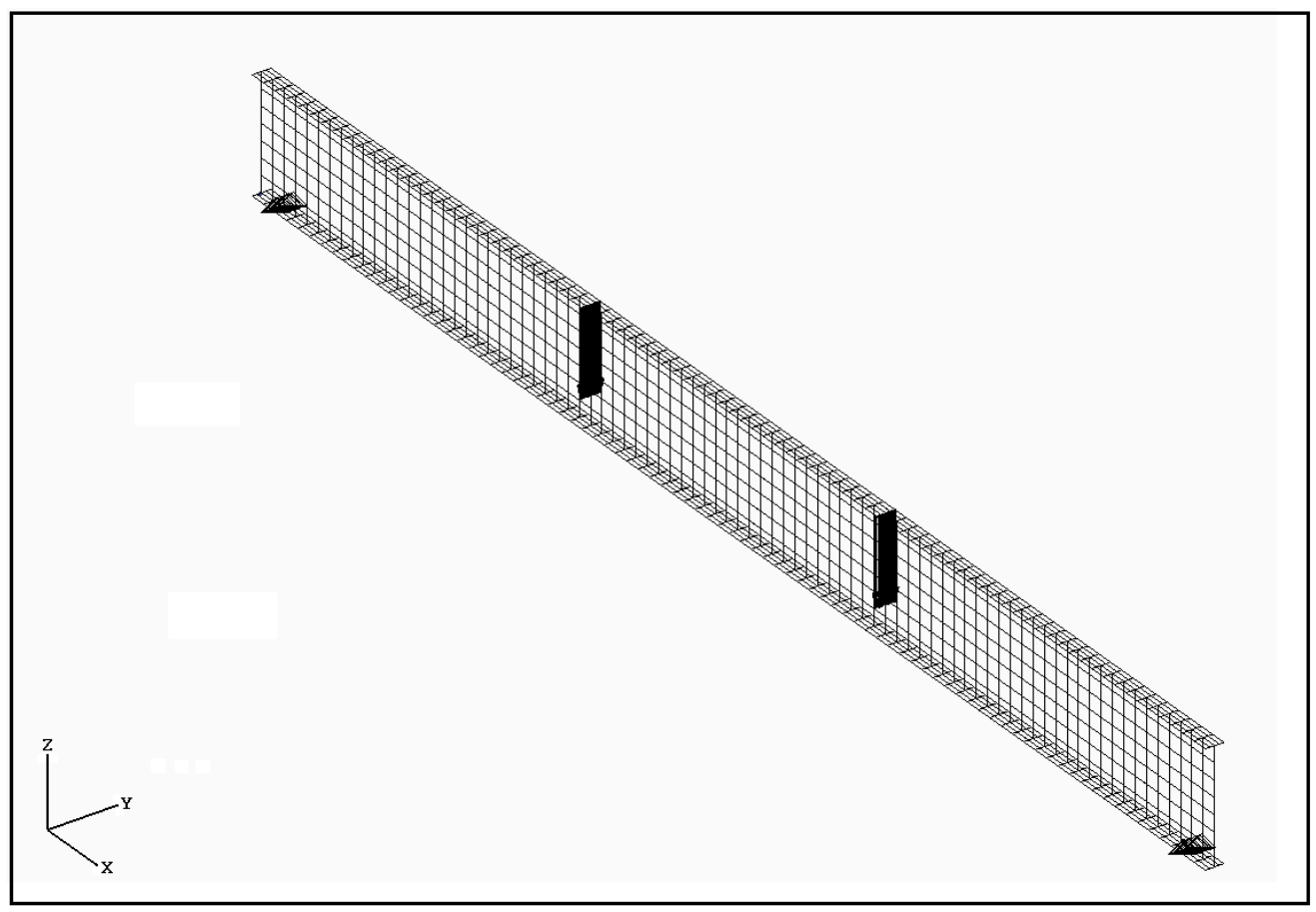


Figure 6.13 Finite Element Model for Beam Under Four-Point Bending

The second case was an analysis of the upper limit of the critical loads. This was achieved by restraining the beam laterally and performing a static analysis. The load was applied and increased until the material strength in either the principle or transverse direction was exceeded. The material strength was obtained from previous research done on the composite web panels (McGraw 2009).

\subsubsection{Results and Discussion}

The results from the finite element analysis are given it Table 6.6. Figure 6.14 shows the deformed shape and stress distribution of an unrestrained joist under critical load. It can be seen from the table and the figure that at relatively low loads, if left unrestrained, the joists will quickly lose stability. Figure 6.15 shows the deformed shape of the laterally restrained joist under critical load, i.e. the upper limit. It can be seen there is no lateral deformation and the joist only fails when the critical material stress is reached.

Table 6.6 Results of the FE Analysis of I-Joist in Bending

\begin{tabular}{ccccc}
\hline & \multicolumn{2}{c}{ Flat Web Joist } & \multicolumn{2}{c}{ Sinusoidal Web Joist } \\
Joist Height (in) & $\mathbf{1 0}$ & $\mathbf{1 6}$ & $\mathbf{1 0}$ & $\mathbf{1 6}$ \\
\hline $\begin{array}{c}\text { Finite Element } \mathbf{P}_{\text {cr }}(\mathbf{l b}) \\
\quad \text { Unrestrained }\end{array}$ & 748 & 513 & 1229 & 1109 \\
$\begin{array}{c}\text { Finite Element } \mathbf{P}_{\text {cr }}(\mathbf{l b}) \\
\text { Laterally Restrained }\end{array}$ & 13680 & 12960 & 7920 & 9000 \\
\hline
\end{tabular}




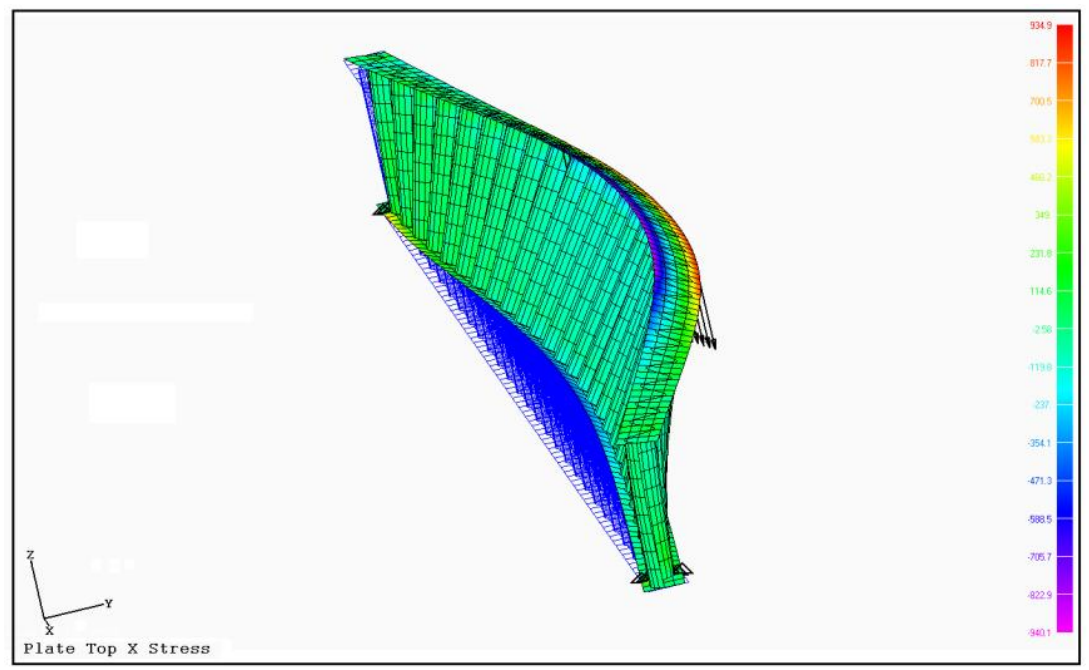

Figure 6.14 Buckling of I-Joist Under Bending From FE Analysis

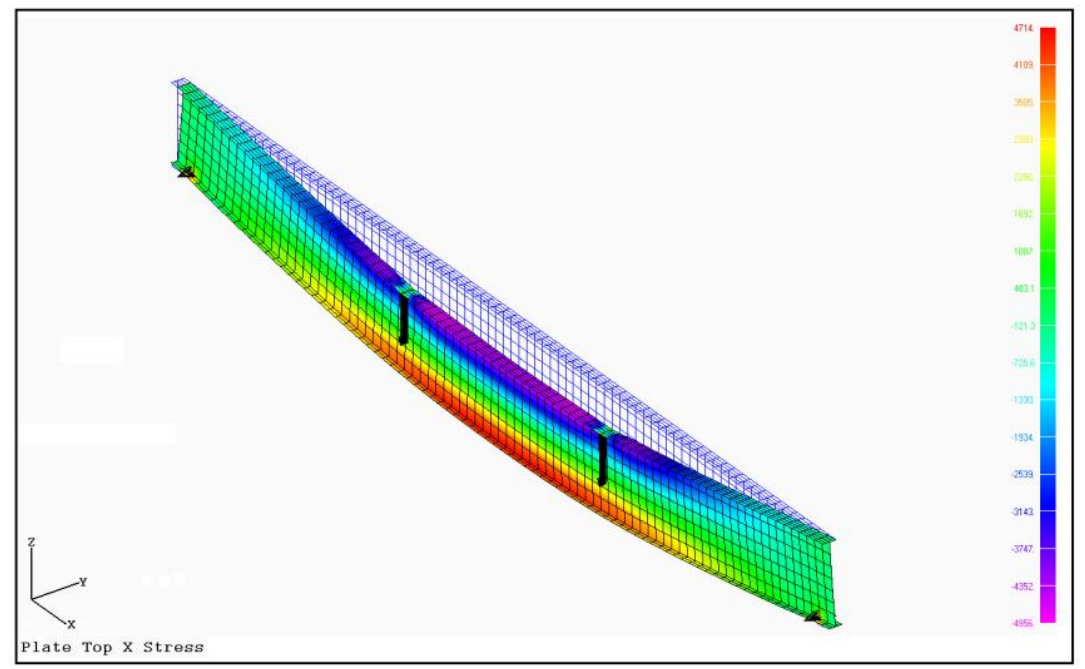

Figure 6.15 Static Analysis of I-Joist Under Bending From FE

\subsection{Comparison of FE and Experimental Results}

A comparison between the critical load obtained from the finite element analysis and the critical loads obtained from the joists evaluated at a span of 160 " is shown in Table 6.7. It can be seen that all joists failed well below the critical load governed by the material strength. All joists are 
safely within the range predicted by the finite element analysis and well above the critical load governed by buckling.

Table 6.7 Comparison of Experimental and FE Results of I-Joist Under Bending

\begin{tabular}{ccccc}
\hline & \multicolumn{2}{c}{ Flat Web Joist } & \multicolumn{2}{c}{ Sinusoidal Web Joist } \\
Joist Height (in) & $\mathbf{1 0}$ & $\mathbf{1 6}$ & $\mathbf{1 0}$ & $\mathbf{1 6}$ \\
\hline $\begin{array}{c}\text { Finite Element } \mathbf{P}_{\text {cr }}(\mathbf{l b}) \\
\text { Unrestrained }\end{array}$ & 748 & 513 & 1229 & 1109 \\
Experimental $\mathbf{P}_{\text {cr }}(\mathbf{l b})$ & 2440 & 1791 & 2505 & 1828 \\
$\begin{array}{c}\text { Finite Element } \mathbf{P}_{\text {cr }}(\mathbf{l b}) \\
\text { Laterally Restrained }\end{array}$ & 13680 & 12960 & 7920 & 9000 \\
\hline
\end{tabular}




\section{CHAPTER 7}

\section{CONCLUSIONS AND RECOMMENDATIONS}

\subsection{Conclusions}

In this thesis, a comprehensive study on the strength evaluation of wood I-joist with sinusoidal web is carried out. Specifically, the behavior of the web in compression, the lateral-torsional buckling resistance of joist, an evaluation of the rotational stiffness through torsion testing, and an evaluation of the bending behavior and stiffness of the joists. Comparisons are made with joists with a flat web of the same material and equivalent volume. Also, a study on the influence of the depth is performed. Finite element analysis is performed to supplement the experimental work. Major findings and conclusions are presented in this section.

\subsubsection{Evaluation of the I-Joist Web in Compression}

Compression tests were carried out to evaluate the effect of the profiling of the web. The goal was to observe the buckling behavior of the web of the joists. However, two failure modes were observed, web buckling and shear failure. The majority of shear failure occurred in the sinusoidal web panels. The critical loads of the sinusoidal samples were much larger than for the samples with flat webs. As expected, the 10" deep joists were more resistant to failure than the 16" joist. However, the 16 " sine web joist outperformed the 10 " flat web joist by 2.5 times. These results 
indicate the sinusoidal web is much more resistant to buckling. However, the sinusoidal web joists reached material shear failure before the buckling load was reached. The 10"joist outperformed the 16 " deep joist by 1.25 times in the case of sinusoidal web. This shows that there is also a height effect involved. Based on the FE analysis the 16" joist did almost reach the critical buckling load even though most samples failed in shear showing that some instability did occur.

The FE analysis provided a good indication of the upper and lower bound limits of critical load for the flat web joists, which generally failed due to buckling. The results from the FE analysis for the sinusoidal web joist both fell below this predicted range. But, since the samples did not fail due to buckling this is reasonable. Based on the FE analysis the 16" joist did almost reach the critical buckling load even though most samples failed in shear showing that some instability did occur. Based on the FE analysis, the 10" only achieved $80-90 \%$ of full capacity. As discussed earlier, the results imply that the effect of the flange-web joint is less critical for the sinusoidal web panels. This as another advantage, since a rigid or clamped condition for this web geometry is very difficult to achieve during manufacturing. Overall, the sinusoidal web clearly outperforms the flat web under compression.

\subsubsection{Lateral-Torsional Buckling Composite I-Joists}

The lateral-torsional buckling resistance of the composite I-joists with sinusoidal web was determined by a cantilever tip-loading test. These joists were evaluated at two different depths as well as joists with flat webs for comparison. The results clearly show that the depth of the joist 
has a significant effect on the resistance to buckling. For both joist geometries, a 6" increase in joist depth translated into an approximate $20 \%$ increase in critical load. However, there was not much difference observe in the experimental critical buckling loads of the flat and sinusoidal web samples. The finite element analysis predicted a 6-8\% increase in lateral buckling load in the sine wave joists. The discrepancies in the experimental results are most likely due to the main issue with these sinusoidal web joists, the flange-to-web connection. This connection is critical and difficult to manufacture in a laboratory setting. Also, the multiple web-to-web connections along the length of the joists may have affected the rigidity of the joist. The finite element analysis did agree well with the experimental results of the flat web joists and fairly closely with the sinusoidal web joists. With a solid flange-to-web connection the sinusoidal web joists should have a notably higher resistance to lateral-torsional buckling and should agree very closely with the FE approximations.

\subsubsection{Evaluation of the I-Joists in Torsion}

An evaluation of the I-joists in torsion was performed to determine the equivalent rotational stiffness values of the joists. There was clear indication from the evaluation of the 10 " joists that the sinusoidal web improves the torsional stiffness of the member. However, for the 16" joists the effect of the sinusoidal web is only a $3 \%$ increase in stiffness. The FE analysis predicts a 30 $40 \%$ increase in stiffness. However, the results from the FE dramatically underestimate the stiffness of the 10 " joists and overestimate the stiffness of the 16 " joist. This could be due to the modeling of the connection between the flanges and the web. This connection was assumed rigid and the nodes at the flange-web interface were either merged or tied. Also, the values of the 
shear stiffness used in the finite element model obtained from Qiao and Davalos (2011) may not have been an accurate representation of the actual properContties of the flanges and web which would lead to inconsistency in the rotations and, therefore, may not be an accurate predictor of the rotational stiffness The torsion machine used for the experimental evaluation was designed to for testing of much stiffer members. The overall scale of the loading beam, turnbuckles, torsion grips and counter-balances of the torsion may have played a significant role in these discrepancies in the testing results of these relatively light structural members. Also, elimination of many of the web-to-web joints and improvement of the flange-to-web connection should lead to improved rotational stiffness.

\subsubsection{Evaluation of the I-Joist in Four-Point Bending}

A four-point bending test was performed to evaluate the stiffness and failure modes of the joists. In this case, the results showed that flat web joist outperformed the sinusoidal web joists in terms of stiffness and flexural strength. This is contrary to what was expected. Though, all joists failed in some form of shear, bending failure was never observed. The results from the finite element analysis show that all joists failed in the low range of the envelope of critical loads predicted. The critical load of all joists was much closer to the unrestrained case than the laterally restrain case. Proper lateral support was provided during testing and significant lateral displacement was not observed in any samples during testing. It was expected that most joists would fail in the high-end range of this load envelope. This is another indication that the joists did not experience bending failure. These results clearly indicate issues with the connections and in some cases shear-through-thickness strength of the web panels. The flange-to-web connection is critical in 
bending performance of the joists and these discrepancies are once again most likely attributed to the lack of quality connections, especially in the case of the sinusoidal web joists. There were also many instances of separation of the web-to-web connections either leading to or propagating from further shear failure. Elimination of so many web-to-web joints should also increase the performance of the joist. While the stiffness was calculated from the linear range of the stressstrain curve, these issues with the shear of the connections and panels obviously affect the corresponding stiffness values calculated from the experimental testing.

\subsubsection{Synopsis}

General trends can be seen throughout the testing and finite element analysis of these joists. In many cases the sinusoidal joist is superior, both in experimental testing and FE analysis. There is much variability in the experimental results due the difficulty in consistently manufacturing high quality panels and connections in a laboratory setting. It is believed that if these joists were manufactured in a plant on an industrial scale these issues with quality and consistency could be controlled, web panels could be produced continuously significantly limiting the number of webto-web connections, and wood composite I-joists with sinusoidal webs could be produced and outperform their flat web counterparts.

\subsection{Recommendations for Future Work}

Although a comprehensive study on the strength evaluation of wood I-joists with sinusoidal web has been presented in this thesis, further investigation is suggested in the following areas. 
A more comprehensive study on the effect depth has on strength, stiffness, and stability should be performed. A few more of the common depths such as 12" and 14" could be evaluated as well as the 32" depth used in commercial applications. Then a proper parametric study could be carried out. Larger samples sizes are also recommend, where proper outliers could be determined, as there was much variation in the testing results from joist to joist.

Improvement of the flange-to-web connection for sinusoidal web I-joists is essential. For the tongue and groove joints, high quality and uniform grooves could be better manufactured in the flanges using tools available to the industry such as a CNC router. Improved attempts at manufacturing the finger joining method of flange and web as discussed in McGraw (2009) and attempted in this project but ultimately abandoned could be made. It is also suggested that sinusoidal web panels be manufactured at constant thickness, which would also greatly improve the quality of this joint. Also, manufacturing joists with continuous webs is recommended. Also, an investigation into the strength and nature of the flange-to-web connection should be done. It was assumed rigid in the finite element modeling and a proper investigation could better define this connection.

Further investigation into the compression of the sinusoidal I-joist sections is recommended. Evaluating different sections of the joist and sine curve is necessary to determine proper locations for placing I-joist hangers. 
An evaluation of the shear properties, particularly shear modulus and shear through-the-thickness should be made to better define the characteristics of the web panel. The proper shear modulus values could then be incorporated into the finite element model. Further attempts to incorporate a core into the web panel should to provide additional shear strength should be made as shear through-the-thickness was an evident problem in the bending evaluation. 


\section{REFERENCES}

Abbas, H. H. (2003). Analysis and design of corrugated web I-girders for bridges using high performance steel, Ph.D. dissertation, Lehigh Univ., Bethlehem, Pa.

ABAQUS User's Manual (Version 6.7) (2007). SIMULIA, Dassault Systems S.A., RI, USA.

ASTM Designation: D5055-05, Standard Specification for Establishing and Monitoring Structural Capacities of Prefabricated Wood I-Joists (2005). ASTM, PA, USA.

Barbero, E. J. and Raftoyiannis, I. G. (1994). "Lateral and distortional buckling of pultruded Ibeams", Composite Structures, 27(3), pp. 261-268.

Bejo, L. (2001). Simulation Based Modeling of the Elastic Properties of Structural Composite Lumber, Ph.D. Dissertation, West Virginia University, Morgantown, WV.

Boresi, A.P. and Schmidt,R.J., (1993). Advanced Mechanics of Materials, $6^{\text {th }}$ Edition, John Wiley \& Sons, Inc., USA.

Brokaw, J.T. (1992). Test Methods to Determine Strength and Stiffness Properties for StressLaminated Timber Bridge Secks, Master Thesis, West Virginia University, Morgantown, WV.

Chan C.L., Khalid Y.A., Sahari B.B., and Hamouda A.M.S. (2002) "Finite element analysis of corrugated web beams under bending", Journal of Constructional Steel Research 58, pp.13911406.

Chui, Y.H., Komatsu, K., Jung, K., Noda, Y., Ohashi, Y., and Toda M. (2008). "Reinforcement of Wood I-Joists with Natural Fibers", Proceedings of the World Conference on Timber Engineering, June 2-5, pp. 175.

Davalos, J. F., and Qiao, P. (1997). "Analytical and Experimental Study of Lateral and Distortional Buckling of FRP Wide-Flange Beams", Journal of Composites for Construction, 1(4), pp. 150-159.

Easley, J. T. (1975). "Buckling formulas for corrugated metal shear diaphragms", Journal of the Structural Division, 101(10), pp. 1403-1417.

Elgaaly, M., Seshadri, A., and Hamilton, R. W. (1997). "Bending strength of steel beams with corrugated webs", Journal of Structural Engineering, 123(6), pp. 772-782. 
Fergus, D.A. (1970). Effect of Web Voids and Stiffeners on Structural Performance of Composite I-Beams, Ph. D. Dissertation, Purdue University, West Lafayette, IN. 255 pp.

Fisette, P. (2000). "The evolution of engineered wood I-joists", Building Material and Wood Technology, http://bct.eco.umass.edu/publications/by-title/the-evolution-of-engineered-wood-ijoists/

FEMAP User's Manual (Version 8.3) (2003). EDS PLM Solutions, Exton, PA.

Forest Products Laboratory (1999). Wood Handbook: Wood as an Engineering Material. FPLGTR-113. USDA Forest Products Laboratory, Madison, WI.

Forest Products Laboratory (2000) Demand for Engineered Wood Products, USDA Forest Products Laboratory, Madison, WI

Hamilton, R. (1993). Behavior of welded girders with corrugated web, Ph.D. Dissertation, Department of Civil Engineering, University of Maine, Orono, Maine.

Hilson, B.O. and Rodd, P.D. (1979). "The Ultimate Shearing Strength of Timber I-Beams with Hardboard Webs”, Structural Engineering, 57B(2), pp. 25-36.

Hindman, D., Manbeck, H. B., and Janowiak, J. J. (2005).“Measurement and prediction of lateral torsional buckling loads of composite wood materials: I-joist sections", Forest Products Journal, Forest Products Society, 55(10), pp. 43-48.

Hughes, O., and Ma, M. (1996). "Lateral distortional buckling of monosymmetric beams under point load", Journal of Engineering Mechanics, ASCE, 122(10), pp. 1022-1029.

Johnson, R. P., and Cafolla, J. (1997). "Local flange buckling in plate girders with corrugated webs", Proceedings of the Institution of Civil Engineers, Structures and Buildings, 122(2), pp. $148-156$.

Leichiti, R. J., Falk, R. H., and Laufenberg, T. L. (1989). "Prefabricated Wood I-Joists: A Literature Review", Wood and Fiber Science, 2(1), pp. 62-79.

Leitcti, R.J. (1986). Assesing the Reliability of Wood Composite I-Beams, Ph.D. Dissertation, Auburn University, Auburn, AL., 265 pp.

Leichti, R., R. Falk, and Laufenberg, T. (1990). "Prefabricated wood composite I-beams: an industry overview", Forest Products Journal, 40(3), pp. 15-20.

Leichti, R. and Tang, R.C. (1983). "Analysis of Wood Composite I-Beams with Glued FlangeWeb Joints", Proceedings, Spring Meeting, Society for Experimental Stress Analysis, Brookfield Center, MA., pp. 45-50. 
Lindner, J. (1990). "Lateral torsional buckling of beams with trapezoidally corrugated webs", Proceedings, Int. Colloquium of Stability of Steel Structures, Budapest, Hungary, pp. 79-86.

Lin, Z. M., Polyzoid, D., and Shah, A. (1996). "Stability of think-walled pultruded structural members by finite element method." Thin-walled Structure, 24(1), pp. 1-18.

Luo, R. and Edlund, B. (1995). "Numerical simulation of shear tests on plate girders with trapezoidally corrugated webs", Division of Steel and Timber Structures, Chalmers University of Technology, Sweden.

Maley, J. D. (1987).“Wood I-joists: A closer look.”, Proceedings of Structures Congress/87, Building Structures, American Society of Civil Engineers, New York.

McGraw, B. (2009). Recycling Veneer-Mill Residues into Engineered Products with Improved Torsional Rigidity, Master Thesis, West Virginia University, Morgantown, WV.

Metwally, A.H. (1998). Prestressed Composite Girders with Corrugated Steel Webs, Master Thesis, The University of Calgary, Calgary, Alberta, Canada. 212 pp.

Mottram, J. T. (1992). "Lateral-torsional buckling of a pultruded I-beam", Composites, 32(2), pp. 81-92.

Pandey, M.D., Kabir, M. Z., and Sherbourne, A. N. (1995). "Flexural-torsional stability of thinwalled composite I-section beams", Composites Engineering, 5(3), pp. 321-342.

Qiao, P. and Davalos, J.F. (2011). Shear Stiffness Evaluation of Wood and Wood Composites. Unpublished Paper.

Qiao, P., Zuo, G., and Davalos, J.F. (2003). "Flexural-Torsional Buckling of Fiber-Reinforced Plasic Composite Cantilever I-Beams”, Composite Structures, 60, pp. 205-217.

Racher, P., Bocquet, J.F., and Bouchair, A. (2007). "Effect of Web Stiffness on the Bending Behaviour of Timber Composite I-Beams", Materials and Design. 28(3). Pp. 844-849.

Rancourt, D.G. (2008). Structural Behavior of Wood I-Joist/OSB Roof Panel Assemblies, Master Thesis, University of Maine, Orono, Maine, $185 \mathrm{pp}$.

Robinson, J.(2001). Analytical and Experimental Study of FRP Honeycomb Sandwich Panels with Sinusoidal Core, Master Thesis, West Virginia University, Morgantown, WV.

Saliklis, E. P., and Mussen, A. L. (2000). "Investigating the buckling behavior of OSB panels", Wood and Fiber Science, 32(3), pp. 259-268.

Salim, H.A. (1997). Modeling and Application of Thin-Walled Composite Beams in Bending and Torsion, Ph.D. Dissertation, West Virginia University, Morgantown, WV. 
Sayed-Ahmed , E.Y. (2005). "Lateral torsion-flexure buckling of corrugated web", Structures and Buildings, 158(SB1), pp. 53-69.

Smith, D. (1992). Behavior of corrugated plates subjected to shear, Master Thesis, University of Maine, Orono, Maine.

Engineered Wood Products (2001). Temperate Forest Foundation, Eco-Link 11(4).

Voevodin, V.MM., and Kondratenko, B.E. (1985). Composite Beams in Wooden House Construction. Derevoobrab. Promst. 11(29).

Wang, X. ( 2003). Behavior of Steel Members with Trapezoidally Corrugated Webs and Tubular Flanges Under Static Loading, Master Thesis, Drexel University, Philadelphia, PA., 212 pp.

Zhu, E.C., Guan, Z.W., Rodd, P.D., and Pope, D.J. (2005). "Buckling of Oriented Strand Board Webbed Wood I-Joists”, Journal of Structural Engineering, 131(10), pp. 1629-1636. 


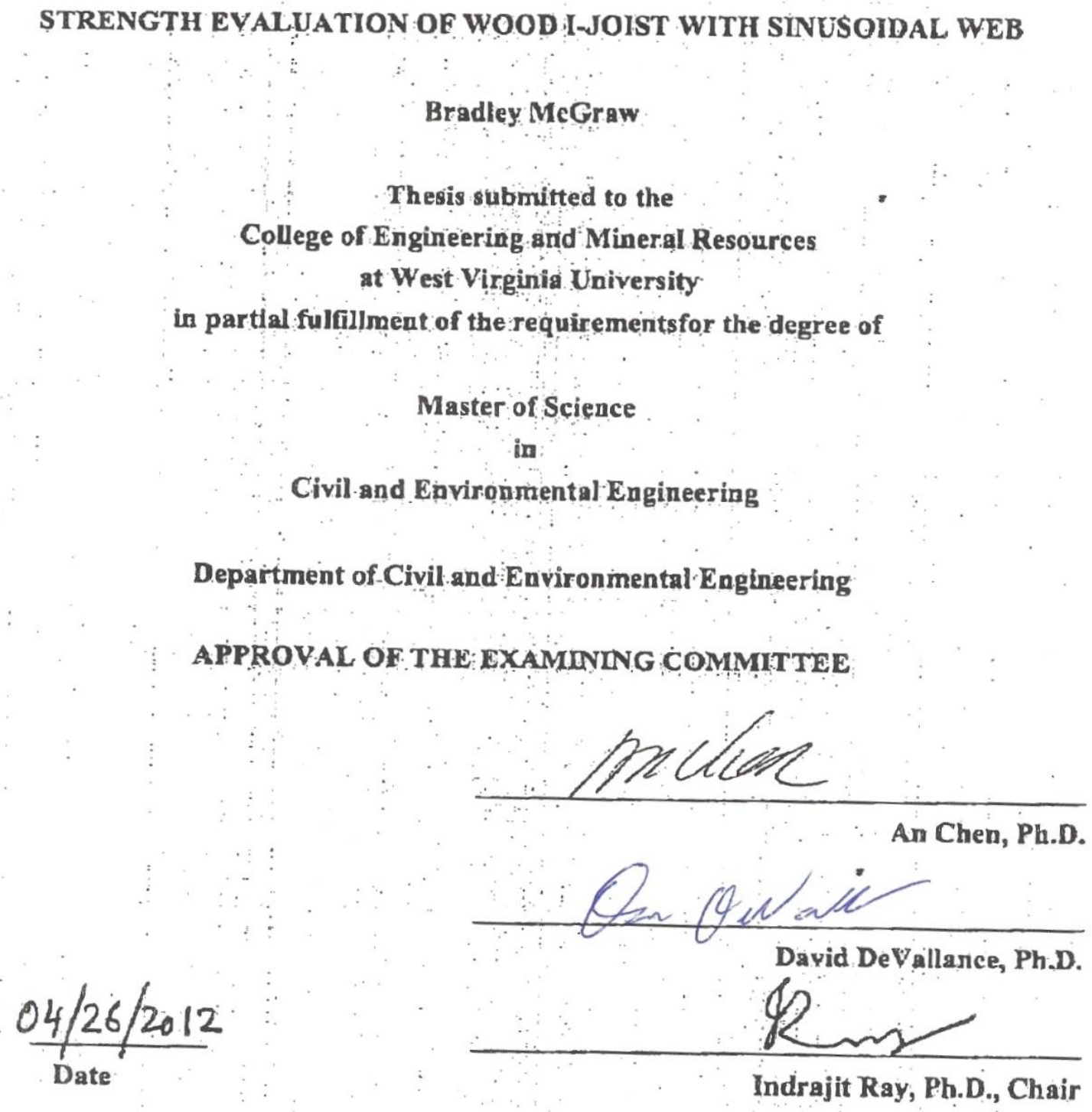

